\title{
Roles of Amphipathicity and Hydrophobicity in the Micelle-Driven Structural Switch of a 14-mer Peptide Core from a Choline- Binding Repeat
}

\author{
Héctor Zamora-Carreras ${ }^{+}{ }^{[a]}$ Beatriz Maestro $^{+},{ }^{[b]}$ Erik Strandberg, ${ }^{[c]}$ Anne S. Ulrich, ${ }^{[c, d]}$ \\ Jesús M. Sanz, ${ }^{*[b, e]}$ and M. Ángeles Jiménez ${ }^{*[a]}$
}

\begin{abstract}
Choline-binding repeats (CBRs) are ubiquitous sequences with a $\beta$-hairpin core that are found in the surface proteins of several microorganisms such as $S$. pneumoniae (pneumococcus). Previous studies on a 14-mer CBR sequence derived from the pneumoccal LytA autolysin (Lyt $\mathrm{A}_{239-252}$ peptide) have demonstrated a switch behaviour for this peptide, so that it acquires a stable, native-like $\beta$ hairpin conformation in aqueous solution but is reversibly transformed into an amphipathic $\alpha$-helix in the presence of detergent micelles. With the aim of understanding the factors responsible for this unusual $\beta$-hairpin to $\alpha$-helix transition, and to specifically assess the role of peptide hydropho-
\end{abstract}

\begin{abstract}
bicity and helical amphipathicity in the process, we designed a series of Lyt $\mathrm{A}_{239-252}$ variants affecting these two parameters and studied their interaction with dodecylphosphocholine (DPC) micelles by solution NMR, circular dichroism and fluorescence spectroscopies. Our results indicate that stabilising cross-strand interactions become essential for $\beta$-hairpin stability in the absence of optimal turn sequences. Moreover, both amphipathicity and hydrophobicity display comparable importance for helix stabilisation of CBR-derived peptides in micelles, indicating that these sequences represent a novel class of micelle/membrane-interacting peptides.
\end{abstract}

\section{Introduction}

The fact that identical amino acid sequences, named "chameleon" sequences, ${ }^{[1]}$ can display distinct secondary structures in different contexts has been an intriguing finding since Kabsch and Sanders ${ }^{[2]}$ found that some pentapeptide sequences adopt

[a] Dr. H. Zamora-Carreras, ${ }^{+}$Dr. M. Á. Jiménez

Instituto de Química Física Rocasolano (IQFR)

Consejo Superior de Investigaciones Científicas (CSIC)

Serrano 119, 28006 Madrid (Spain)

E-mail:majimenez@iqfr.csic.es

[b] Dr. B. Maestro, ${ }^{+}$Dr. J. M. Sanz

Instituto de Biología MolecularyCelular

Universidad Miguel Hernández

Elche, 03202 Alicante (Spain)

[c] Dr. E. Strandberg, Prof. A. S. Ulrich

Institute of Biological Interfaces (IBG-2)

Karlsruhe Institute of Technology (KIT)

P.O. Box 3640, 76021 Karlsruhe (Germany)

[d] Prof. A. S. Ulrich

Institute of Organic Chemistry

Karlsruhe Institute of Technology (KIT)

Fritz-Haber-Weg 6, 76131 Karlsruhe (Germany)

[e] Dr. J. M. Sanz

Biological Research Centre (CIB)

Consejo Superior de Investigaciones Científicas (CSIC)

Ramiro de Maeztu 9, 28040 Madrid (Spain)

E-mail:jmsanz@cib.csic

$\left.{ }^{+}\right]$These authors contributed equally to this work.

$\square$ Supporting information and the ORCID number(s) for the author(s) of this D article can be found under https://doi.org/10.1002/chem.201704802. helical or extended conformations when located in different proteins. As more protein structures have been determined, longer chameleon sequences of 10-11 residues have been identified. ${ }^{[1 a, b]}$ The explanation is that such sequences lack an unambiguous intrinsic tendency to form a particular secondary structure, and therefore can adapt themselves to a particular environment.

Choline-binding repeats (CBRs) are widespread motifs of approximately 20 amino acids that usually consist of a $\beta$-hairpin of 14 amino acids followed by a linker of $6-7$ residues. ${ }^{[3]}$ They are employed in a number of surface proteins for the recognition of choline in the cell wall of various microorganisms such as Streptococcus pneumoniae (pneumococcus), and play an essential role in bacterial viability and virulence. The CBRs belong, in turn, to the extensive CW binding 1 motif family that can be found in many different species (PFAM code PF01473, http://pfam.xfam.org/family/PF01473).

In this context, we have recently described the folding of a 14-mer peptide ( $\left.\operatorname{Lyt}_{239-252}\right)$, corresponding to the hairpin core of a CBR from the pneumococcal LytA autolysin. ${ }^{[4]}$ This peptide forms a very stable, native-like $\beta$-hairpin in aqueous solution and is transformed into an $\alpha$-helix in the presence of detergent micelles and in small unilamellar phospholipid vesicles (Figure 1). In contrast to the absence of any secondary structural tendency shown by most chameleon sequences, predictions for the Lyt $_{239-252}$ sequence show a bias for $\beta$-hairpin formation. ${ }^{[4]}$ Moreover, the observed peptide conformation depends on the solvent conditions, and not on the protein con- 
A)
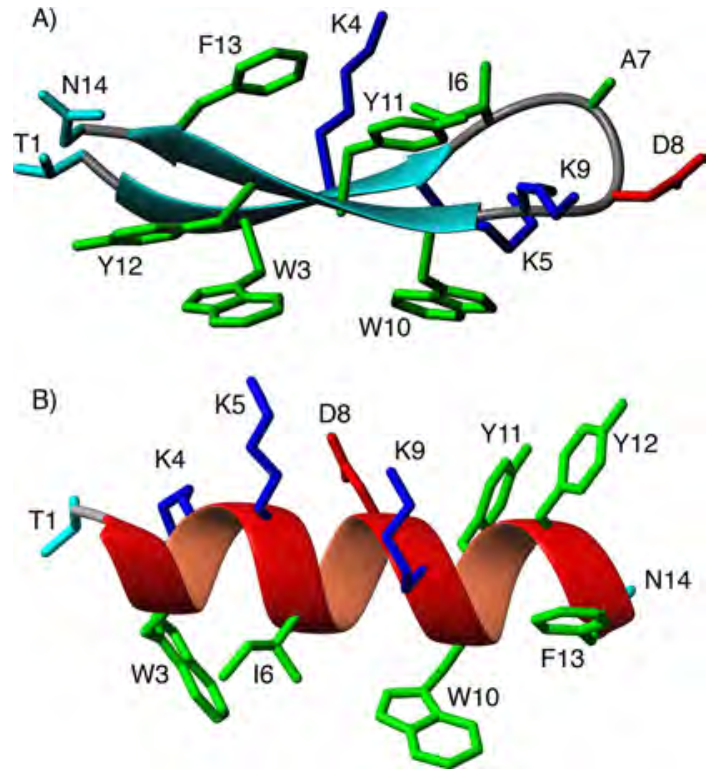

Figure 1. Ribbon representations of $A$ ) the $\beta$-hairpin and B) the $\alpha$-helix formed by peptide Lyt $A_{239-252}$ in aqueous solution and in the presence of micelles, respectively. ${ }^{[4]}$ Aromatic $(F, Y, W)$ and aliphatic $(\mathrm{I}, \mathrm{A})$ residues are in green, polar residues $(T, N)$ in cyan, Lys in blue, and Asp in red.

text. Therefore, Lyt $\mathrm{A}_{239-252}$ can be described as a conformational switch. ${ }^{[5]}$ It should be noted that the structural transition observed in Lyt $\mathrm{A}_{239-252}$ is reversible and occurs between two wellfolded structures, instead of the more commonly observed change between a disordered state and a folded form, or the transition from a folded state to an aggregate. ${ }^{[5,6]}$

The mechanisms of amphipathic peptide interaction with lipid membranes have been the subject of intense investigation for a long time, and in this sense the so-called Eisenberg plot is a common bioinformatics tool that allows transmembrane, surface-seeking and globular (i.e., non lipid-interacting) $\alpha$-helices to be predicted on the basis of mean hydrophobicity and hydrophobic moment theoretical calculations. ${ }^{[7]}$

In this context, we aimed to get insights into the sequence determinants for the micelle-induced structural switch shown by Lyt $\mathrm{A}_{239-252}$, and to increase our understanding of the contributions of amphipathicity and hydrophobicity to $\alpha$-helix formation and stability in micelles. To that end, we designed a series of Lyt $_{239-252}$ variants with clearly different values of these two parameters. We examined their conformational behaviour in aqueous solution and in the presence of dodecylphosphocholine (DPC) micelles, using NMR, circular dichroism $(C D)$, and fluorescence spectroscopies. Our results show that both the hydrophobic moment (amphipathicity) and the hydrophobicity of predicted helices contribute to drive the interaction of these peptides with micelles, but in a different fashion than that predicted by Eisenberg analysis, ${ }^{[7 c, 8]}$ suggesting that CBR-type sequences may constitute a new class of lipidor micelle-interacting peptides.

\section{Results}

\section{Peptide variants design}

The different side chain spatial distributions displayed by Lyt $A_{239-252}$ as a $\beta$-hairpin and an $\alpha$-helix can be clearly appreciated in Figure 1. The various degrees of amphipathicity shown by the variants described in this work can be visualised in the schematic $\beta$-hairpin and $\alpha$-helical wheel representations in Figure 2. This Figure is useful to follow the design criteria. Although the sequence of the wild-type peptide corresponds to

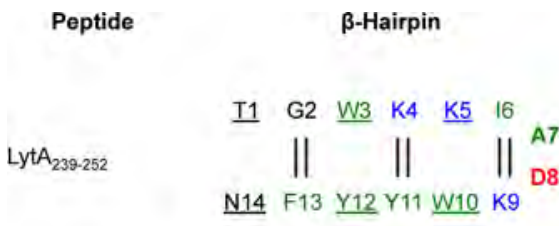

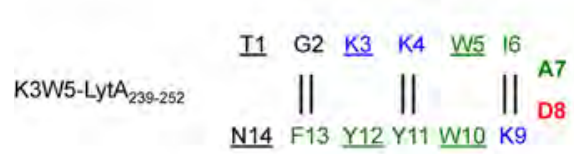

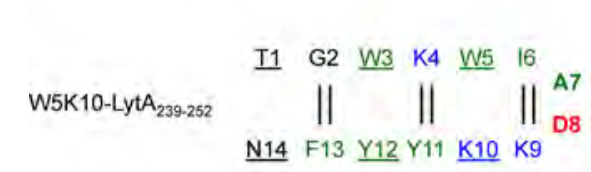

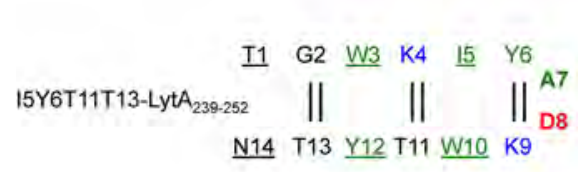
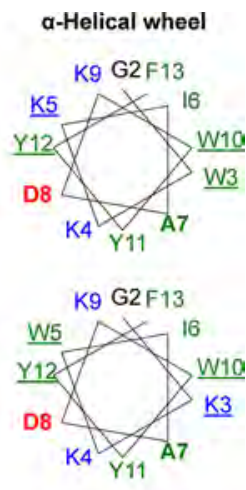

K9 G2F13

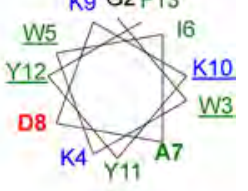

k9 G2 T13

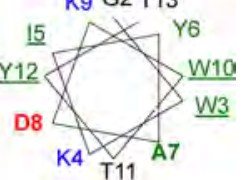

K9 G2F13

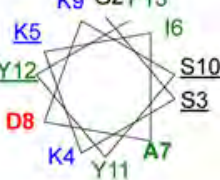

K9 G2F13

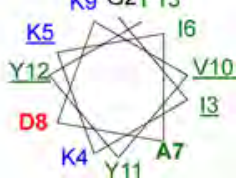

Figure 2. $\beta$-Hairpin schemes and $\alpha$-helical wheel representations for the structures formed by peptide Lyt $_{239-252}$ in aqueous solution and in the presence of detergent micelles, respectively, ${ }_{r}^{[4]}$ and putative for the designed Lyt $_{239-252}$ variants. In the $\beta$-hairpin schemes, hydrogen bonds are indicated by vertical lines, residues at non-hydrogen bond sites are underlined, and turn residues are marked in bold. Side-chains for residues at non-hydrogenbonded sites point towards the same $\beta$-sheet face (face 1), and those at hydrogen-bonded sites towards the opposite face (face 2). Aromatic ( $F, Y, W$ ) and aliphatic $(\mathrm{I}, \mathrm{V}, \mathrm{A})$ residues are in green, Lys residues in blue, Asp residues in red, and polar (S, T, N) and Gly residues in black. T1 and N14 were not included in the helical wheels because they do not belong to the helix in Lyt $\mathrm{A}_{239-252}$ 


\begin{tabular}{|c|c|c|c|c|c|c|c|}
\hline Peptide & $\langle\beta\rangle$ & $\langle\alpha\rangle$ & $\langle H\rangle$ & $\left\langle\mu_{H}\right\rangle^{\text {Heliquest }}$ & $\left\langle\mu_{H}\right\rangle^{\text {\mbooss }}$ & $z$ & $D$ \\
\hline LytA $^{239-252}$ & 1.46 & 0.98 & 0.446 & 0.515 & 0.420 & +3 & 1.47 \\
\hline K3W5-LytA ${ }^{239-252}$ & 1.46 & 0.98 & 0.446 & 0.318 & 0.273 & +3 & 1.29 \\
\hline W5K10-LytA ${ }^{239-252}$ & 1.46 & 0.98 & 0.446 & 0.239 & 0.220 & +3 & 1.21 \\
\hline 15Y6T11T13-LytA ${ }^{239-252}$ & 1.51 & 0.92 & 0.426 & 0.289 & 0.185 & +2 & 0.93 \\
\hline S3S10-LytA $239-252$ & 1.25 & 0.96 & 0.119 & 0.230 & 0.294 & +3 & 1.21 \\
\hline I3V10-LytA ${ }^{239-252}$ & 1.51 & 0.99 & 0.340 & 0.415 & 0.475 & +3 & 1.38 \\
\hline
\end{tabular}

segment 239-252 of LytA, residues are numbered from 1 to 14 hereafter for clarity. All residue changes are intended to maintain as much as possible the intrinsic $\beta$-sheet and $\alpha$-helical propensities of the sequence (see $\langle\beta\rangle$ and $\langle\alpha\rangle$ in Table 1).

In the first place, to assess the role of $\alpha$-helix amphipathicity as a driving force for the $\beta$-hairpin-to- $\alpha$-helix switch, we designed some Lyt $\mathrm{A}_{239-252}$ variants with decreased amphipathicity of the corresponding helix, whilst maintaining as much as possible the mean hydrophobicity of the sequence and the nonamphipathic character of the native $\beta$-hairpin. With this aim, we exchanged the position of the charged Lys5 residue with

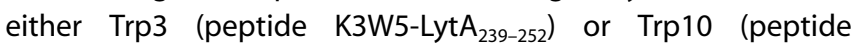
W5K10-Lyt $A_{239-252}$ ). These exchanges were expected to disrupt the $\alpha$-helix amphipathicity by introducing a positively charged side chain in the hydrophobic face (Figure 2, Table 1). Considering that the side chains of residues Trp3, Lys5 and Trp10 are on the same face of the $\beta$-sheet (Figure 1 and Figure 2), propensity to $\beta$-hairpin formation would be expected to be hardly affected (Table 1). In another approach, we tested a peptide sequence with four changes (peptide 15Y6T11T13-Lyt $\mathrm{A}_{239-252}$ ) that also presents a similar mean hydrophobicity and a diminished $\alpha$-helix amphipathicity, but with an increase in $\beta$-hairpin amphipathicity (Figure 2 ). In this case, the Trp-containing $\beta$-sheet face should become more hydrophobic by changing the charged Lys residue at position 5 to a hydrophobic, $\beta$ branched residue (lle). Moreover, the other $\beta$-sheet face should become more hydrophilic by replacing the aromatic residues Tyr11 and Phe13 for the more polar Thr residues, and lle6 for a Tyr. Thr residues at positions 11 and 13 were selected because of their high $\beta$-sheet propensities. ${ }^{[9]}$ Finally, the two Trp residues ( 3 and 10 ) were substituted, leading to peptides S3S10-

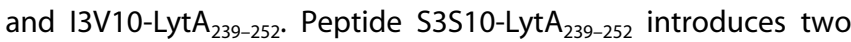
polar side chains into the hydrophobic $\alpha$-helix face (Figure 2), thereby decreasing both $\alpha$-helix amphipathicity and mean hydrophobicity. In this case, $\beta$-hairpin formation might be affected because the $\beta$-sheet propensity is lower for Ser than for Trp ${ }^{\left[{ }^{[9]}\right.}$ in fact, it shows the lowest $\langle\beta\rangle$ amongst all the designed variants (Table 1). In the I3V10-Lyt $\mathrm{A}_{239-252}$ peptide, the two Trp residues were replaced by hydrophobic Ile and Val, so that the peptide should maintain much of the helical amphipathicity and hydrophobicity. $\beta$-Hairpin formation in aqueous solution should also be maintained because it is known that $\beta$ branched amino acids tens to be good $\beta$-sheet-formers. ${ }^{[9]}$ Finally, the I3V10- and S3S10-Lyt $A_{239-252}$ peptides are also useful to find out whether the Trp residues per se are essential for micelle-triggered $\alpha$-helix formation.

\section{Conformational study in aqueous solution}

To check the structure of the designed peptide variants in aqueous solution, we analysed a series of 2D NMR spectra acquired for each peptide in $\mathrm{H}_{2} \mathrm{O}_{/} \mathrm{D}_{2} \mathrm{O} 9: 1 \mathrm{v} / \mathrm{v}$ and in $\mathrm{D}_{2} \mathrm{O}$ at $\mathrm{pH} 3.0$ and $25^{\circ} \mathrm{C}$ (the experimental conditions used for the wild-type peptide). The ${ }^{1} \mathrm{H}$ and ${ }^{13} \mathrm{C}$ NMR chemical shifts were fully assigned for all the peptide variants by the standard strategy (see Experimental Section and Supporting Information, Tables S1-S5). Once the chemical shifts were assigned, the plots of the conformational shifts for $\mathrm{H}_{\alpha}$ protons $\left(\Delta \delta_{\mathrm{H \alpha}}=\right.$ $\left.\delta_{H \alpha}{ }^{\text {observed }}-\delta_{H \alpha}{ }^{\mathrm{RC}}, \mathrm{ppm}\right)$, for $\mathrm{C}_{\alpha}\left(\Delta \delta_{C \alpha}=\delta_{C \alpha}{ }^{\text {observed }}-\delta_{C \alpha}{ }^{\mathrm{RC}}, \mathrm{ppm}\right)$ and for $C_{\beta}$ carbons $\left(\Delta \delta_{C \beta}=\delta_{C \beta}{ }^{\text {observed }}-\delta_{C \beta}{ }^{\mathrm{RC}}, \mathrm{ppm}\right)$ as a function of sequence provide a very simple way to delineate secondary structures in proteins and peptides. The method is based on the existence of a well-established empirical relationship between the dihedral $\phi$ and $\psi$ angles and the ${ }^{1} \mathrm{H}_{\alpha,}{ }^{13} \mathrm{C}_{\alpha}$ and ${ }^{13} \mathrm{C}_{\beta}$ chemical shifts. ${ }^{[1]}$ The profiles characteristic of $\beta$-hairpins display two stretches of positive $\Delta \delta_{H \alpha}$ and $\Delta \delta_{C \beta}$ values for the $\beta$ strands, separated by a short stretch of negative values at the turn region, and two stretches of negative $\Delta \delta_{C_{\alpha}}$ values divided by a short region of positive values. ${ }^{[12]}$ The conformational shifts shown by the variants K3W5- and W5K10-Lyt $\mathrm{A}_{239-252}$ conform to these patterns (see the Supporting Information, Figure $\mathrm{S} 1$ ), although the $\Delta \delta_{H \alpha}$ values for some residues deviate from the expected ones, which is not uncommon in aromaticcontaining peptides. In particular, negative $\Delta \delta_{H \alpha}$ values have been reported previously for residues facing a Trp in $\beta$-hairpin peptides, ${ }^{[13]}$ as occurs for $\mathrm{K} 10$ in front of $\mathrm{W} 5$ in W5K10-LytA $A_{239-252}$, and Y12 facing W3 in both W5K10-LytA $A_{239-252}$ and in the wild-type peptide (Figure 2 and Figure S1). On the whole, the profiles of conformational shifts indicate that they form $\beta$-hairpin structures in aqueous solution, similar to the wild-type peptide $\mathrm{LytA}_{239-252}{ }^{[4]}$ The negative $\Delta \delta_{H \alpha}$ values for 16 and $\mathrm{K} 9$ in the variant $\mathrm{K} 3 \mathrm{~W} 5-\mathrm{LytA}_{239-252}$ might suggest that this variant has some geometrical differences at the turn region relative to the wild-type peptide. Further and stronger evidence about $\beta$-hairpin formation in the two peptides comes from the sets of nonsequential NOEs. In $\beta$-hairpins, the nonsequential NOEs involving side chain protons can be classified into two subsets, one for each face of the $\beta$-hairpin. In $\mathrm{LytA}_{239-252}$, one 
A

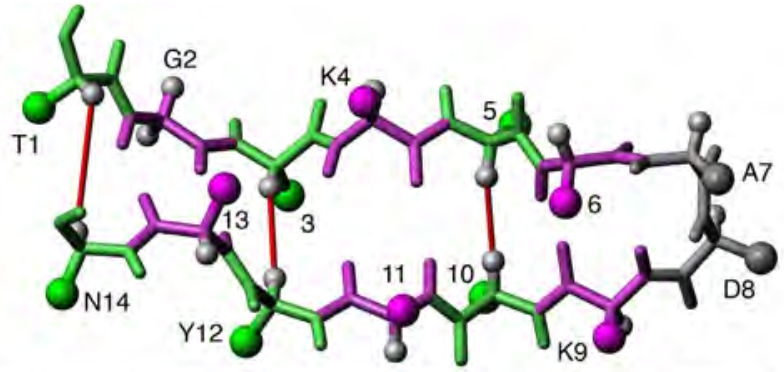

B

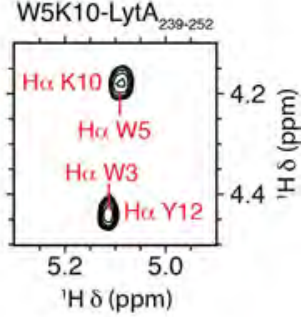

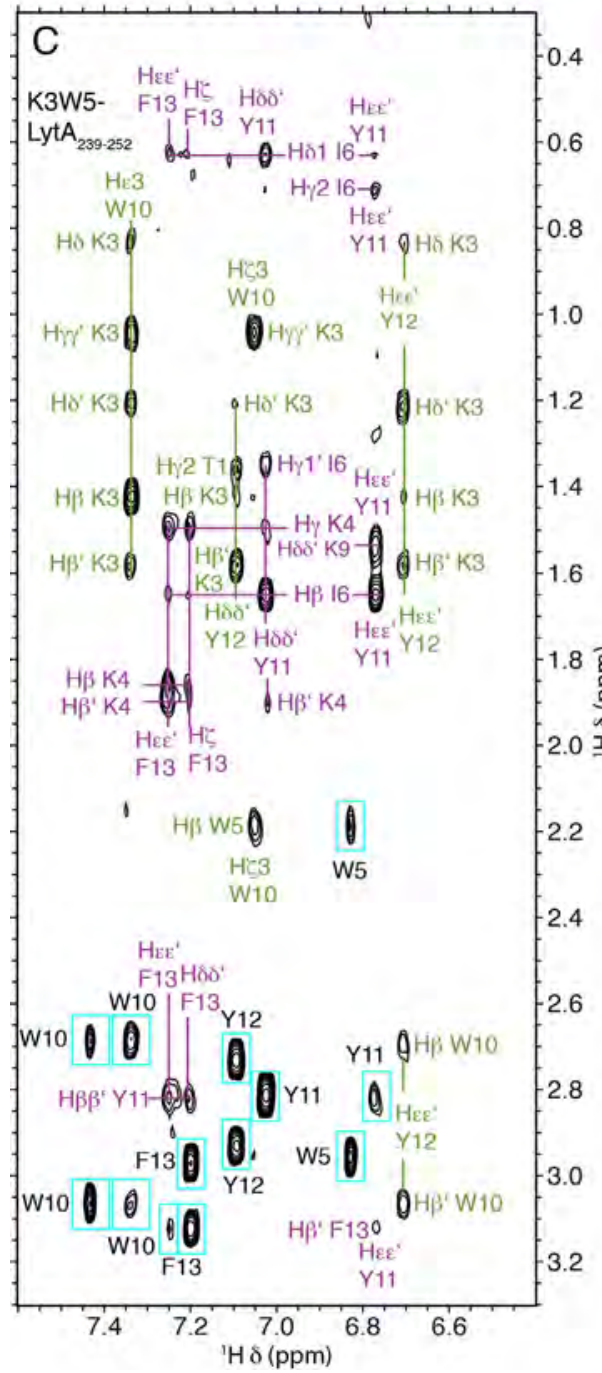

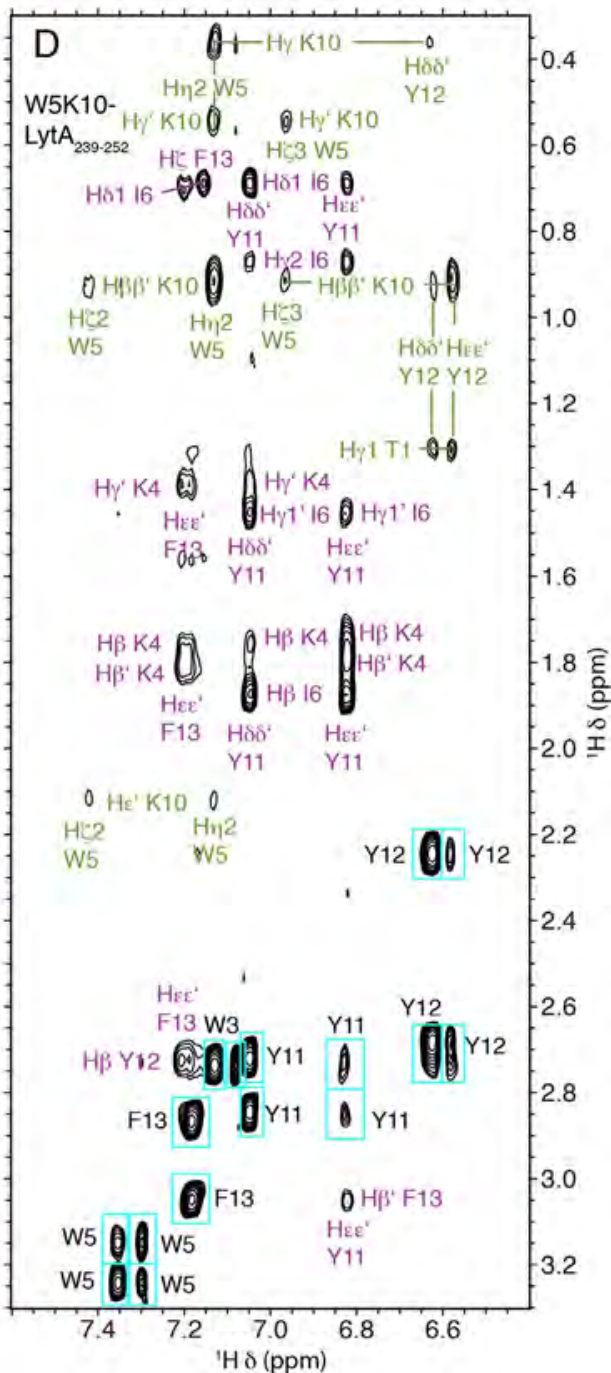

Figure 3. A) Backbone structure of the Lyt $\mathrm{A}_{239-252} \beta$-hairpin. Non-hydrogen-bonded sites are coloured in green, hydrogen-bonded sites in magenta, and turn residues in grey. The $\mathrm{H}_{\alpha}$ protons are displayed as small white spheres, and those pointing inwards are connected by a red line. The side chain $C_{\beta}$ carbons are shown as large spheres coloured according to their location at non-hydrogen-bonded sites (green), hydrogen-bonded sites (magenta) and turn residues (dark grey). Labels indicate the residue number, and also the type of residue if maintained in all the designed variants. Side-chains for residues at hydrogenbonded sites (magenta) point upwards (face 1), and those at non-hydrogen-bonded sites (green) downwards (face 2). B-D) Selected NOESY spectral regions of K3W5-Lyt $\mathrm{A}_{239-252}$ and W5K10-Lyt $\mathrm{A}_{239-252}$ in $\mathrm{D}_{2} \mathrm{O}$ at pH 3.0 and $25^{\circ} \mathrm{C}(150 \mathrm{~ms}, 600 \mathrm{MHz})$. Panel B shows the $\mathrm{H}_{\alpha}-\mathrm{H}_{\alpha} \mathrm{NOEs}$ observed for W5K10-Lyt $\mathrm{A}_{239-252}$. Panels $\mathrm{C}$ and $\mathrm{D}$ show nonsequential NOEs involving side chain protons of K3W5-Lyt $\mathrm{A}_{239-252}$ and W5K10-Lyt $\mathrm{A}_{239-252}$, respectively. Those from hydrogen-bonded residues (face 1) are labelled in magenta, and those from non-hydrogen-bonded residues (the Trp-containing face; face 2 ) are in green. Intra-residual NOE cross-peaks are boxed in cyan. They correspond to NOEs between aromatic protons and $\mathrm{H}_{\beta \beta^{\prime}}$ protons.

face comprises side chains from residues $1,3,5,10,12$ and 14 (all those at non-hydrogen-bonded sites; face 2 at Figure 2 and Figure $3 \mathrm{~A}$ ), and the other side chains from residues $4,6,9,11$ and 13 (all those at hydrogen-bonded sites; face 1 at Figure 2 and Figure $3 \mathrm{~A}$ ). Thus, the presence of a large number of NOEs involving protons from side chains within the same face in peptides K3W5- and W5K10-LytA $\mathrm{A}_{239-252}$ evidences $\beta$-hairpin formation (Figure 3 and Table S6). In addition, NOEs between the $H_{\alpha}$ protons of the residue pairs 3,12 and 5, 10, which are the most distinctive nonsequential NOEs involving backbone pro- 


\begin{tabular}{|c|c|c|c|c|c|c|c|}
\hline Peptide & $\begin{array}{l}\text { Aqueous } \\
\Delta \delta_{H \alpha} \\
{[\mathrm{ppm}]}\end{array}$ & $\begin{array}{l}\Delta \delta_{c \alpha} \\
{[\mathrm{ppm}]}\end{array}$ & $\begin{array}{l}\Delta \delta_{c \beta} \\
{[\mathrm{ppm}]}\end{array}$ & $\begin{array}{l}\% \\
\beta \text {-hairpin } \\
{\left[{ }^{[a]}\right.}\end{array}$ & $\begin{array}{l}\text { DPC micelles } \\
\Delta \delta_{H \alpha} \\
{[\mathrm{ppm}]^{[\mathrm{b}]}}\end{array}$ & $\begin{array}{l}\Delta \delta_{c \alpha} \\
{[p p m]}\end{array}$ & $\begin{array}{l}\% \\
\alpha \text {-helix }{ }^{[a, b]}\end{array}$ \\
\hline LytA ${ }^{239-252}$ & 0.43 & -0.52 & 2.12 & 100 & $-0.26(-0.28)$ & 1.5 & $67(71)$ \\
\hline K3W5-LytA ${ }^{239-252}$ & 0.31 & -0.53 & 1.88 & 79 & $-0.23(-0.25)$ & 1.4 & $60(64)$ \\
\hline W5K10-LytA ${ }^{239-252}$ & 0.28 & -0.39 & 1.35 & 70 & $-0.22(-0.24)$ & 1.6 & $57(62)$ \\
\hline 15Y6T11T13-LytA ${ }^{239-252}$ & 0.06 & -0.14 & 0.67 & 16 & $-0.16(-0.18)$ & 1.2 & $43(45)$ \\
\hline S3S10-LytA ${ }^{239-252}$ & $<0.01$ & -0.09 & 0.26 & 0 & $-0.08(-0.11)$ & 0.5 & $21(28)$ \\
\hline 13V10-LytA ${ }^{239-252}$ & $0.07^{[c]}$ & -0.13 & 0.52 & 0 & $-0.21(-0.28)$ & 2.0 & $58(71)$ \\
\hline
\end{tabular}

[a] Assuming an experimental error of $\pm 0.01 \mathrm{ppm}$ in the measurement of ${ }^{1} \mathrm{H} \delta$-values, the error in the estimated populations are $\pm 3 \%$. [b] Values at $80 \mathrm{~mm}$ DPC are given in parentheses. [c] This value corresponds only to residues $3-5$.

tons in $\beta$-hairpins, are found in peptide W5K10-Lyt $\mathrm{A}_{239-252}$ (Figure $3 \mathrm{~B}$ ). These NOEs could not be observed in peptide K3W5Lyt $A_{239-252}$ because the $H_{\alpha}$ protons of the facing residues have almost identical, overlapping ${ }^{1} \mathrm{H}$ chemical shifts in the two pairs.

The profiles of the wild type and these variants differ mainly in the magnitudes of the conformational shifts (Figure S1), which points to differences in $\beta$-hairpin populations. Based on the magnitude of the $\Delta \delta_{H \alpha}, \Delta \delta_{C \alpha}$ and $\Delta \delta_{C \beta}$ values averaged for the strand residues (3-6 and 9-13; see Table 2), estimated $\beta$-hairpin populations followed the order LytA $_{239-252}>$ K3W5-LytA ${ }_{239-252}>$ W5K10-LytA ${ }_{239-252}$. Indeed, the $\beta$ hairpin percentages estimated from the $\Delta \delta_{H \alpha}$ averaged for the $\beta$-strand residues are $79 \%$ for peptide $\mathrm{K} 3 \mathrm{~W} 5$-Lyt $\mathrm{A}_{239-252}$ and $70 \%$ for W5K10-LytA ${ }_{239-252}$, which should be compared to ca. $100 \%$ for the wild-type peptide (Table 2). In brief, peptides K3W5- and W5K10-LytA ${ }_{239-252}$ in aqueous solution form $\beta$-hairpin structures, but to a slightly less degree than the parent peptide Lyt $_{239-252}$.

To visualise the features of the highly populated $\beta$-hairpins formed by these two peptides, we calculated their structures on the basis of upper limit distance restraints obtained from these sets of observed NOEs plus dihedral angle restraints derived from chemical shifts (see Experimental section and the Supporting Information, Table S7). Figure 4 displays the resulting structures, which are well defined (Table S7).
(A) K3W5-LytA
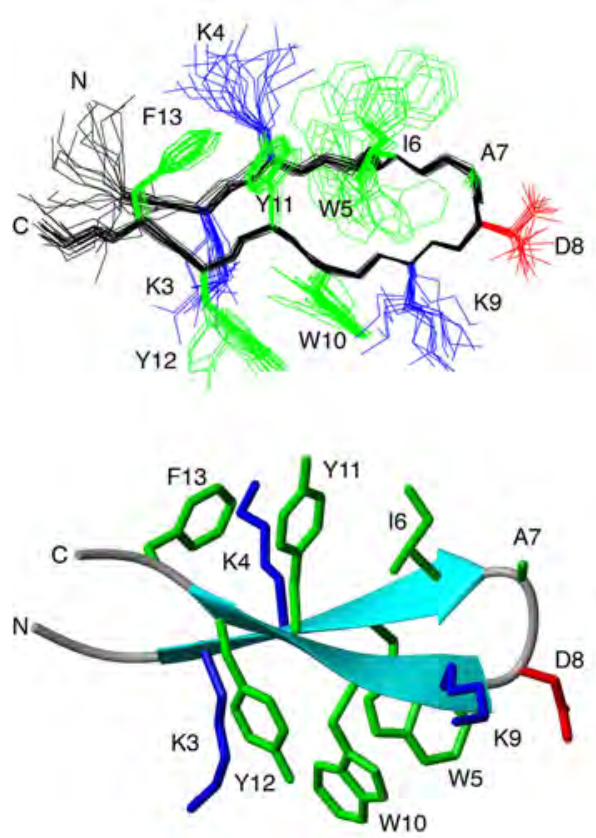

(B) W5K10-LytA
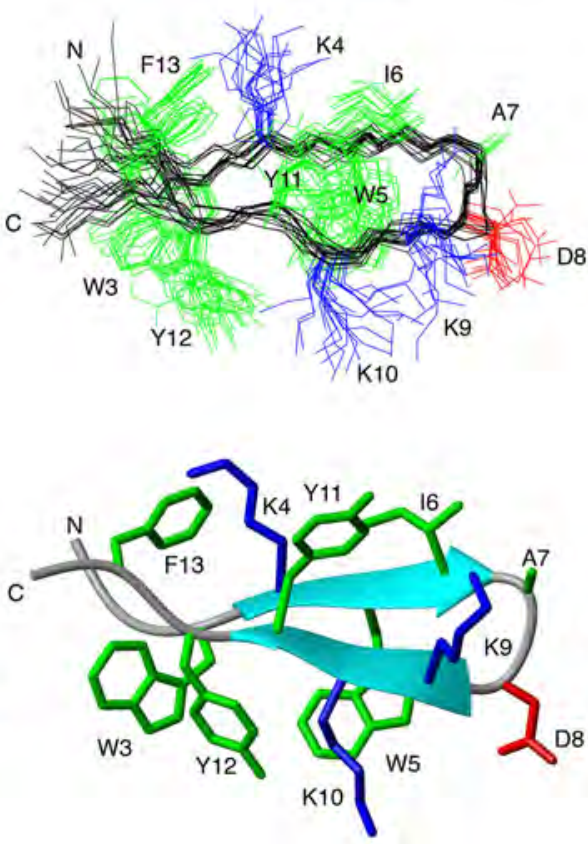

(C) 15Y6T11T13-LytA
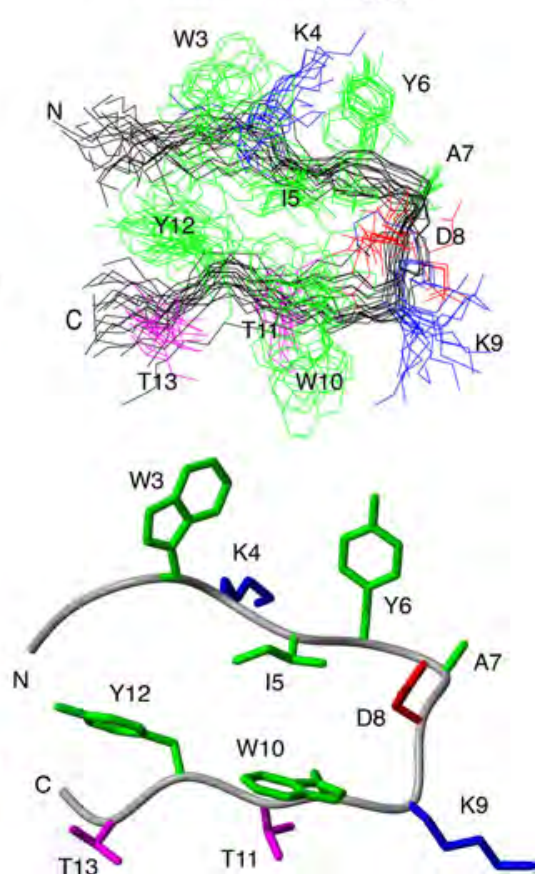

Figure 4. $\beta$-Hairpin structures calculated for the variants K3W5- (A), W5K10- (B) and I5Y6T11T13-Lyt $\mathrm{A}_{239-252}$ (C) in aqueous solution. (Top) Ensemble of the 20 lowest target function conformers overlaid onto the backbone atoms (black). (Bottom) A representative conformer in which the backbone is shown as a ribbon and side chains in neon. $\mathrm{K}$ side chains are coloured in blue, $\mathrm{D}$ in red, $\mathrm{T}$ in magenta, and all the others in green. 
Peptide 15Y6T11T13-LytA $A_{239-252}$ also shows $\Delta \delta_{H \alpha}, \Delta \delta_{C \alpha}$ and $\Delta \delta_{C \beta}$ profiles similar to those of the wild type, but magnitudes are small (Figure S1). This indicates that the peptide forms a $\beta$ hairpin structure, but with a lower propensity than the wildtype peptide, contrary to theoretical predictions (Table 1). In fact, the $\beta$-hairpin population estimated from the $\Delta \delta_{H \alpha}$ values averaged for the $\beta$-strand residues is only around $16 \%$ (Table 2). $\beta$-Hairpin formation is confirmed by the nonsequential NOEs observed in the NOESY spectrum of this peptide (Figure S2), which are compatible with the $\beta$-hairpin structure. Given the small number of these NOEs (Table S6), which is also in accordance with a low populated $\beta$-hairpin structure in aqueous solution, the structure calculated for peptide 15Y6T11T13-Lyt $\mathrm{A}_{239-252}$ is poorly defined, but it shows a $\beta$-hairpin-like shape (Figure $4 C$ ).

The S3S10- and I3V10-Lyt $\mathrm{A}_{239-252}$ variants exhibit quite similar conformational behaviour in aqueous solution. Both peptides show very low magnitudes of the conformational shifts (Figure S1), which lie mostly within the range typical of disordered peptides; that is, $\left|\Delta \delta_{H \alpha}\right| \leq 0.05 \mathrm{ppm},\left|\Delta \delta_{C \alpha}\right| \leq 0.2 \mathrm{ppm}$, and $\left|\Delta \delta_{c \beta}\right| \leq 0.2 \mathrm{ppm}$, indicating that these peptides are mainly random coil. The only conformational shifts that are clearly outside the random coil range are those observed for the $C_{\alpha}$ and $C_{\beta}$ of residue Asp8 in the two peptides, which is suggestive of a certain turn tendency around this residue (Figure S1). The absence of nonsequential NOEs in peptide S3S10-Lyt $A_{239-252}$ (Figure S3A), and the presence of only a few very weak nonsequential NOEs in peptide I3V10-Lyt $\mathrm{A}_{239-252}$ (Figure $\mathrm{S} 3 \mathrm{~B}$ ) are in agreement with the two peptides being mainly random coil, but they might maintain certain $\beta$-turn formation around Asp8. Furthermore, the few nonsequential NOEs observed for peptide 13V10-Lyt $\mathrm{A}_{239-252}$ (Figure S3B) suggest that some very low population of the target $\beta$-hairpin is present within the random coil ensemble.

Lack of significant $\beta$-hairpin formation in the Trp-free peptides suggests an essential role for these aromatic residues in the stability of this structure, probably by cross-strand sidechain pair interactions. In the Trp-containing peptides, some such interactions can be qualitatively identified on the basis of 1) side-chain-to-side-chain NOEs, which indicate the closeness of the corresponding side-chains (Table S6) and 2) anisotropy effects from aromatic rings ${ }^{[14]}$ (Table S8), and also seen in the structures calculated for the well-populated $\beta$-hairpins formed by K3W5- and W5K10-LytA $A_{239-252}$ (Figure 4, A, B). In the case of 15Y6T11T13-Lyt $A_{239-252}$, side chain examination is meaningless because of the poor structure quality of the low-populated $\beta$ hairpin (Figure 4C and Table 2). Thus, a face-to-edge interaction between Trp3 and Tyr12 in the wild-type peptide Lyt $\mathrm{A}_{239-252}$ (Figure $1 \mathrm{~A}$ ) is shown by the numerous NOEs involving side-chain protons of Trp3 and Tyr12 (Table S6) and by the upfield chemical shifts observed for the side-chain protons of Tyr12, which are characteristic of edge Tyr rings in an edge-toface interaction with another aromatic ring (Table S8). ${ }^{[14]}$ In this peptide, a cation- $\pi$ interaction between Lys 5 and $\operatorname{Trp} 10$ is deduced from the NOEs between their side-chain protons, and by the ${ }^{1} \mathrm{H}$ chemical shifts of the Lys5 side chain being upfieldshifted due to the anisotropy effects from the Trp10 indole ring (Table S8). By analogous criteria, a face-to-edge Trp3/Tyr12 interaction and a cation- $\pi \operatorname{Trp} 5 /$ Lys 10 pair are identified in the W5K10-Lyt $\mathrm{A}_{239-252}$ variant (see NOEs in Table S6, ${ }^{1} \mathrm{H}$ chemical shifts of Tyr12 and Lys10 in Table S8, and Figure 4B); a cation$\pi$ Lys3/Tyr12 interaction and an edge-to-face Trp5/Trp10 pair, in which the Trp5 indole ring occupies the edge position, in the case of the K3W5-LytA $\mathrm{A}_{239-252}$ variant (see Figure $4 \mathrm{~A}$, and Lys3 and Trp5 in Table S8); and a face-to-edge Trp3/Tyr12 pair and a hydrophobic lle5/Trp10 interaction in the 15Y6T11T13Lyt $\mathrm{A}_{239-252}$ variant (see Tyr12 and lle5 in Table S8). The fact that the magnitudes of these chemical shift deviations are smaller in these three variants than in the parent peptide agrees with their $\beta$-hairpins being less populated in the variants than in the parent (Table 2). Indeed, the 15Y6T11T13-LytA ${ }_{239-252}$ variant, which has the lowest $\beta$-hairpin population amongst the Trpcontaining variants, displays the smallest in magnitude ${ }^{1} \mathrm{H}$ chemical shift deviations of side chains (Table 2 and Table S8).

The far-UV CD spectra of these peptides in aqueous solution (Figure 5) are in concordance with the NMR results. Thus, the Trp-containing variants show the prominent, positive contribution around $230 \mathrm{~nm}$ seen in the wild-type peptide, which is observed upon acquisition of native-like $\beta$-hairpin conformation in CBRs. ${ }^{[15]}$ In the case of K3W5-LytA ${ }_{239-252}$ this band is appreciably enhanced, probably due to the new edge-to-face interaction between the indole groups of Trp5 and Trp10 (Figure 2 and Figure $4 \mathrm{~A}$ ). The low intensity of this band in peptide 15Y6T11T13-Lyt $A_{239-252}$ is in agreement with the decreased $\beta$ hairpin population as deduced from the NMR data (Table 2). On the other hand, both S3S10- and I3V10-LytA $239-252$ show almost featureless spectra, with a single minimum around $195 \mathrm{~nm}$ (Figure 5), typical of random-coil structures and in con-

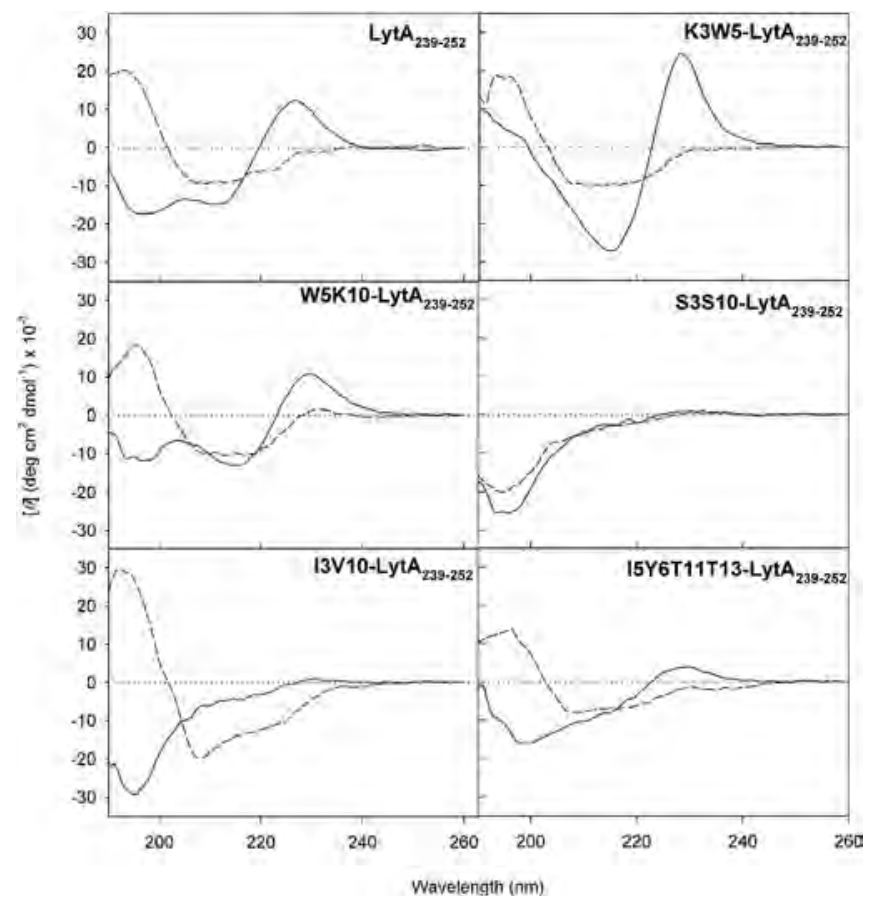

Figure 5. Far-UV CD spectra of Lyt $\mathrm{A}_{239-252}$ peptide variants in $20 \mathrm{~mm} \mathrm{HCl-Gly}$ buffer, $\mathrm{pH} 3.0$ in the absence (solid line) and in the presence of $30 \mathrm{~mm}$ DPC (dashed line) at $30^{\circ} \mathrm{C}$. 
cordance with the loss of structure as assessed by NMR spectroscopic analysis (Table 2).

\section{Conformational study in the presence of DPC}

The far-UV CD spectra registered in the presence of $30 \mathrm{~mm}$ DPC (above CMC, $1.2 \mathrm{~mm}^{[4]}$ ) show, in all cases except for S3S10-Lyt 239-252, clear signs of $\alpha$-helical structure, with positive bands at ca. $197 \mathrm{~nm}$ and negative bands at 208 and $222 \mathrm{~nm} .{ }^{[16]}$ Therefore, it is confirmed that these peptides show switch behaviours similar to that found for the wild-type peptide $\mathrm{LytA}_{239-252}{ }^{[4]}$ and for the full-length C-LytA module. ${ }^{[4]}$

Even at detergent concentrations above the $C M C$, a low population of detergent monomers exists in equilibrium with the micelles. To establish whether the conformational change observed by $C D$ is due to the presence of DPC micelles, as in the case of the parent peptide $\operatorname{LytA}_{239-252{ }^{2]}}$ or due to DPC monomers, we acquired NMR spectra of the peptide variants at concentrations below and above CMC of DPC $(0.6 \mathrm{mM}$ and $30 \mathrm{~mm}$ DPC, respectively; the CMC of DPC in our experimental conditions is $\left.1.2 \mathrm{mM}^{[4]}\right)$. The NMR spectra recorded at $0.6 \mathrm{~mm}$ DPC are essentially identical to those recorded in aqueous solution in the complete absence of DPC, but many NMR signals are seen to be shifted strongly at $30 \mathrm{~mm}$ DPC in all peptides

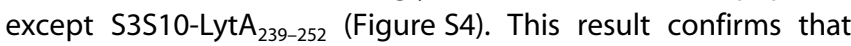
DPC micelles, but not DPC monomers, induce the conformational transition. The fact that NMR cross-peaks of S3S10Lyt $\mathrm{A}_{239-252}$ in the presence of DPC micelles move slightly or not at all is consistent with the absence of conformational transitions as deduced from the CD data.

We then proceeded to characterise the peptide structures by NMR spectroscopy in $30 \mathrm{~mm}$ DPC. As in aqueous solution, once the ${ }^{1} \mathrm{H}$ and ${ }^{13} \mathrm{C}$ chemical shifts were fully assigned by following standard strategies (see Experimental section and the Supporting Information, Tables S1-S5), we analysed the conformational shifts $\left(\Delta \delta_{H \alpha}\right.$ and $\left.\Delta \delta_{C \alpha}\right)$ and the set of NOEs. In agreement with $C D$ data, peptides K3W5-, W5K10-, I3V10- and 15Y6T11T12-Lyt $\mathrm{A}_{239-252}$ in DPC micelles displayed negative $\Delta \delta_{\mathrm{Ho}}$ values for residues $3-13$ and positive $\Delta \delta_{C \alpha}$ values for residues 2-13 (Figure S5), which supports the conclusion that the four peptides form a helix spanning residues $3-13$. The $\Delta \delta_{C \beta}$ values are not a reliable parameter to identify helice ${ }^{[11]}$ because they can be almost zero in many cases. ${ }^{[1]]}$ Further evidence concerning helix formation comes from the sets of NOEs, which include strong sequential $\mathrm{NN}(i, i+1) \mathrm{NOEs}$, and medium-range NOEs $\alpha \beta(i, i+3), \alpha \mathrm{N}(i, i+3), \alpha \mathrm{N}(i, i+2), \alpha \mathrm{N}(i$, $i+4)$, and $\mathrm{NN}(i, i+2)$ (Figure S6), all of them representative of helices. Based on the averaged $\Delta \delta_{H a}$ for residues $3-13$, the estimated $\alpha$-helix populations for these peptides in $30 \mathrm{~mm}$ DPC ranged from $43 \%$ to $60 \%$ at $25^{\circ} \mathrm{C}$, which is slightly lower than in the parent peptide (Table 2). The structures formed by these peptides in the presence of DPC, which were calculated on the basis of NOE-derived distance and chemical-shift-derived angle restraints (see Experimental section and the Supporting Information, Table S7), were well-defined, continuous $\alpha$-helices in peptides K3W5-, W5K10-, and I3V10-LytA $239-252$ (Figure 6), but only the $\mathrm{N}$-terminal segment (residues 3-9) was helical in
15Y6T11T12-LytA ${ }_{239-252 .}$ This is consistent with the fact that the magnitude of the $\Delta \delta_{H \alpha}$ and $\Delta \delta_{C \alpha}$ in this variant is larger at the $\mathrm{N}$-terminal region (residues 3-9) than at the C-terminal half (Figure S5). The $\alpha$-helix in this variant may only transiently extend up to residue 13 .

In the case of the peptide S3S10-Lyt $\mathrm{A}_{239-252}$, in line with the $\mathrm{CD}$ results (Figure 5), the profiles of $\Delta \delta_{H \alpha}$ and $\Delta \delta_{C \alpha}$ values observed in DPC micelles change very little relative to those in aqueous solution (Figure S5). Although their magnitudes increase somewhat, most of the $\Delta \delta_{H \alpha}$ and $\Delta \delta_{C \alpha}$ values remain within the range typical of random coil peptides, except for those of residues 9-12. Furthermore, the only two detected nonsequential NOEs involved residue Lys9; that is, $\alpha \mathrm{N}(i, i+3)$ between Lys9 and Tyr12, and that between the $\mathrm{H}_{\alpha}$ of lle6 and $\mathrm{H}_{\gamma \gamma^{\prime}}$ of Lys9, and the observed sequential $\mathrm{NN}(i, i+1)$ are $6-7$, $9-10,11-12$, and 13-14. Together, these data suggest that peptide S3S10-Lyt $\mathrm{A}_{239-252}$ in the presence of DPC micelles is a mainly random coil peptide with a low populated short $\alpha$ helix, which in the calculated structure spans residues 9-12 (Figure 6, Experimental section, and the Supporting Information, Table S7).

Given that DPC micelles are formed by $44-61$ monomers, ${ }^{[17]}$ under the experimental conditions employed $(0.5-1.0 \mathrm{~mm}$ peptide concentration and $30 \mathrm{~mm} \mathrm{DPC})$, the peptide/micelle ratios are in the range $1: 1$ to $2: 1$. Although we did not observe any NOEs indicative of peptide/peptide interactions, to discard the possibility that peptide oligomerisation could contribute to $\alpha$ helix stability, we recorded a series of NMR spectra at $1 \mathrm{~mm}$ peptide concentration and $80 \mathrm{~mm}$ DPC. Under these conditions, the peptide/micelle ratio is $2: 3$, so that average peptide occupancy per micelle is less than 1. NMR spectra for the parent peptide and the Trp-containing variants were essentially identical at both DPC concentrations, although some crosspeaks were slightly shifted in the Trp-lacking variants (Figure S7). The profiles of $\mathrm{H}_{\alpha}$ conformational shifts were also quite similar, but their magnitudes increase, particularly in the case of the Trp-lacking variants (Figure S8). The $\alpha$-helix populations estimated from the averaged $\Delta \delta_{H \alpha}$ for residues 3-13 were slightly higher at $80 \mathrm{~mm}$ DPC than at $30 \mathrm{~mm}$ DPC in the Trpcontaining peptides (ca. 2-5\%; almost within the experimental error; Table 2), and they were clearly higher in the I3V10Lyt $\mathrm{A}_{239-252}$ variant $(71 \%$ versus $58 \%$; Table 2 ). The population was also higher at $80 \mathrm{~mm}$ DPC in the S3S10-LytA $\mathrm{L}_{239-252}$ variant, although only residues 9-12 showed $\Delta \delta_{H \alpha}$ values outside the random coil range, as occurs at $30 \mathrm{~mm}$ DPC. On the whole, these data point to a 1:1 peptide/micelle stoichiometry, and do not support contributions of peptide/peptide interactions to $\alpha$-helix stability.

\section{Peptide/DPC micelle interactions}

To characterise the interaction between peptide helices and micelles, we looked for intermolecular NOE cross-peaks in the 2D NOESY spectra of the peptide variants in DPC micelles. As reported for the wild-type peptide ${ }^{[4]}$ we could not detect any intermolecular NOE, even though the intramolecular DPC signals were observed (with a DPC deuteration of $98 \%$, the aver- 

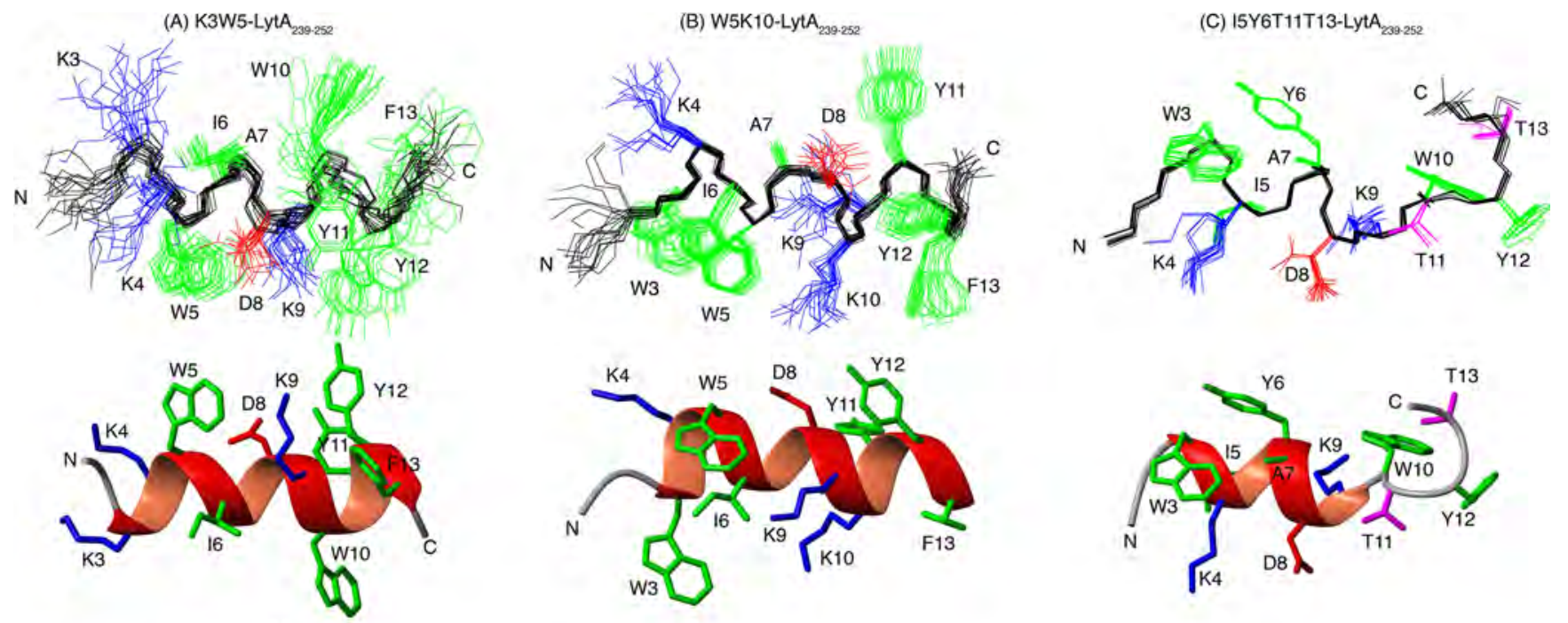

(D) $13 \mathrm{~V} 10-$ LytA $_{239.250}$
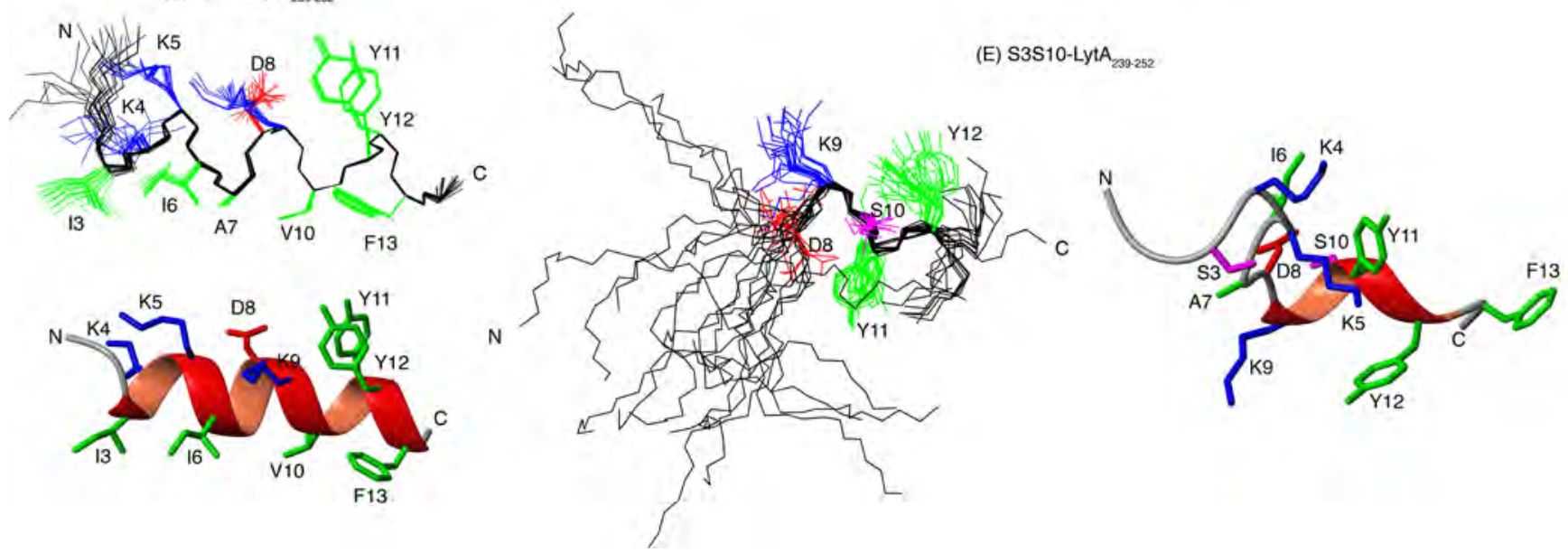

Figure 6. $\alpha$-Helical structures calculated for the variants A) K3W5-, B) W5K10-, C) I5Y6T11T13-, D) I3V10-, and E) S3S10-LytA $239-252$ in DPC micelles. (Top of Panels $A-D$ and left of Panel E) Ensemble of the 20 lowest target function conformers overlaid onto the backbone atoms (black). (Bottom of Panels A-D and right of Panel E) A representative conformer in which the backbone is shown as a ribbon and side chains in neon. $\mathrm{K}$ side chains are coloured in blue, $\mathrm{D}$ in red, $\mathrm{T}$ in magenta, and all the others in green.

age concentration of non-deuterated DPC in a $30 \mathrm{~mm}$ deuterated DPC sample was $0.6 \mathrm{~mm}$ ). Most likely, this is a consequence of the dynamic properties of the system; that is, the detergent micelle/monomer equilibrium and the free peptide/ micelle-bound peptide equilibrium. However, considering that intermolecular NOEs were observed in other peptide/micelle systems using combinations of non-deuterated/deuterated detergent, ${ }^{[18]}$ we acquired 2D NOESY spectra of the wild type and its variants in a mixture of $15 \mathrm{~mm}\left[\mathrm{D}_{38}\right]$-DPC and $15 \mathrm{~mm}$ nondeuterated DPC (150 ms, $600 \mathrm{MHz})$. Under these conditions, intermolecular NOEs between peptide and micelles were observed for the wild-type peptide and its variants (Figure 7 and Figure S9-10), including the mainly disordered peptide S3S10-LytA $\mathrm{A}_{239-252}$. The most intense and numerous NOE signals were observed between the nuclei of the central region of the DPC aliphatic tail and the aromatic side chains of the peptides. This observation indicates that the aromatic hydrophobic side chains physically interact with the micelle core. In addition, some NOEs between aromatic residues with the choline methyl groups and with atoms from the polar head were observed. This could be explained by the dynamics of the interaction process, because the peptides are probably continuously moving from the solvent to the micelle and vice versa, establishing transient interactions with the DPC polar heads, which are solvent-exposed.

In the case of the Trp-containing peptides (K3W5-, W5K10-

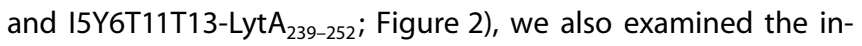
trinsic fluorescence spectra in aqueous solution and in the presence of $30 \mathrm{~mm}$ DPC (Figure 8). The three variants in aqueous solution show a redshift of their maxima compared with the parent peptide, which is compatible with a higher accessibility of the indole rings to the solvent, at least partly attributed to the appreciably decreased population of folded structure seen by NMR (Table 2). A blueshift concomitant with an increase in fluorescence intensity was observed upon the addition of DPC both for the parent and variant peptides, indicating Trp burial in the hydrophobic interior of micelles (Figure 8). 

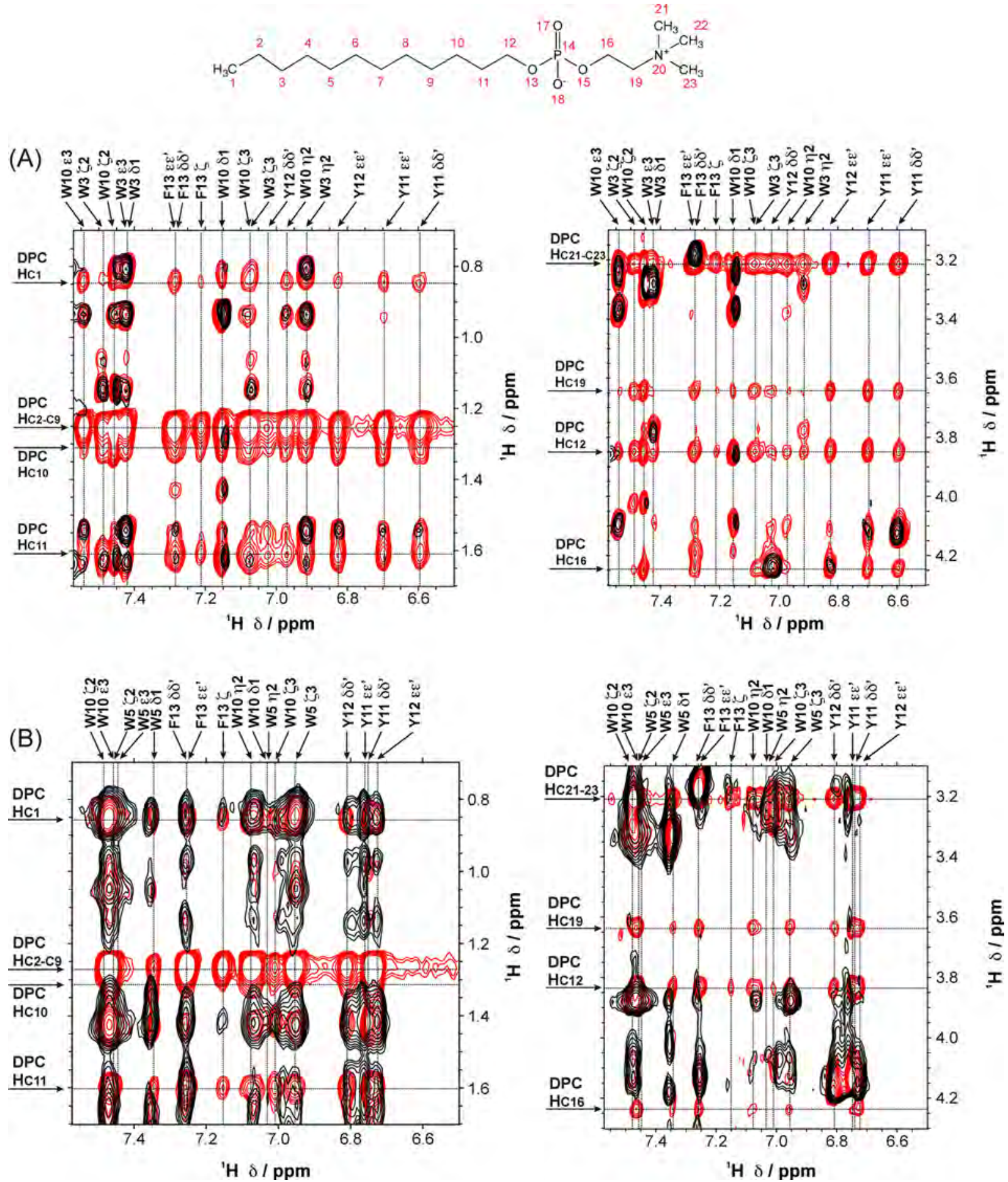

Figure 7. ${ }^{1} \mathrm{H},{ }^{1} \mathrm{H}$-NOESY $(150 \mathrm{~ms}, 600 \mathrm{MHz})$ spectral regions of $\left.\mathrm{A}\right) \mathrm{LytA}_{239-252}$ and B) K3W5-Lyt $\mathrm{A}_{239-252}$ in $15 \mathrm{~mm}\left[\mathrm{D}_{38}\right] \mathrm{DPC}$ and $15 \mathrm{~mm}$ non-deuterated DPC (red) overlap onto the same regions in $30 \mathrm{~mm}\left[\mathrm{D}_{38}\right] \mathrm{DPC}$ (black). Spectra were recorded at $25^{\circ} \mathrm{C}$ and pH 3.0. DPC and aromatic protons are indicated with arrows in the left vertical axis and in the top horizontal axis, respectively. The structure of a DPC molecule is shown on top (heavy atoms are numbered).

Thus, intermolecular peptide/DPC NOEs and Trp-fluorescence indicate that the $\alpha$-helices formed by the Trp-containing variants (K3W5-, W5K10- and I5Y6T11T13-Lyt $\mathrm{A}_{239-252}$; Figure 6) are, at least partially, immersed in the DPC micelle, with the indole rings pointing towards the micelle hydrophobic core, as has been described for the parent peptide. ${ }^{[4]}$ The fact that the Trp residues are arranged differently in these peptides relative to the wild type probably translates into different immersion modes. In the tryptophan-free I3V10-LytA $\mathrm{L}_{239-252}$ variant (Figure 6), the intermolecular NOEs also indicate that the $\alpha$-helix is, at least transiently, immersed in the DPC micelle. We could speculate that the hydrophobic Ile and Val side chains would also look towards the micelle core, but we lack experimental data about them. In the case of S3S10- 


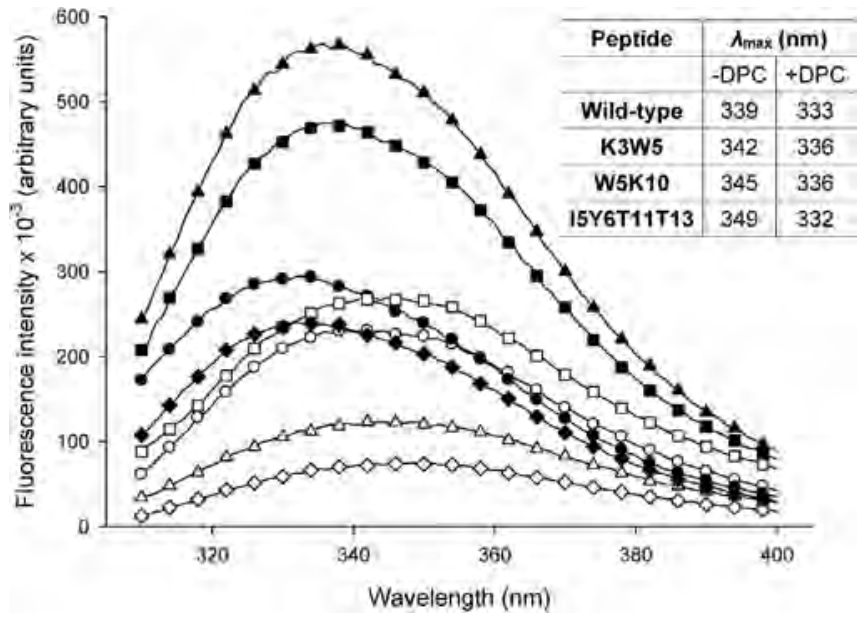

Figure 8. Intrinsic fluorescence emission spectra of the peptides: wild-type LytA $_{239-252}(\circ, \bullet)$, K3W5-LytA ${ }_{239-252}(\triangle, \mathbf{\Delta})$, W5K10-LytA $239-252(\square, \mathbf{\bullet})$ and I5Y6T11T13-LytA $239-252(\diamond, \diamond)$ at $25^{\circ} \mathrm{C}$ in $20 \mathrm{~mm} \mathrm{HCl-Gly} \mathrm{buffer} \mathrm{(open} \mathrm{symbols)}$ or with addition of $30 \mathrm{~mm}$ DPC (closed symbols). The inset lists the $\lambda_{\max }$ in the absence and in the presence of DPC.

Lyt $\mathrm{A}_{239-252}$, which remains mainly disordered in the presence of DPC micelles, the intermolecular NOEs suggest that the C-terminal region of the peptide, in which a low-populated $\alpha$-helix is detected (see above), interacts transiently with the micelle core.

\section{Theoretical analysis of peptides}

From the spectroscopic data discussed above (NMR, CD and fluorescence), it can be deduced that peptides derived from
CBRs are amenable to variations in their sequence whilst keeping, to a variable extent, their ability to interact with DPC micelles. Moreover, the existence of a stable $\beta$-hairpin conformation is not a prerequisite for a productive insertion in the micelles, because the I3V10-Lyt $\mathrm{A}_{239-252}$ variant, which is unfolded in solution, acquires an $\alpha$-helical structure in the presence of DPC micelles to almost the same extent as the wild-type sequence (Table 2).

First, we examined whether the peptides with higher helix populations were those with higher intrinsic $\alpha$-helical propensities. However, the plot of helix content (Table 2 ) versus $\langle\alpha\rangle$ (Table 1) shows no correlation (see the Supporting Information, Figure S11).

Next, to investigate the roles of hydrophobicity and amphipathicity as driving forces for peptide insertion in DPC micelles, we examined the so-called "lipid-binding discrimination factor" $(D)$ of the peptides (Table 1). ${ }^{[8]}$ This parameter, which is calculated from the hydrophobic moment $\left(\left\langle\mu_{H}\right\rangle\right)$ and the net charge of the sequences (see the Experimental section), is indicative of lipid-binding regions when it acquires a value above $0.68 .^{[8]}$ However, although all peptides clearly comply with this prerequisite (Table 1), our results indicate that the disordered S3S10-Lyt $\mathrm{A}_{239-252}$ only displays a minimal interaction with DPC, as deduced from the observed peptide/DPC intermolecular NOEs (Figure S10).

On the other hand, we represented the values of mean hydrophobic moment $\left(\left\langle\mu_{H}\right\rangle\right)$ and mean hydrophobicity $(\langle H\rangle)$ of the peptides, estimated using the Heliquest server, in an Eisenberg plot, ${ }^{[7 a, b]}$ as modified by Keller (Figure $9 A$ ). ${ }^{[7]}$ According to this graph, values in or above the line $\left\langle\mu_{H}\right\rangle=0.654-0.324\langle H\rangle$ usually correspond to "surface-seeking" $\alpha$-helical segments.
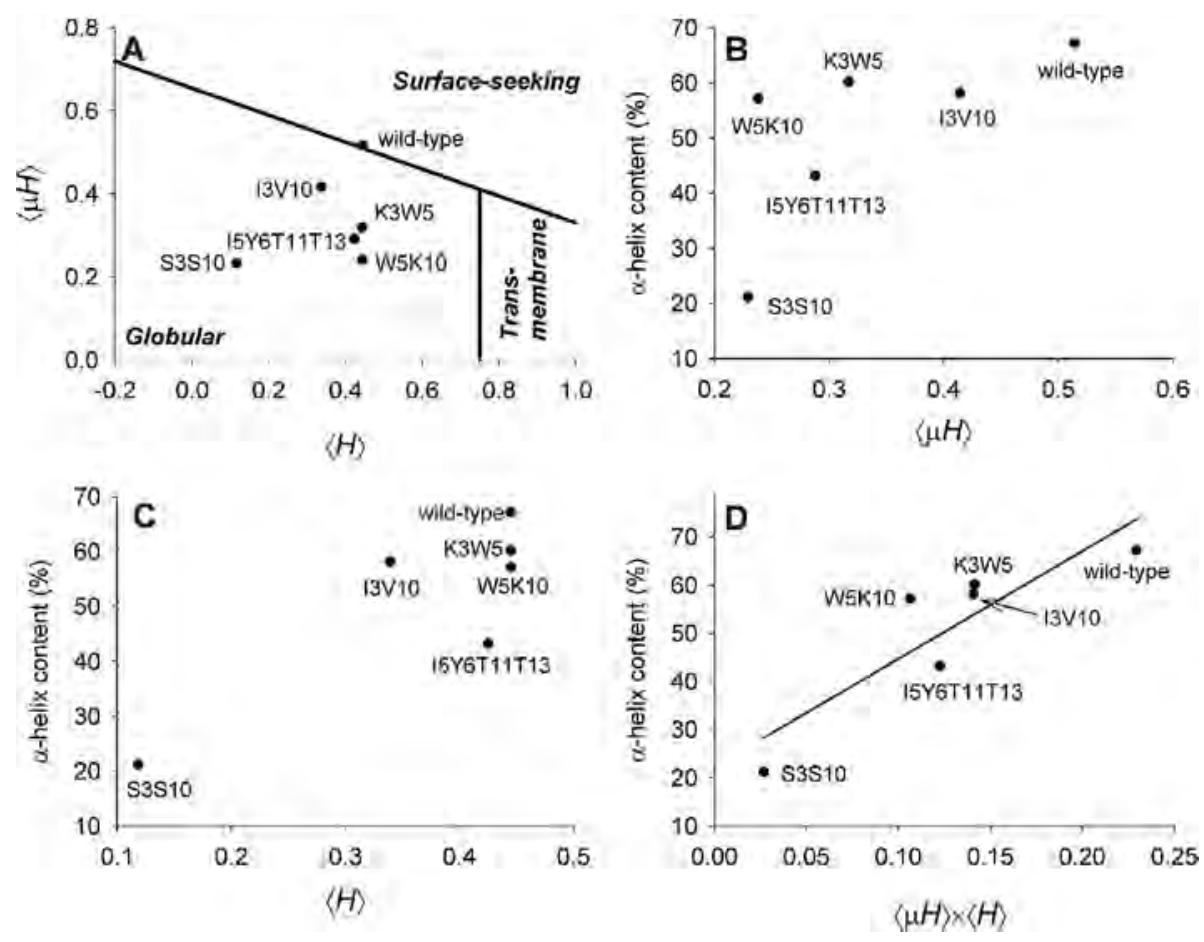

Figure 9. A) Eisenberg plot of the wild type peptide and its variants; B, C and D) graph representation of the NMR-calculated amount of $\alpha$-helix in DPC micelles as a function of $\left\langle\mu_{H}\right\rangle,\langle H\rangle$, and the product $\left\langle\mu_{H}\right\rangle \times\langle H\rangle$, respectively. Panel $D$ also shows a linear regression only intended for visual clarity. 
However, with the exception of wild-type Lyt $_{239-252}$, the rest of the variants fall clearly below that boundary; that is, in the "globular region".

If we consider the NMR-estimated extent of $\alpha$-helix induced by DPC as a measure of peptide-micelle interaction, there is no satisfactory correlation of the helix population with neither $\left\langle\mu_{H}\right\rangle$ nor $\langle H\rangle$ values alone (Figure 9B-C). This absence of correlation occurs independently of the procedure used to obtain the $\left\langle\mu_{H}\right\rangle$ values (Heliquest, and Emboss hmoment; Table 1). However, plotting the helix populations versus the product $\left\langle\mu_{H}\right\rangle \times\langle H\rangle$ exhibits a certain linear dependence $\left(r^{2}=0.75\right.$; Figure 9D). This product is not intended to represent any physical feature, but rather to suggest that both hydrophobic moment and hydrophobicity have comparable importance in the peptide-micelle interaction, and that a decreased value of one quantity may be compensated by an increase of the other to achieve an effective interaction with DPC micelles. We also examined whether the incorporation of $\alpha$-helical propensities, which show no correlation by themselves (see above), or that of $\beta$-sheet propensities might improve the correlation. However, the correlation remains unaffected. These data suggest that the peptides derived from CBRs constitute a new type of micelle/lipid interacting motif that is not predicted on theoretical grounds such as by Eisenberg analysis. ${ }^{[7 c]}$

\section{Discussion}

\section{Determinants of $\beta$-hairpin stabilities in peptides derived from CBRs}

Lyt $\mathrm{A}_{239-252}$ and its variants showed a large variability in their tendency to form native-like $\beta$-hairpin structures, even though the variants were carefully designed on theoretical grounds to affect $\beta$-hairpin formation as little as possible. This peptide system is probably very sensitive to changes along the strands, because the sequence at the $\beta$-turn $\left(\right.$ Ile $^{i} \mathrm{Ala}^{\mathrm{i}+1} \mathrm{Asp}^{\mathrm{i}+2} \mathrm{Lys}^{\mathrm{i}+3}$; Figure 2 ) is not optimal for $\beta$-hairpin stability, ${ }^{[19]}$ and the turn is known to play an essential role in $\beta$-hairpin formation. ${ }^{[20]}$ This intrinsic instability may contribute to the ability of the peptide to switch between conformations when confronted with changes in the environment. In this context of marginal stability, cross-strand interactions may play an essential role in maintaining the hairpin architecture. ${ }^{[20 \mathrm{~b}, \mathrm{c}, \mathrm{f}, \mathrm{i}, 21]}$

In the case of the K3W5- and W5K10-LytA $\mathrm{A}_{239-252}$ variants, for which the positions of two residues were exchanged on the same face of the $\beta$-hairpin (Figure 2 ), the theoretical $\beta$-sheet propensities and overall hydrophobicity do not change at all with respect to the parent peptide (Table 1), and hence only the differences in cross-strand interactions can account for the observed differences in $\beta$-hairpin populations (Table 2 ). In the parent peptide, ${ }^{[4]}$ there are two stabilising cross-strand side chain interactions; namely, a face-to-edge interaction between Trp3 and Tyr12, and a cation- $\pi$ interaction between Lys 5 and Trp10 (Figure 1 A and Figure 2). These two cross-strand pair interactions are also present in the W5K10-LytA $\mathrm{A}_{239-252}$ variant, but the directionality of the Lys/Trp interaction is reversed (Figure 2 and Figure 4B). This altered directionality must there- fore be responsible for the observed differences in $\beta$-hairpin populations (Table 2), with the Lys5/Trp10 pair being more stabilising than the Trp5/Lys 10 pair. The existence of directionality effects of this type has been observed previously for crossstrand pair interactions in other peptide systems. ${ }^{[22]}$ The K3W5Lyt $\mathrm{A}_{239-252}$ variant does not maintain any of the two interactions (Trp3/Tyr12 and Lys5/Trp10) present in the parent peptide, but are replaced by a cation- $\pi$ interaction between Lys 3 and Tyr 12 and an edge-to-face interaction between the Trp residues at positions 5 and 10 (Figure 2 and Figure 4A). Given that $\operatorname{Trp}$ is generally considered a better $\pi$-donor than $\mathrm{Tyr}_{1}^{[14 b]}$ the Lys/Tyr interaction likely implies a reduction in terms of stabilising energy relative to the Lys/Trp present in the parent peptide. This may overcome the otherwise stabilising edge-toface Trp/Trp interaction present in this variant, which has been analysed in other systems. ${ }^{[14 b, 23]}$

The S3S10- and 13V10-LytA $\mathrm{A}_{239-252}$ variants are mainly disordered in aqueous solution (Table 2). In these variants, substitution of the two Trp leads to slight differences in $\beta$-sheet theoretical propensities (Table 1). In the S3S10-Lyt $\mathrm{A}_{239-252}$ variant, the lower $\beta$-sheet propensity of Ser $(0.86)$ in comparison with $\operatorname{Trp}(1.90)^{[9]}$ and, above all, the loss of cross-strand interactions involving tryptophans (the new Ser/Tyr and Ser/Lys pair interactions are unfavourable $\left.{ }^{[24]}\right)$, undoubtedly contribute to $\beta$-hairpin destabilisation in aqueous solution. This also explains the complete loss of $\beta$-hairpin formation in the case of the I3V10Lyt $_{239-252}$ variant, which is somewhat unexpected given that the high $\beta$-sheet propensities for Ile and Val (2.02 and 2.31, respectively) are even higher than for Trp (1.90). ${ }^{[9]}$ Nevertheless, although the cross-strand Ile3/Tyr12 hydrophobic interaction is favourable, the one involving Lys5/Val10 cannot substitute the highly stabilising cation- $\pi$ interaction between Lys 5 and Trp10 in the native hairpin (Figure 2).

The multiple sequence differences between I5Y6T11T13Lyt $\mathrm{A}_{239-252}$ variant and the parent peptide (Figure 2) do not allow a simple explanation for the remarkable loss of $\beta$-hairpin stability in terms of particular contributing cross-strand interactions. On the one hand, the overall $\beta$-sheet propensity is even higher than for the parent peptide (Table 1). ${ }^{[9]}$ Moreover, there are two favourable cross-strand interactions in this variant, the face-to-edge Trp3/Tyr12 interaction, preserved from the parent peptide, and the hydrophobic cross-strand lle5/Trp10 interaction. However, the latter may not be able to compensate for the stability provided by the cation- $\pi$ Lys $5 / \operatorname{Trp} 10$ pair observed in the parent peptide, which is also missing in the unfolded S3S10- and I3V10-Lyt $\mathrm{A}_{239-252}$ variants (see above). Interactions at the non-Trp containing face (face 2 ), which are completely

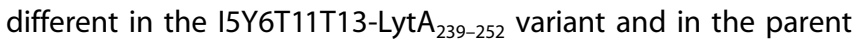
peptide (Figure 2), might also account for the differences in $\beta$ hairpin stability (Table 2).

On the whole, these results reinforce the idea that details of the cross-strand interactions, particularly with the participation of Trp residues, ${ }^{[14 b, 23 d, 25]}$ are essential to $\beta$-hairpin formation in CBRs, as a consequence of the sub-optimal $\beta$-turn sequences. In fact, residues Trp3, Lys5, Trp10 and Tyr12 are extremely conserved in these positions $(>30 \%)$ in the approximately 90 CBRs already described for $S$. pneumoniae, ${ }^{[3]}$ pointing to an es- 
sential dual role for these amino acids both as native hairpin stabilisers and as participants in choline binding. ${ }^{[3]}$

\section{Determinants of $\alpha$-helix formation in micelles}

All designed variants either maintain or decrease to a variable extent both the hydrophobicity of the peptides and the amphipathicity of the putative $\alpha$-helix to be inserted in DPC micelles (Table 1); hence, an increase of helix propensity was not necessarily expected. Nevertheless, all variants except S3S10Lyt $\mathrm{A}_{239-252}$ still acquire a significant extent of $\alpha$-helical conformation in the presence of DPC micelles (Table 2), comparable to the wild-type form, demonstrating that incorporation of some polar side chains in the hydrophobic face of the helix (leading to a decreased hydrophobic moment) does not prevent insertion into a micelle.

The Lyt $\mathrm{A}_{239-252}$ sequence contains two Trp residues that are both located at the hydrophobic face of the detergent-induced $\alpha$-helix and oriented towards the micelle core (Figure 1). ${ }^{[4]}$ Trp residues have been described to be important for peptide/ membrane and protein/membrane interactions. ${ }^{[26]}$ However, the Trp-free 13V10-Lyt $\mathrm{A}_{239-252}$ variant interacts with the micelles almost as effectively as the wild-type sequence does (Table 2 , Figure 5), suggesting that the specific contribution of Trp residues to helix stability is small in this system. On the other hand, the introduction of two polar Ser residues in positions 3 and 10 in the S3S10-Lyt $A_{239-252}$ peptide clearly abolishes helix formation, as expected for a dramatic decrease in both hydrophobicity and helix amphipathicity (Figure 2 and Table 1, Table 2).

In the search for theoretical determinants that control the insertion of CBR-derived peptides into micelles, we analysed several general parameters of the peptides, such as mean hydrophobicity and mean hydrophobic moment, and applied the usual analysis for lipid/micelles interacting sequences. The lipid-binding discrimination factor, $D_{1}^{[8]}$ predicts that all these peptides should interact with micelles to a significant extent, even though S3S10-Lyt $\mathrm{A}_{239-252}$ acquires an almost negligible $\alpha$ helical conformation (Table 2, Figure 5). On the other hand, the commonly used Eisenberg plot suggests that all sequences (except the wild type) belong to the "globular" type with no predicted association to lipids/micelles (Figure 9A). Finally, neither hydrophobic moment $\left\langle\mu_{H}\right\rangle$ nor mean hydrophobicity $\langle H\rangle$ alone display a straightforward correlation with the amount of DPC-induced $\alpha$-helix (Figure 9B, C). Nevertheless, we have observed a linear relation between $\alpha$-helix content and the product of both parameters (Figure 9D), suggesting that both factors (amphipathicity and hydrophobicity) contribute together to the micelle insertion propensities of CBR-derived peptides. The underlying physical phenomenon behind this result deserves further investigation. In any case, it seems evident that peptides derived from CBRs not only constitute a unique example of micelle-induced $\beta$-hairpin to $\alpha$-helix transitions, ${ }^{[4]}$ but also represent a novel kind of micelle/lipid-interacting peptide that cannot be predicted as such with the usual procedures. A detailed characterization of these mechanisms will help to better understand biological mechanisms like translocation across membranes by signal peptide-independent, CBR-containing pneumococcal proteins such as the wild type LytA autolysin. Furthermore, these studies will also pave the way towards rational design of peptides, the structure of which can be modulated or changed in a controlled way by using micelle-forming agents as conformational-switch triggers, as well as the design of new types of lipid-inserting peptides with antimicrobial properties.

\section{Conclusion}

The $\beta$-hairpin core of pneumococcal CBRs owes much of its stability to cross-chain interactions involving the aromatic side chains. This dependence probably arises from the fact that the $\beta$-turn sequence is sub-optimal for a 2:2 $\beta$-hairpin. On the other hand, the interaction of these CBR-derived peptides with detergent micelles is less sensitive to changes in sequence. The capacity of these peptides to interact with micelles through a conformational $\beta \rightarrow \alpha$ switch cannot be predicted by using the usual bioinformatic procedures such as lipid-binding discrimination factor or Eisenberg plots. Remarkably, the extent of micelle insertion is directly proportional to both the mean hydrophobic moment and the mean hydrophobicity. All these results point to CBRs as representative sequences displaying a novel mechanism for peptide-lipid interactions.

\section{Experimental Section}

\section{Materials}

Dodecylphosphocholine (DPC) was purchased from Avanti Polar Lipids. The deuterated compounds $\left[\mathrm{D}_{38}\right] \mathrm{DPC}(98 \%)$, and $\mathrm{D}_{2} \mathrm{O}$ (99.9\%) were from Cambridge Isotope Lab (USA).

\section{Peptide synthesis}

Peptides, with free amino and carboxylate ends, were synthesised using Fmoc (fluorenyl-9-methyloxycarbonyl) solid-phase protocols and purified by reverse-phase HPLC up to $95 \%$ or more purity by Caslo Aps (Lyngby, Denmark). Peptide characterisation data are provided as Supporting Information.

\section{Theoretical analysis of peptide characteristics}

For all the peptide variants, the averaged $\beta$-sheet propensity $\langle\beta\rangle$ was obtained from Equation (1):

$\langle\beta\rangle=\frac{1}{n} \sum_{k} \beta_{k}$

in which $\beta_{k}$ is the $\beta$-sheet propensity for residue $k$ at the $\beta$-strand (residues 2-6 and 9-13) as reported by Fujiwara et al., ${ }^{[9]}$ and $n$ is the number of residues at the strands (10, in this case; Figure 2). The averaged $\alpha$-helical propensity $\langle\alpha\rangle$ was calculated from Equation (2):

$\langle\alpha\rangle=\frac{1}{n} \sum_{k} \alpha_{k}$ 
in which $\alpha_{k}$ is the $\alpha$-helical propensity for residue $k$ (residues 2-13) taken from Fujiwara et al., ${ }^{[9]}$ and $n$ is the number of helical residues $\left(12\right.$, in this case) ${ }^{[9]}$

The mean hydrophobicity $\langle H\rangle$ was calculated by using the Heliquest utilities (http://heliquest.ipmc.cnrs.fr) ${ }^{[27]}$ as Equation (3):

$\langle H\rangle=\frac{1}{N} \sum_{k=1}^{N} H_{k}$

in which $N$ is the total number of residues and $H_{k}$ is the hydrophobicity of residue $k$ using the Fauchere and Pliska scale. ${ }^{[10]}$

The mean hydrophobic moments $\left\langle\mu_{H}\right\rangle$ were calculated according to Eisenberg (1982), ${ }^{[7]}$ using the Heliquest utilities (http://heliquest.ipmc.cnrs.fr $)^{[27]}$ and the hmoment tool at the EMBOSS server (http://www.bioinformatics.nl/emboss-explorer) [Eq. (4)].

$$
\left\langle\mu_{H}\right\rangle=\mu_{H} / N
$$

in which $\mu_{H}$ is calculated by [Eq. (5)].

$\mu_{H}=\left(\left[\sum_{k=1}^{N} H_{k} \sin (k \delta)\right]^{2}+\left[\sum_{k=1}^{N} H_{k} \cos (k \delta)\right]^{2}\right)^{1 / 2}$

in which $\delta$ denotes the angle between two residues in an $\alpha$-helix $\left(100^{\circ}\right)$ and $H_{k}$ is the hydrophobicity of residue $k$. Heliquest uses the Fauchere and Pliska scale ${ }^{[10]}$ and EMBOSS the consensus Eisenberg scale. ${ }^{[7 a, b]}$

The lipid-binding discrimination factor $D$ was calculated as described by Keller [Eq. (6)]:[7c,8]

$D=0.944\langle H\rangle+0.33 z$

in which $z$ is the net charge of the peptide at the experimental $\mathrm{pH} 3.0$ (Table 1) and $\langle H\rangle$ is the mean hydrophobicity using the Fauchere scale mentioned above. ${ }^{[10]}$

The Eisenberg plot was conformed as primarily described by Eisenberg $^{[7 b]}$ and subsequently modified by Keller. ${ }^{[7]}$ Surface-seeking peptides are predicted to occur in or above the line [Eq. (7)]:

$\left\langle\mu_{H}\right\rangle=0.654-0.324\langle H\rangle$

Peptides below this boundary but with $\langle H\rangle>0.75$ are considered as transmembrane peptides. The rest are considered as globular (non-lipid-interacting).

\section{NMR study}

To prepare the NMR samples the lyophilised peptide was dissolved in $0.5 \mathrm{~mL}$ of solvent (Table 3). Peptide concentrations were 0.5
1.0 m M, unless otherwise indicated. Sodium 2,2-dimethyl-2-silapentane-5-sulfonate (DSS) was added as internal reference for ${ }^{1} \mathrm{H}$ chemical shifts. Minimal amounts of $\mathrm{NaOD}$ or $\mathrm{DCl}$ were used to adjust $\mathrm{pH}$, which was measured with a glass micro-electrode and not corrected for isotopic effects. Once adjusted to $\mathrm{pH} 3.0$, the samples were placed in $5 \mathrm{~mm}$ NMR tubes. Approximate peptide/ detergent ratios are indicated in each case. The peptide/detergent ratio was around 5:3 in the samples at sub-CMC detergent concentrations.

A Bruker Avance-600 spectrometer operating at a proton frequency of $600.1 \mathrm{MHz}$ and equipped with a cryoprobe was used for NMR spectra acquisition. Cryoprobe temperature was calibrated using a methanol sample. 1D ${ }^{1} \mathrm{H}$ NMR and 2D phase-sensitive two-dimensional correlated spectroscopy (COSY), total correlated spectroscopy (TOCSY), nuclear Overhauser enhancement spectroscopy (NOESY), and ${ }^{13} \mathrm{C}$ natural abundance ${ }^{1} \mathrm{H}-{ }^{13} \mathrm{C}$ heteronuclear single quantum coherence (HSQC) spectra were recorded by standard techniques at $25^{\circ} \mathrm{C}$, as previously reported. ${ }^{[4]}$ TOCSY and NOESY mixing times were $60 \mathrm{~ms}$ and $150 \mathrm{~ms}$, respectively. Some NOESY spectra were also acquired at a short mixing time $(80 \mathrm{~ms})$ to check the absence of spin diffusion in the presence of DPC micelles. Data were processed using the standard TOPSPIN program (Bruker Biospin, Karlsruhe, Germany), as described. ${ }^{[4]}{ }^{13} \mathrm{C} \delta$-values were indirectly referenced against the IUPAC-IUB recommended ${ }^{1} \mathrm{H} /{ }^{13} \mathrm{C}$ chemical shift ratio (0.25144953). ${ }^{[29]}$

Assignment of ${ }^{1} \mathrm{H}$ NMR signals was performed by analyses of the 2D NMR spectra using the SPARKY software (T. D. Goddard and D. G. Kneller, SPARKY 3, University of California, San Francisco) and following the standard sequential assignment strategy. ${ }^{[30]}$ The ${ }^{13} \mathrm{C}$ resonances were straightforwardly identified from the cross-peaks between the protons and the bound carbons observed in the ${ }^{1} \mathrm{H},{ }^{13} \mathrm{C}$ HSQC spectra. Tables $\mathrm{S} 1-\mathrm{S} 5$ list the ${ }^{1} \mathrm{H}$ and ${ }^{13} \mathrm{C}$ chemical shifts.

Structure populations were estimated from the ${ }^{1} \mathrm{H}_{\alpha}$ chemical shifts by following previously reported procedures ${ }^{[4,31]}$ which assumes a two-state folded/unfolded transition, with the folded state being a $\beta$-hairpin in aqueous solution and an $\alpha$-helix in the presence of DPC micelles. $\beta$-Hairpin percentages were obtained from the average of the positive $\Delta \delta_{H \alpha}$ values at the strand residues divided by $+0.40 \mathrm{ppm},{ }^{[11 \mathrm{a}]}$ which is the mean $\Delta \delta_{H \alpha}$ at protein $\beta$-strands, and multiplied by 100 . The $\alpha$-helix populations were obtained by multiplying by 100 the result obtained by dividing the average of the negative $\Delta \delta_{H \alpha}$ values of the helical residues by $-0.39 \mathrm{ppm}^{[11 \mathrm{al}]}$ which is the mean $\Delta \delta_{H \alpha}$ at protein $\alpha$-helices. Assuming an experimental error of $\pm 0.01 \mathrm{ppm}$ in the measurement of ${ }^{1} \mathrm{H} \delta$-values, the errors in the estimated populations are $\pm 3 \%$.

\section{Structure calculation}

Structure calculation was done by applying the standard iterative procedure for automatic NOE assignment of the CYANA 2.1 pro-

Table 3. Solution conditions used for NMR peptide samples.

Conditions

Detailed solvent compositions

\begin{tabular}{|c|c|c|}
\hline Aqueous solution & $\mathrm{H}_{2} \mathrm{O} / \mathrm{D}_{2} \mathrm{O} 9: 1(\mathrm{v} / \mathrm{v})$ & $\mathrm{D}_{2} \mathrm{O}(99.96 \%$ purity) \\
\hline DPC micelles ${ }^{[a]}$ & $\begin{array}{l}30 \mathrm{mM}\left[\mathrm{D}_{38}\right] \mathrm{DPC} \text { in } \mathrm{H}_{2} \mathrm{O} / \mathrm{D}_{2} \mathrm{O} 9: 1(\mathrm{v} / \mathrm{v}) \\
15 \mathrm{mM}\left[\mathrm{D}_{38}\right] \mathrm{DPC}+15 \mathrm{mM} \text { DPC in } \mathrm{H}_{2} \mathrm{O} / \mathrm{D}_{2} \mathrm{O} 9: 1(\mathrm{v} / \mathrm{v})\end{array}$ & $\begin{array}{l}30 \mathrm{mM}\left[\mathrm{D}_{38}\right] \mathrm{DPC} \text { in } \mathrm{D}_{2} \mathrm{O} \\
15 \mathrm{mM}\left[\mathrm{D}_{38}\right] \mathrm{DPC}+15 \mathrm{mM} \mathrm{DPC} \text { in } \mathrm{D}_{2} \mathrm{O} 9: 1(\mathrm{v} / \mathrm{v}) \\
80 \mathrm{mM}\left[\mathrm{D}_{38}\right] \mathrm{DPC} \text { in } \mathrm{D}_{2} \mathrm{O}\end{array}$ \\
\hline DPC monomer ${ }^{[a]}$ & $0.5 \mathrm{mM}\left[\mathrm{D}_{38}\right] \mathrm{DPC}$ in $\mathrm{H}_{2} \mathrm{O} / \mathrm{D}_{2} \mathrm{O} 9: 1(\mathrm{v} / \mathrm{v})$ & $0.5-0.6 \mathrm{mM}\left[\mathrm{D}_{38}\right] \mathrm{DPC}$ in $\mathrm{D}_{2} \mathrm{O}$ \\
\hline
\end{tabular}


gram, which performs seven cycles of combined automated NOE assignment and structure calculation of 100 conformers per cycle. ${ }^{[32]}$ As experimental input data, we used the lists of: 1) assigned chemical shifts, 2) NOE integrated cross-peaks observed in 150 ms NOESY spectra, and 3) $\phi$ and $\psi$ dihedral angle restraints, which were derived from ${ }^{1} \mathrm{H}$ and ${ }^{13} \mathrm{C}$ chemical shifts using TALOSn webserver. ${ }^{[33]} \mathrm{NOE}$ cross-peaks were integrated by the automatic integration subroutine of SPARKY software (T. D. Goddard and D. G. Kneller, SPARKY 3, University of California, San Francisco). The program MOLMOL ${ }^{[34]}$ was used to visualize and examine the final ensembles of the 20 lowest target function conformers, and PROCHECK/NMR as implemented at the Protein Structure Validation Suite server (PSVS server: http://psvs-1_4-dev.nesg.org/) to assess their quality.

\section{CD study}

First, stock solutions of the peptides at a nominal concentration of $1 \mathrm{mg} \mathrm{mL}^{-1}$ were prepared by dissolving them in milliQ-water. For samples in aqueous solution, dilutions of the peptide stocks were made in $\mathrm{Gly}-\mathrm{HCl}$ buffer ( $\mathrm{pH}$ 3.0). For samples in DPC micelles, dilutions were made from a $30 \mathrm{~mm}$ DPC stock solution in $\mathrm{Gly}-\mathrm{HCl}$ buffer ( $\mathrm{pH}$ 3.0). In both conditions, peptide final concentrations were $30 \mu \mathrm{m}$.

CD spectra of these samples were recorded with a J-815 spectropolarimeter (JASCO, Groß-Umstadt, Germany). Measurements were performed in quartz glass cells (Suprasil, Hellma, Müllheim, Germany) of $1 \mathrm{~mm}$ path length, between 260 and $180 \mathrm{~nm}$ at $0.1 \mathrm{~nm}$ intervals. Spectra were recorded at $30^{\circ} \mathrm{C}$, using a water-thermostatted rectangular cell holder. Three repeat scans at a scan-rate of $10 \mathrm{~nm} \mathrm{~min}^{-1}, 8 \mathrm{~s}$ response time and $1 \mathrm{~nm}$ bandwidth, were averaged for each sample and for the baseline of the corresponding peptide-free sample. After subtracting the baseline spectra from the sample spectra, CD data were processed with the adaptive smoothing method, which is part of the Jasco Spectra Analysis software, and then converted into mean residue ellipticities ([$\theta])$.

\section{Fluorescence}

Intrinsic fluorescence measurements were performed at $25^{\circ} \mathrm{C}$ with a PTI-QuantaMaster fluorimeter (Birmingham, NJ, USA), model QM$62003 \mathrm{SE}$, using a $5 \times 5 \mathrm{~mm}$ path-length cuvette and peptide concentrations of $1 \mu \mathrm{M}$. Buffer was $20 \mathrm{~mm}$ glycine at pH 3.0. Tryptophan emission spectra were acquired using an excitation wavelength of $280 \mathrm{~nm}$, with excitation and emission slits of $1.0 \mathrm{~nm}$ and a scan rate of $60 \mathrm{~nm} \mathrm{~min}^{-1}$.

\section{Acknowledgements}

This work was supported by the Spanish MINECO grants (co-financed by European FEDER funds): CTQ2017-84371-P, CTQ2014-52633-P, BIO2016-79323-R and BIO2013-47684-R; and by the German Helmholtz Gemeinschaft. H. Zamora-Carreras was a recipient of a FPI scholarship (BES-2012-057717), and his stay at KIT, Germany was financed by the Spanish MINECO short stay grant EEBB-I-14-08805. We thank Dr. Jochen Bürck and his team for the CD facilities at IBG2. We also thank $M$. Garzón and R. Aldomar for excellent technical assistance.

\section{Conflict of interest}

The authors declare no conflict of interest.

Keywords: micelles - peptides - protein folding • protein structures $\cdot$ structural biology

[1] a) D. L. Minor, Jr., P. S. Kim, Nature 1996, 380, 730-734; b) W. Li, L. N. Kinch, P. A. Karplus, N. V. Grishin, Protein Sci. 2015, 24, 1075-1086; c) M. Lella, R. Mahalakshmi, Biochemistry 2017, 56, $2971-2984$.

[2] W. Kabsch, C. Sander, Proc. Natl. Acad. Sci. USA 1984, 81, 1075-1078.

[3] B. Maestro, J. M. Sanz, Antibiotics 2016, 5, 21.

[4] H. Zamora-Carreras, B. Maestro, E. Strandberg, A. S. Ulrich, J. M. Sanz, M. A. Jiménez, Chem. Eur. J. 2015, 21, 8076-8089.

[5] a) X. I. Ambroggio, B. Kuhlman, Curr. Opin. Struct. Biol. 2006, 16, $525-$ 530; b) K. Pagel, B. Koksch, Curr. Opin. Chem. Biol. 2008, 12, 730-739.

[6] R. S. Signarvic, W. F. Degrado, J. Am. Chem. Soc. 2009, 131, 3377-3384.

[7] a) D. Eisenberg, R. M. Weiss, T. C. Terwilliger, Nature 1982, 299, 371 -374; b) D. Eisenberg, R. M. Weiss, T. C. Terwilliger, Proc. Natl. Acad. Sci. USA 1984, 81, 140-144; c) R. C. Keller, Int. J. Mol. Sci. 2011, 12, 5577-5591.

[8] R. C. Keller, Cell Mol. Biol. Lett. 2011, 16, 40-54.

[9] K. Fujiwara, H. Toda, M. Ikeguchi, BMC Struct. Biol. 2012, 12, 18.

[10] J. L. Fauchere, V. Pliska, Eur. J. Med. Chem. 1983, 18, 369-375.

[11] a) D. S. Wishart, B. D. Sykes, F. M. Richards, J. Mol. Biol. 1991, 222, 311 333 ; b) S. Spera, A. Bax, J. Am. Chem. Soc. 1991, 113, 5490-5492.

[12] a) C. M. Santiveri, M. Rico, M. A. Jiménez, J. Biomol. NMR 2001, 19, 331 345 ; b) R. M. Fesinmeyer, F. M. Hudson, K. A. Olsen, G. W. White, A. Euser, N. H. Andersen, J. Biomol. NMR 2005, 33, 213-231.

[13] a) C. M. Santiveri, E. León, M. Rico, M. A. Jiménez, Chem. Eur. J. 2008, 14, 488-499; b) C. M. Santiveri, M. Rico, M. A. Jiménez, Protein Sci. 2000, 9, $2151-2160$.

[14] a) N. H. Andersen, K. A. Olsen, R. M. Fesinmeyer, X. Tan, F. M. Hudson, L. A. Eidenschink, S. R. Farazi, J. Am. Chem. Soc. 2006, 128, 6101-6110 b) C. M. Santiveri, M. A. Jiménez, Biopolymers 2010, 94, 779-790.

[15] a) J. M. Sánchez-Puelles, J. M. Sanz, J. L. García, E. García, Eur J Biochem 1992, 203, 153-159; b) B. Maestro, J. M. Sanz, Biochem. J. 2005, 387, $479-488$.

[16] W. C. Johnson, Jr., Annu. Rev. Biophys. Biophys. Chem. 1988, 17, $145-$ 166.

[17] S. Abel, F. Y. Dupradeau, M. Marchi, J. Chem. Theory Comput. 2012, 8, 4610-4623.

[18] a) G. Wang, W. D. Treleaven, R. J. Cushley, Biochim. Biophys. Acta 1996, 1301, 174-184; b) X. Gao, T. C. Wong, Biopolymers 2001, 58, 20-32; c) M. Adrover, P. Sanchis, B. Vilanova, K. Pauwels, G. Martorell, J. J. Perez, RSC Adv. 2015, 5, 83074-83088.

[19] E. de Alba, M. A. Jiménez, M. Rico, J. Am. Chem. Soc. 1997, 119, $175-$ 183.

[20] a) C. M. Santiveri, J. Santoro, M. Rico, M. A. Jiménez, J. Am. Chem. Soc. 2002, 124, 14903-14909; b) S. H. Gellman, Curr. Opin. Chem. Biol. 1998 2, 717-725; c) H. E. Stanger, S. H. Gellman, J. Am. Chem. Soc. 1998, 120 4236-4237; d) F. Blanco, M. Ramirez-Alvarado, L. Serrano, Curr. Opin. Struct. Biol. 1998, 8, 107-111; e) E. de Alba, M. Rico, M. A. Jiménez, Protein Sci. 1999, 8, 2234-2244; f) F. A. Syud, H. E. Stanger, S. H. Gellman, J. Am. Chem. Soc. 2001, 123, 8667-8677; g) T. Blandl, A. G. Cochran, N. J. Skelton, Protein Sci. 2003, 12, 237-247; h) R. Rai, S. Raghothama, P. Balaram, J. Am. Chem. Soc. 2006, 128, 2675-2681; i) M. A. Jiménez, Meth ods Mol. Biol. 2014, 1216, 15-52; j) J. M. Anderson, B. Jurban, K. N. Huggins, A. A. Shcherbakov, I. Shu, B. Kier, N. H. Andersen, Biochemistry 2016, 55, 5537-5553.

[21] a) E. de Alba, M. Rico, M. A. Jiménez, Protein Sci. 1997, 6, 2548-2560; b) M. S. Searle, Biopolymers 2004, 76, 185-195; c) R. M. Hughes, M. L. Waters, Curr. Opin. Struct. Biol. 2006, 16, 514-524.

[22] L. Wu, D. McElheny, T. Takekiyo, T. A. Keiderling, Biochemistry 2010, 49, $4705-4714$.

[23] a) S. J. Russell, A. G. Cochran, J. Am. Chem. Soc. 2000, 122, 12600 12601 ; b) A. G. Cochran, N. J. Skelton, M. A. Starovasnik, Proc. Natl. Acad. Sci. USA 2001, 98, 5578-5583; c) R. M. Fesinmeyer, F. M. Hudson, N. H. Andersen, J. Am. Chem. Soc. 2004, 126, 7238-7243; d) R. Mahalakshmi, 
S. Raghothama, P. Balaram, J. Am. Chem. Soc. 2006, 128, 1125-1138; e) Y. Mirassou, C. M. Santiveri, M. J. P. de Vega, R. González-Muñiz, M. A. Jiménez, Chembiochem 2009, 10,902-910.

[24] M. A. Wouters, P. M. Curmi, Proteins 1995, 22, 119-131.

[25] K. M. Makwana, R. Mahalakshmi, Protein Sci. 2015, 24, 1920-1933.

[26] a) M. R. de Planque, B. B. Bonev, J. A. Demmers, D. V. Greathouse, R. E. Koeppe II, F. Separovic, A. Watts, J. A. Killian, Biochemistry 2003, 42, 5341-5348; b) W. M. Yau, W. C. Wimley, K. Gawrisch, S. H. White, Biochemistry 1998, 37, 14713-14718.

[27] R. Gautier, D. Douguet, B. Antonny, G. Drin, Bioinformatics 2008, 24, 2101-2102.

[28] a) C. R. Sanders, F. Sonnichsen, Magn. Reson. Chem. 2006, 44, S24-S40; b) P. Palladino, F. Rossi, R. Ragone, J. Fluoresc. 2010, 20, 191-196.

[29] J. L. Markley, A. Bax, Y. Arata, C. W. Hilbers, R. Kaptein, B. D. Sykes, P. E. Wright, K. Wüthrich, Pure Appl. Chem. 1998, 70, 117-142.
[30] a) K. Wüthrich, M. Billeter, W. Braun, J. Mol. Biol. 1984, 180, 715-740 b) K. Wüthrich, NMR of proteins and nucleic acids, Wiley, New York, 1986.

[31] R. Vila, I. Ponte, M. A. Jiménez, M. Rico, P. Suau, Protein Sci. 2002, 11, 214-220.

[32] P. Güntert, Methods Mol. Biol. 2004, 278, 353-378.

[33] Y. Shen, A. Bax, J. Biomol. NMR 2013, 56, 227-241.

[34] R. Koradi, M. Billeter, K. Wüthrich, J. Mol. Graphics 1996, 14, 51-55.

Manuscript received: October 11, 2017

Accepted manuscript online: January 25, 2018

Version of record online: $\mathbf{\square} \mathbf{\square I}, 0000$ 


\section{FULL PAPER}

Peptide Folding

H. Zamora-Carreras, B. Maestro, E. Strandberg, A. S. Ulrich, J. M. Sanz, * M. Á. Jiménez*

Roles of Amphipathicity and Hydrophobicity in the Micelle-Driven Structural Switch of a 14-mer Peptide Core from a Choline-Binding Repeat
TGWKKIADKWYYFN

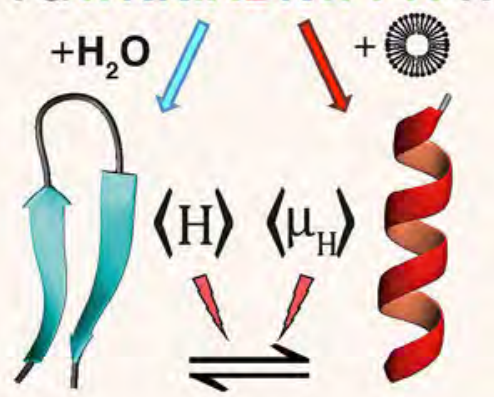

Switch hunt: In the micelle-induced $\beta$ hairpin to $\alpha$-helix switch of a 14-mer peptide derived from a choline-binding repeat, Trp sidechain interactions are essential for $\beta$-hairpin stability in aqueous solution, and both amphipathicity and hydrophobicity contribute to helix stability in the presence of detergent micelles. 


\section{CHEMISTRY A European Journal}

\section{Supporting Information}

Roles of Amphipathicity and Hydrophobicity in the Micelle-Driven Structural Switch of a 14-mer Peptide Core from a CholineBinding Repeat

Héctor Zamora-Carreras ${ }_{,}^{[a]}$ Beatriz Maestro ${ }^{+[b]}$ Erik Strandberg, ${ }^{[c]}$ Anne S. Ulrich, ${ }^{[c, d]}$ Jesús M. Sanz, ${ }^{*[b, e]}$ and M. Ángeles Jiménez ${ }^{*[a]}$

chem_201704802_sm_miscellaneous_information.pdf 


\section{Supporting information}

\section{List of contents:}

Additional experimental details: Peptide characterisation data and measurement of peptide concentration

\section{References}

Figure S1. Profiles of ${ }^{1} \mathrm{H}_{\alpha}{ }^{13} \mathrm{C}_{\alpha}$ and ${ }^{13} \mathrm{C}_{\beta}$ conformational shifts for $\mathrm{Lyt}_{239-252}$ and the designed variants in aqueous solution.

Figure S2. 2D ${ }^{1} \mathrm{H},{ }^{1} \mathrm{H}-\mathrm{NOESY}$ spectra for I5Y6T11T13-LytA ${ }_{239-252}$ in aqueous solution.

Figure S3. 2D ${ }^{1} \mathrm{H},{ }_{1}^{1} \mathrm{H}-\mathrm{NOESY}$ spectra for S3S10- and I3V10-LytA ${ }_{239-252}$ in aqueous solution.

Figure S4. Effect of DPC below and above CMC on LytA $\mathrm{A}_{239-252}$ variants monitored by NMR.

Figure S5. Profiles of ${ }^{1} \mathrm{H}_{\alpha}$ and ${ }^{13} \mathrm{C}_{\alpha}$ conformational shifts for $\mathrm{Lyt}_{239-252}$ and the designed variants in $30 \mathrm{mM}$ DPC.

Figure S6. NOE summaries for the peptides K3W5-, W5K10-, I3V10- and I5Y6T11T12-LytA $239-252$ in the presence of DPC micelles.

Figure S7. Effect of peptide/micelle ratio on $\mathrm{LytA}_{239-252}$ and the designed variants monitored by NMR.

Figure S8. Profiles of ${ }^{1} \mathrm{H}_{\alpha}$ conformational shifts for $\mathrm{LytA}_{239-252}$ and the designed variants in $30 \mathrm{mM}$ DPC and in $80 \mathrm{mM}$ DPC.

Figures S9-S10. 2D ${ }^{1} \mathrm{H},{ }^{1} \mathrm{H}-\mathrm{NOESY}$ spectra showing peptide/DPC NOEs.

Figure S11. Graph representations of the NMR-calculated amount of $\alpha$-helix in DPC micelles as a function of $\langle\alpha\rangle$

Tables S1-S5. List of chemical shifts for the designed variants in aqueous solution and in the presence of DPC micelles.

Table S6. Summary of non-sequential cross-strand NOEs involving side chain protons observed in aqueous solution

Table S7. Structural statistics parameters for the ensemble of the 20 lowest target function conformers calculated for peptide $\mathrm{LytA}_{239-252}$ in aqueous solution and in micelles.

Table S8. ${ }^{1} \mathrm{H}$ chemical shifts $(\delta$, ppm) for side chains of $3 / 12$ and $5 / 10$ cross-strand pairs in Trp-containing peptides in aqueous solution. 


\section{Additional experimental details}

\section{Peptide characterisation data}

LytA239-252 (TGWKKIADKWYYFN): RP-HPLC: $\mathrm{t}_{\mathrm{R}}=10.9 \mathrm{~min} ; 98.4 \%$ (linear 18-36 \% B gradient in 18 min; buffer A: $0.05 \%$ TFA in $\mathrm{H}_{2} \mathrm{O} / \mathrm{CH}_{3} \mathrm{CN}$ 98:2; buffer B: $0.05 \%$ TFA in $\mathrm{H}_{2} \mathrm{O} / \mathrm{CH}_{3} \mathrm{CN} 1$ :9). HRMS: Theoretical molecular weight $=1820.10$; Found $[\mathrm{M}+\mathrm{H}]^{+}=$ 1820.56. (Reported in Chem. Eur. J. 2015) ${ }^{[1]}$

K3W5-LytA239-252 (TGKKWIADKWYYFN): RP-HPLC: $t_{\mathrm{R}}=10.6 \mathrm{~min} ; 99.6 \%$ (linear 22-37 \% B gradient in 18 min; buffer A: $0.05 \%$ TFA in $\mathrm{H}_{2} \mathrm{O} / \mathrm{CH}_{3} \mathrm{CN}$ 98:2; buffer B: 0.05 $\%$ TFA in $\mathrm{H}_{2} \mathrm{O} / \mathrm{CH}_{3} \mathrm{CN}$ 1:9). HRMS: Theoretical molecular weight $=1820.10$; Found $[\mathrm{M}+\mathrm{H}]^{+}=1820.17$.

W5K10-LytA239-252 (TGWKWIADKKYYFN): RP-HPLC: $\mathrm{t}_{\mathrm{R}}=10.8 \mathrm{~min} ; 98.7 \%$ (linear 22-37 \% B gradient in 18 min; buffer A: $0.05 \%$ TFA in $\mathrm{H}_{2} \mathrm{O} / \mathrm{CH}_{3} \mathrm{CN}$ 98:2; buffer B: 0.05 $\%$ TFA in $\mathrm{H}_{2} \mathrm{O} / \mathrm{CH}_{3} \mathrm{CN}$ 1:9). HRMS: Theoretical molecular weight $=1820.10$; Found $[\mathrm{M}+\mathrm{H}]^{+}=1821.11$.

I5Y6T11T13-LytA239-252 (TGWKIYADKWTYTN): RP-HPLC: $t_{\mathrm{R}}=9.9 \mathrm{~min} ; 98.6 \%$ (linear 22-37 \% B gradient in 15 min; buffer A: $0.05 \%$ TFA in $\mathrm{H}_{2} \mathrm{O} / \mathrm{CH}_{3} \mathrm{CN} 98: 2$; buffer B: $0.05 \%$ TFA in $\mathrm{H}_{2} \mathrm{O} / \mathrm{CH}_{3} \mathrm{CN}$ 1:9). HRMS: Theoretical molecular weight $=1746.96$; Found $[\mathrm{M}+\mathrm{H}]^{+}=1747.70$.

S3S10-LytA239-252 (TGSKKIADKSYYFN): RP-HPLC: $\mathrm{t}_{\mathrm{R}}=12.0 \mathrm{~min} ; 99.3 \%$ (linear 12$30 \%$ B gradient in 18 min; buffer A: $0.05 \%$ TFA in $\mathrm{H}_{2} \mathrm{O} / \mathrm{CH}_{3} \mathrm{CN}$ 98:2; buffer B: $0.05 \%$ TFA in $\mathrm{H}_{2} \mathrm{O} / \mathrm{CH}_{3} \mathrm{CN}$ 1:9). HRMS: Theoretical molecular weight $=1621.82$; Found $[\mathrm{M}+\mathrm{H}]^{+}=1823.78$.

I3V10-LytA239-252 (TGIKKIADKVYYFN): RP-HPLC: $\mathrm{t}_{\mathrm{R}}=9.9 \mathrm{~min} ; 98.1 \%$ (linear 18$33 \%$ B gradient in 15 min; buffer A: $0.05 \%$ TFA in $\mathrm{H}_{2} \mathrm{O} / \mathrm{CH}_{3} \mathrm{CN}$ 98:2; buffer $\mathrm{B}: 0.05 \%$ TFA in $\mathrm{H}_{2} \mathrm{O} / \mathrm{CH}_{3} \mathrm{CN}$ 1:9). HRMS: Theoretical molecular weight $=1659.96$; Found $[\mathrm{M}+\mathrm{H}]^{+}=1660.17$.

\section{Measurement of peptide concentration}

Peptide concentration was calculated by UV-absorbance spectroscopy. Absorption spectra were recorded from 340 to $240 \mathrm{~nm}$ in a quartz glass half-micro-cuvette with $1 \mathrm{~cm}$ optical path length (Hellma, Müllheim). Theoretical molar extinction coefficients of the peptides were calculated for each case on the basis of amino acid composition using the values of $1490 \mathrm{~L} \mathrm{~mol}^{-1} \mathrm{~cm}^{-1}$ and $5500 \mathrm{~L} \mathrm{~mol}^{-1} \mathrm{~cm}^{-1}$ for the Tyr and Trp absorption at 280 $\mathrm{nm}$, respectively. ${ }^{[2]}$

\section{References}

[1] H. Zamora-Carreras, B. Maestro, E. Strandberg, A. S. Ulrich, J. M. Sanz, M. A. Jimenez, Chemistry 2015, 21, 8076-8089.

[2] C. N. Pace, F. Vajdos, L. Fee, G. Grimsley, T. Gray, Protein Sci 1995, 4, 2411 2423.

[3] D. S. Wishart, C. G. Bigam, A. Holm, R. S. Hodges, B. D. Sykes, J Biomol NMR 1995, 5, 67-81. 

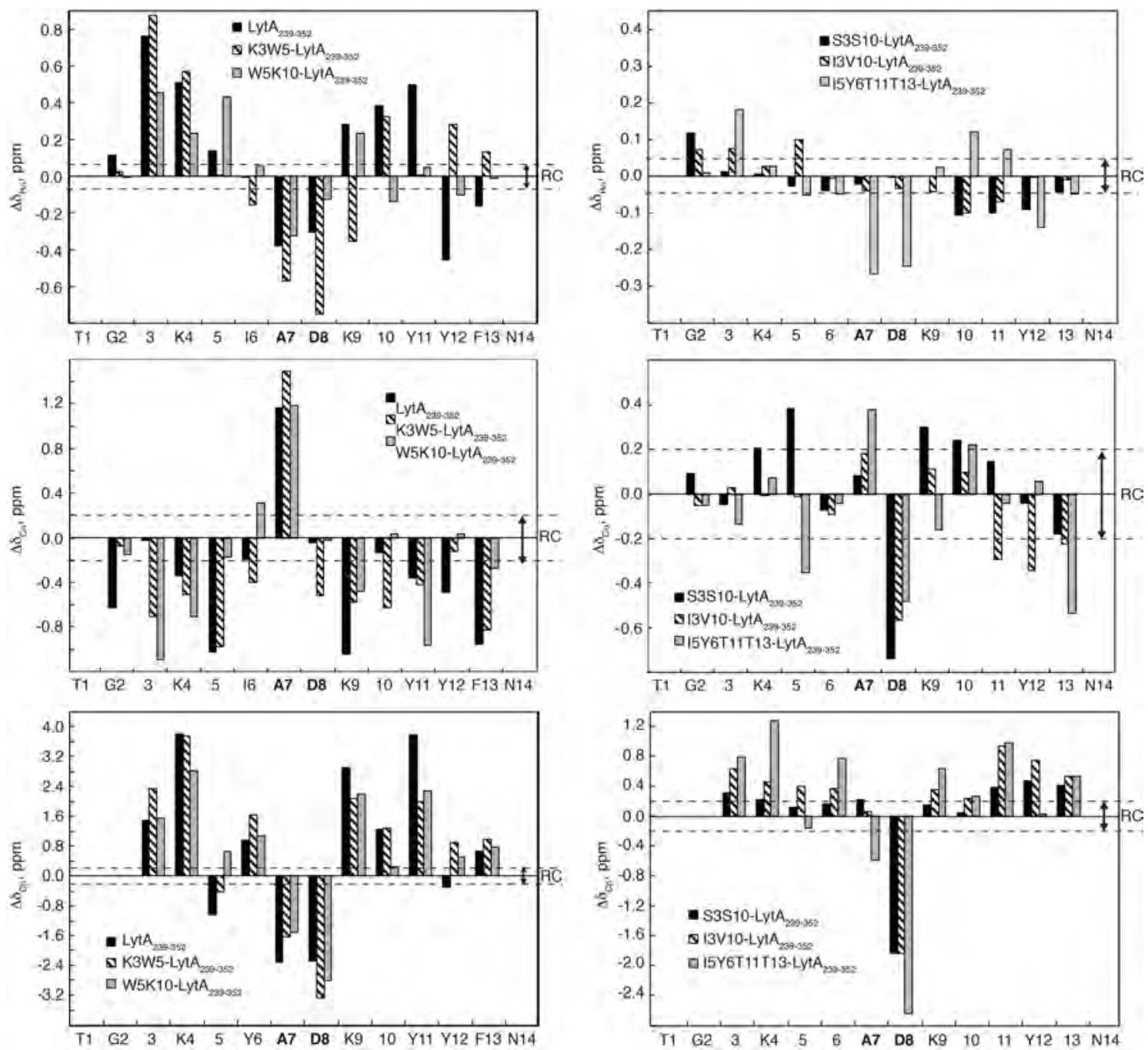

Figure S1. Bar plots of $\Delta \delta_{\mathrm{H} \alpha}\left(\Delta \delta_{\mathrm{H} \alpha}=\delta_{\mathrm{H} \alpha}{ }^{\text {observed }}-\delta_{\mathrm{H} \alpha}{ }^{\mathrm{RC}}, \mathrm{ppm}\right), \Delta \delta_{\mathrm{C} \alpha}\left(\Delta \delta_{\mathrm{C} \alpha}=\delta_{\mathrm{C} \alpha}{ }^{\text {observed }}\right.$ $\left.\delta_{\mathrm{C} \alpha}{ }^{\mathrm{RC}}, \mathrm{ppm}\right)$ and $\Delta \delta_{\mathrm{C} \beta}\left(\Delta \delta_{\mathrm{C} \beta}=\delta_{\mathrm{C} \beta}{ }^{\text {observed }}-\delta_{\mathrm{C} \beta}{ }^{\mathrm{RC}}\right.$, ppm) as a function of sequence for LytA239-252 and the designed peptide variants in $\mathrm{D}_{2} \mathrm{O}$ at $\mathrm{pH} 3.0$ and $25^{\circ} \mathrm{C} . \delta_{\mathrm{H \alpha}}{ }^{\mathrm{RC}}, \delta_{\mathrm{C} \alpha}{ }^{\mathrm{RC}}$ and $\delta_{C \beta}{ }^{\mathrm{RC}}$ values were taken from Wishart et al. 1995. ${ }^{[3]}$ Values for the $\mathrm{N}$ - and C-terminal residues are not shown. The averaged value of the two $\mathrm{H} \alpha$ and $\mathrm{H} \alpha$ ' protons is shown for G2. At the X-axis, residues differing from wild type sequence are labelled only by number. Turn residues are marked in bold. The dashed lines indicate the random coil (RC) range. Unit spaces at the vertical scale of the right panels are twice those of the top panel. 


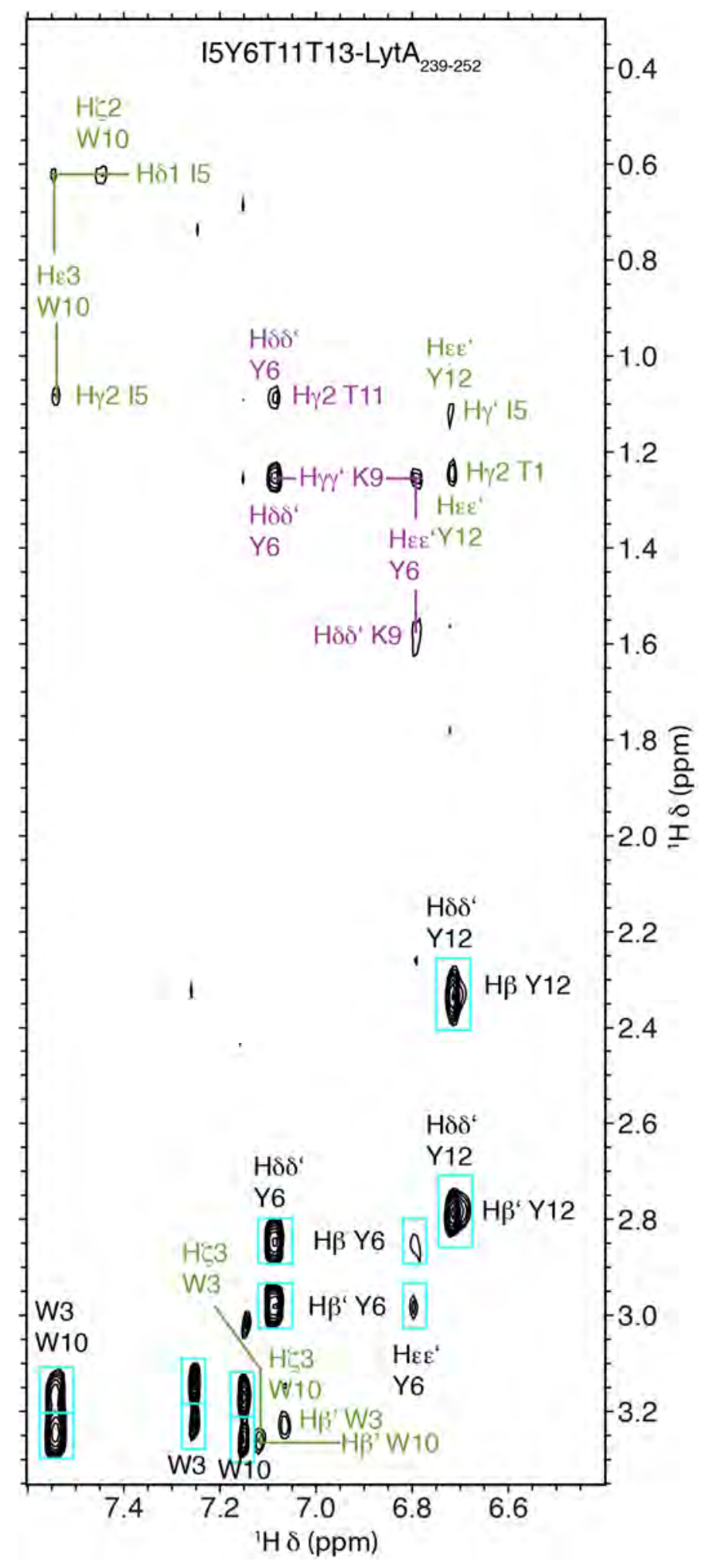

Figure S2. Selected 2D ${ }^{1} \mathrm{H},{ }^{1} \mathrm{H}-\mathrm{NOESY}$ spectral region of peptide I5Y6T11T13-LytA239252 in $\mathrm{D}_{2} \mathrm{O}$ at $\mathrm{pH} 3.0$ and $25{ }^{\circ} \mathrm{C}$ showing non-sequential NOEs involving side chain protons. Those from H-bonded residues (face 1) are labelled in magenta, and those from non-H-bonded residues (the Trp-containing face; face 2) are in green. Intra-residual NOE cross-peaks are boxed in cyan. They correspond to NOEs between aromatic protons and $\mathrm{H}_{\beta \beta}$, protons. 


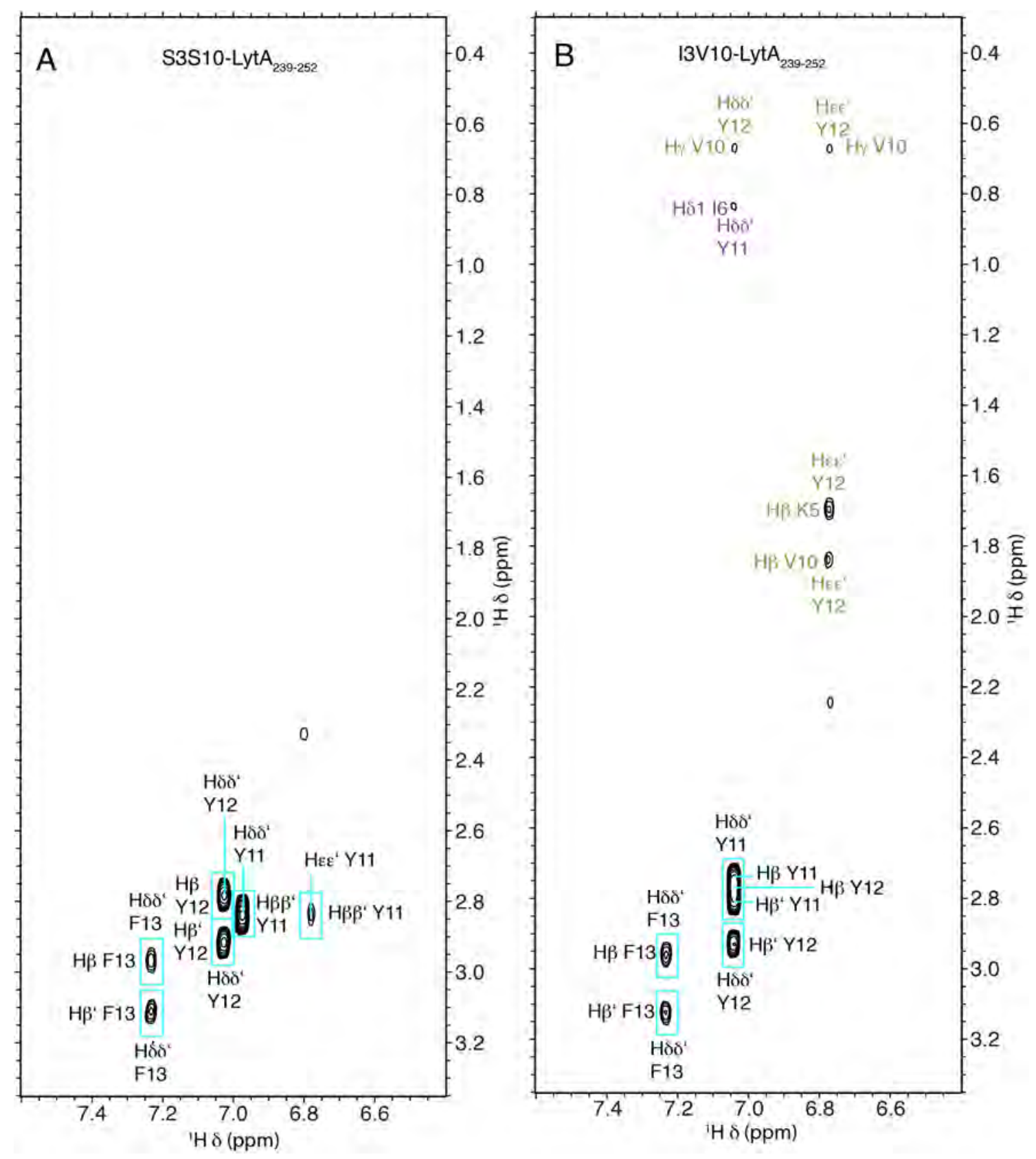

Figure S3. 2D ${ }^{1} \mathrm{H},{ }^{1} \mathrm{H}-\mathrm{NOESY}$ spectra of peptides S3S10-LytA $239-252$ (A) and I3V10LytA239-252 (B) in $\mathrm{D}_{2} \mathrm{O}$ at $\mathrm{pH} 3.0$ and $25^{\circ} \mathrm{C}$. Region showing NOEs between aromatic protons (from Y11, Y12 and F13) and aliphatic protons. Those from H-bonded residues (face 1) are labelled in magenta, and those from non-H-bonded residues (face 2) are in green. Intra-residual NOE cross-peaks are boxed in cyan. They correspond to NOEs between aromatic protons and $\mathrm{H}_{\beta \beta}$, protons, as indicated. 


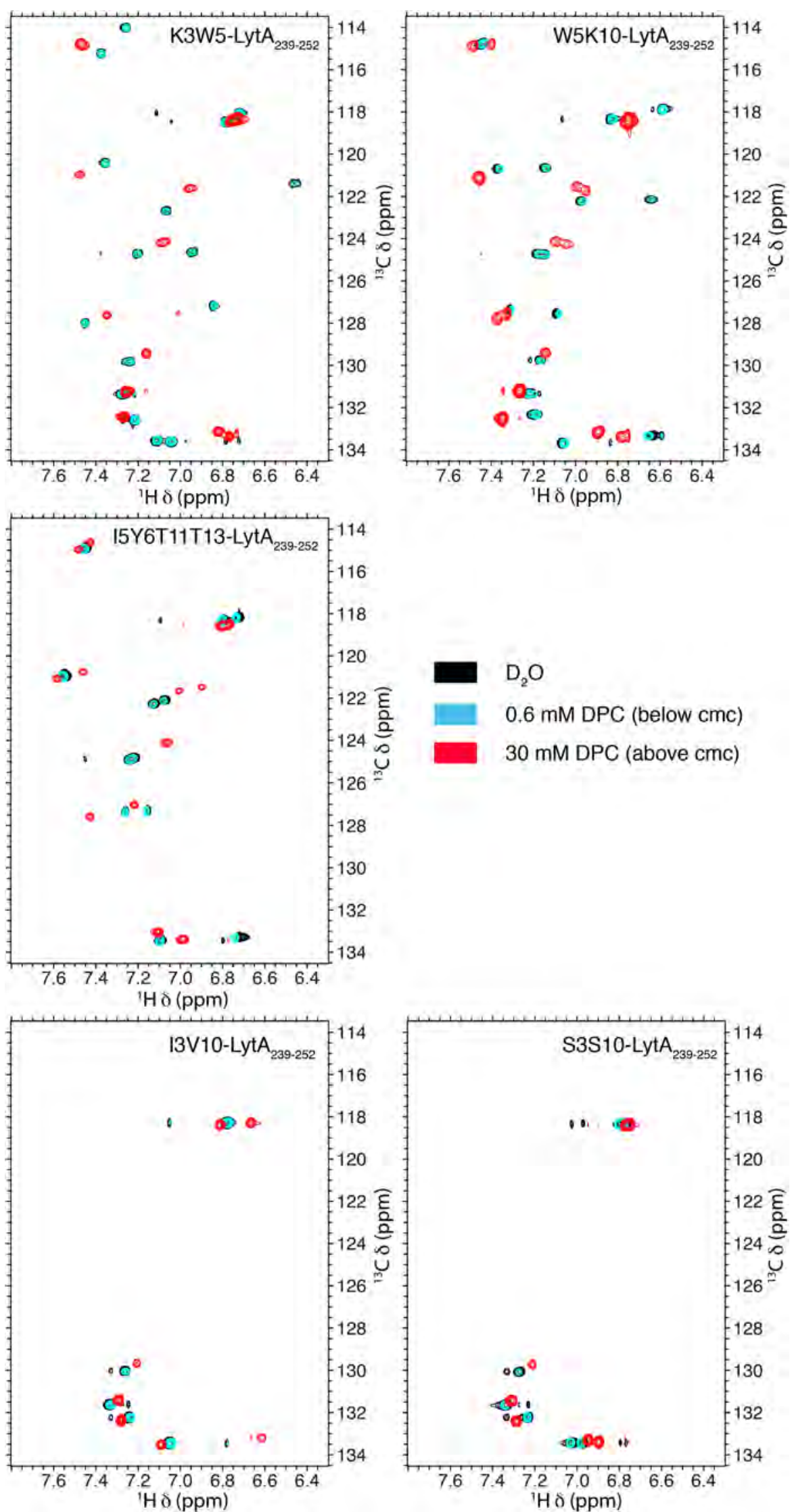

Figure S4. Superposition of $2 \mathrm{D}{ }^{1} \mathrm{H},{ }^{13} \mathrm{C}-\mathrm{HSQC}$ spectra of LytA239-252 variants in $\mathrm{D}_{2} \mathrm{O}$ (black contours), in $0.6 \mathrm{mM}$ [D38]-DPC (below CMC; cyan contours), and in $30 \mathrm{mM}$ [D38]-DPC (above cmc; red contours). All spectra recorded at $25^{\circ} \mathrm{C}$ and $\mathrm{pH} 3.0$. The cross-peaks of the aromatic Trp, Tyr, and Phe rings are seen. 

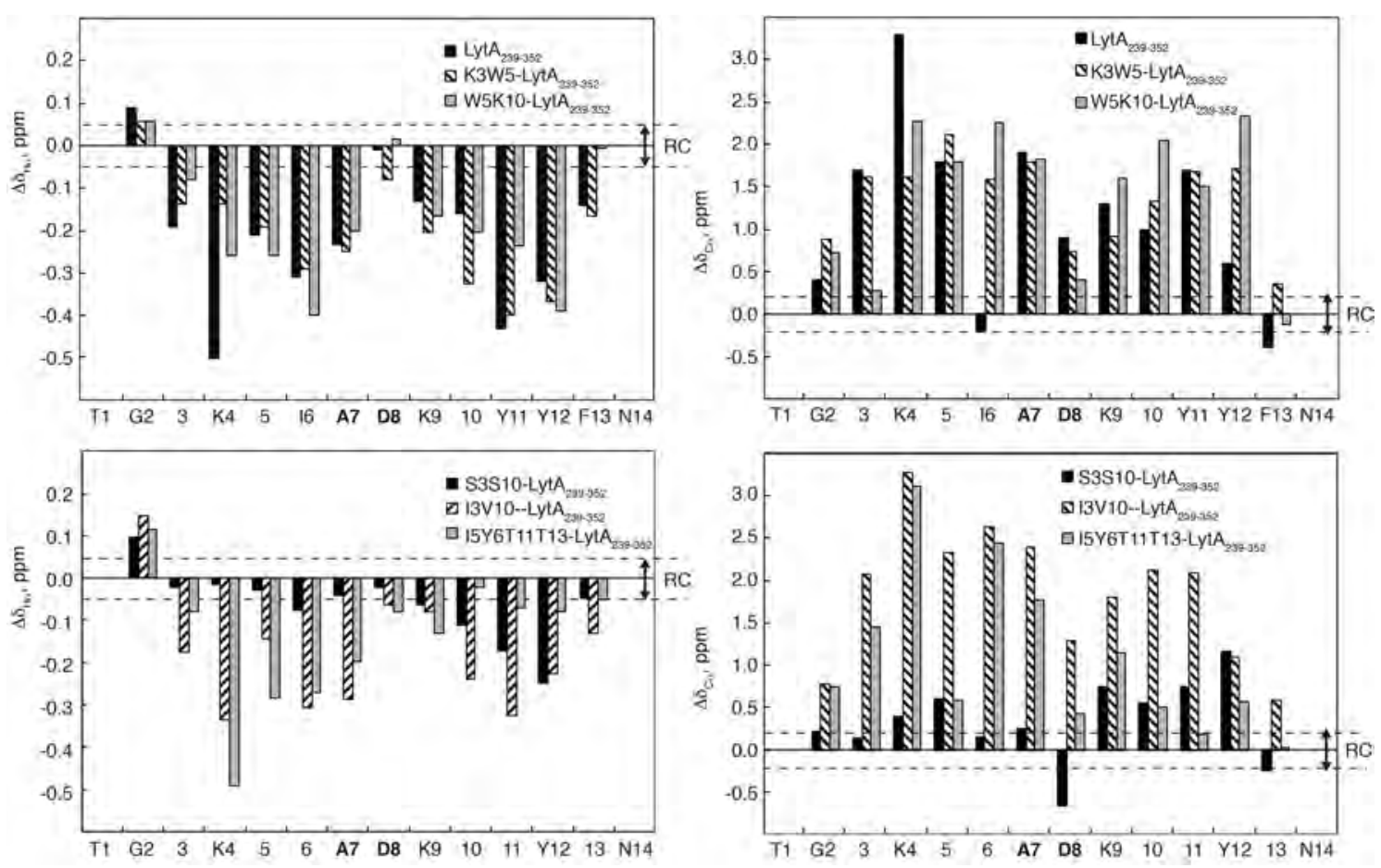

Figure S5. Bar plots of $\Delta \delta_{\mathrm{H} \alpha}\left(\Delta \delta_{\mathrm{H} \alpha}=\delta_{\mathrm{H} \alpha}{ }^{\text {observed }}-\delta_{\mathrm{H} \alpha}{ }^{\mathrm{RC}}, \mathrm{ppm}\right)$ and $\Delta \delta_{\mathrm{C} \alpha}\left(\Delta \delta_{\mathrm{C} \alpha}=\delta_{\mathrm{C} \alpha}{ }^{\text {observed }}\right.$ $\left.-\delta_{\mathrm{Ca}}^{\mathrm{RC}}, \mathrm{ppm}\right)$ as a function of sequence for LytA239-252 and the designed peptide variants in $30 \mathrm{mM}\left[\mathrm{D}_{38}\right]-\mathrm{DPC}$ in $\mathrm{D}_{2} \mathrm{O}$ at $\mathrm{pH} 3.0$ and $25^{\circ} \mathrm{C} . \delta_{\mathrm{H} \alpha}{ }^{\mathrm{RC}}$ and $\delta_{\mathrm{C} \alpha}{ }^{\mathrm{RC}}$ values were taken from Wishart et al. ${ }^{[3]}$ Values for the $\mathrm{N}$ - and C-terminal residues are not shown. At the $\mathrm{x}$-axis, residues differing from the wild type sequence are labelled only by number. Turn residues are in bold. The dashed lines indicate the random coil (RC) range. The vertical scale of the bottom panel is twice that of the top panel. 


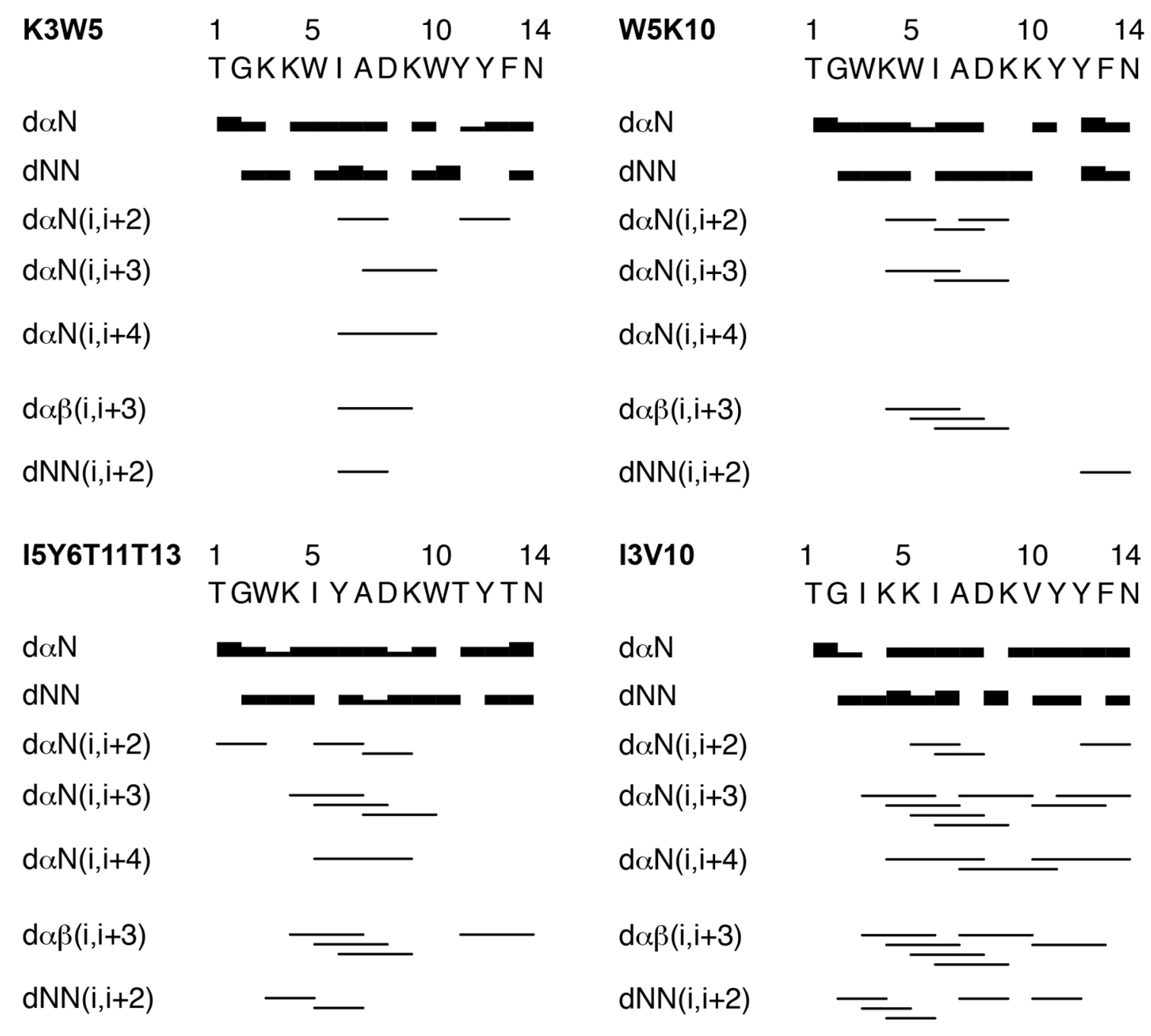

Figure S6. NOE summaries for the peptides K3W5-, W5K10-, I3V10-, and I5Y6T11T13-LytA239-252 in $30 \mathrm{mM}$ [D38]-DPC, at $25{ }^{\circ} \mathrm{C}$ and $\mathrm{pH}$ 3.0. The intensities of the sequential NOEs (strong, medium and weak) are indicated by the thickness of the lines. 

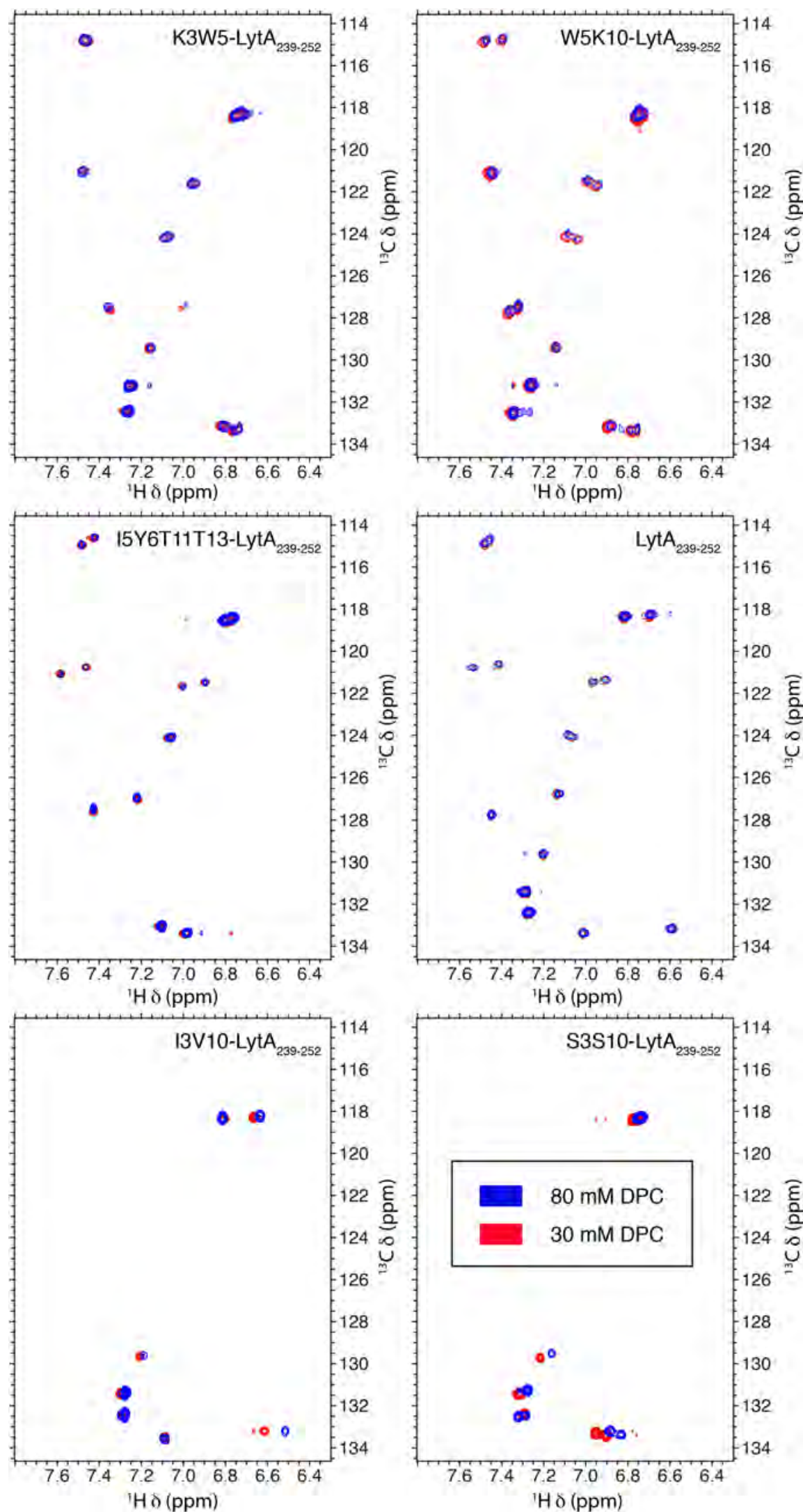

Figure S7. Superposition of $2 \mathrm{D}{ }^{1} \mathrm{H},{ }^{13} \mathrm{C}-\mathrm{HSQC}$ spectra of LytA $239-252$ and the designed variants in $30 \mathrm{mM}$ (red contours) and $80 \mathrm{mM}$ [D38]-DPC (blue contours). All spectra recorded at $25^{\circ} \mathrm{C}$ and $\mathrm{pH} 3.0$. The cross-peaks of the aromatic Trp, Tyr, and Phe rings are seen. 

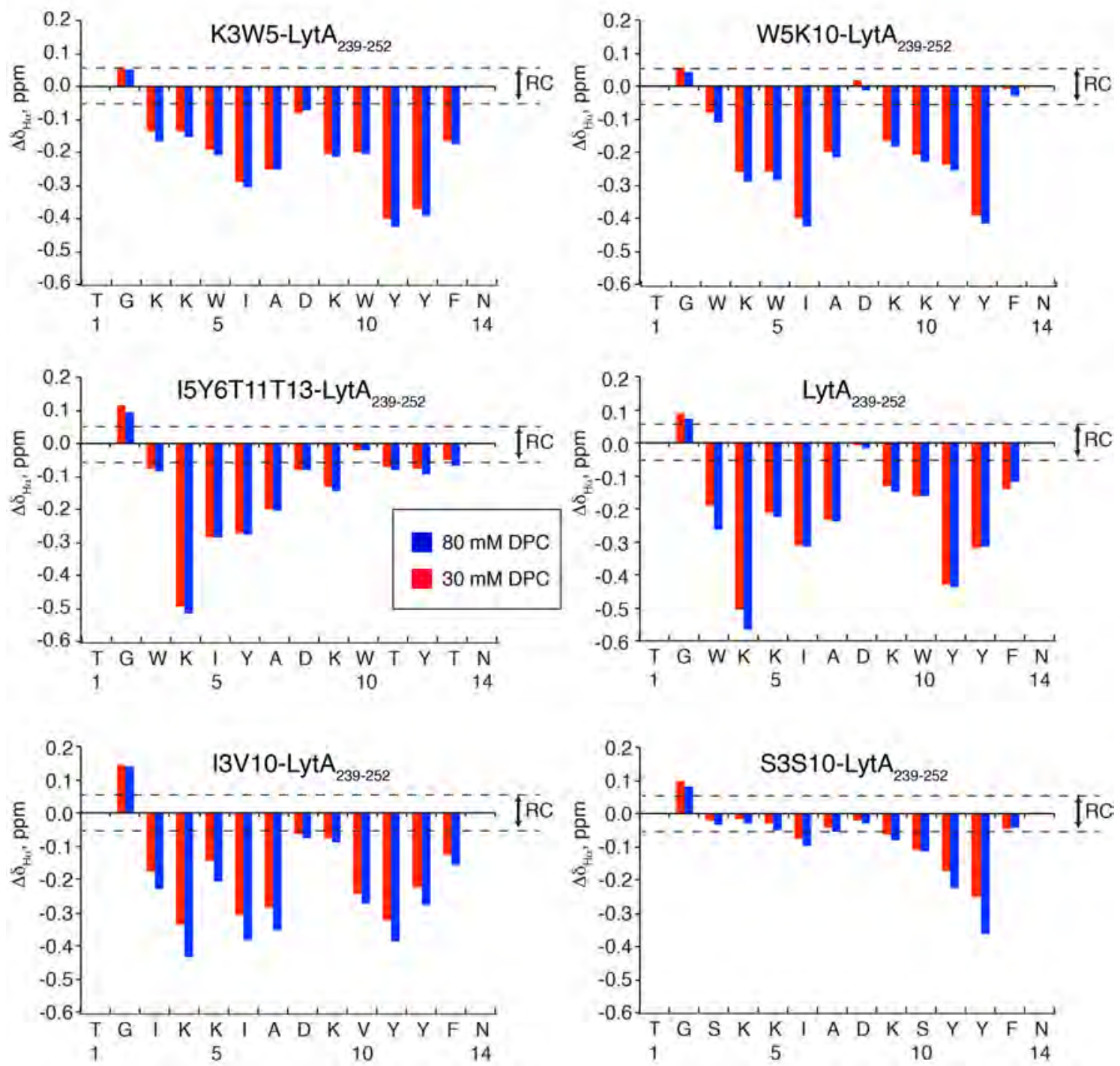

Figure S8. Bar plots of $\Delta \delta_{\mathrm{H} \alpha}\left(\Delta \delta_{\mathrm{H} \alpha}=\delta_{\mathrm{H} \alpha}{ }^{\text {observed }}-\delta_{\mathrm{H} \alpha}{ }^{\mathrm{RC}}, \mathrm{ppm}\right)$ as a function of sequence for LytA239-252 and the designed peptide variants in $30 \mathrm{mM}\left[\mathrm{D}_{38}\right]-\mathrm{DPC}$ (red contours) and in $80 \mathrm{mM}\left[\mathrm{D}_{38}\right]-\mathrm{DPC}$ (blue contours) at $\mathrm{pH} 3.0$ and $25^{\circ} \mathrm{C} . \delta_{\mathrm{C} \beta}{ }^{\mathrm{RC}}$ values were taken from Wishart et al., 1995. ${ }^{[3]}$ Values for the N- and C-terminal residues are not shown. The dashed lines indicate the random coil $(\mathrm{RC})$ range. 


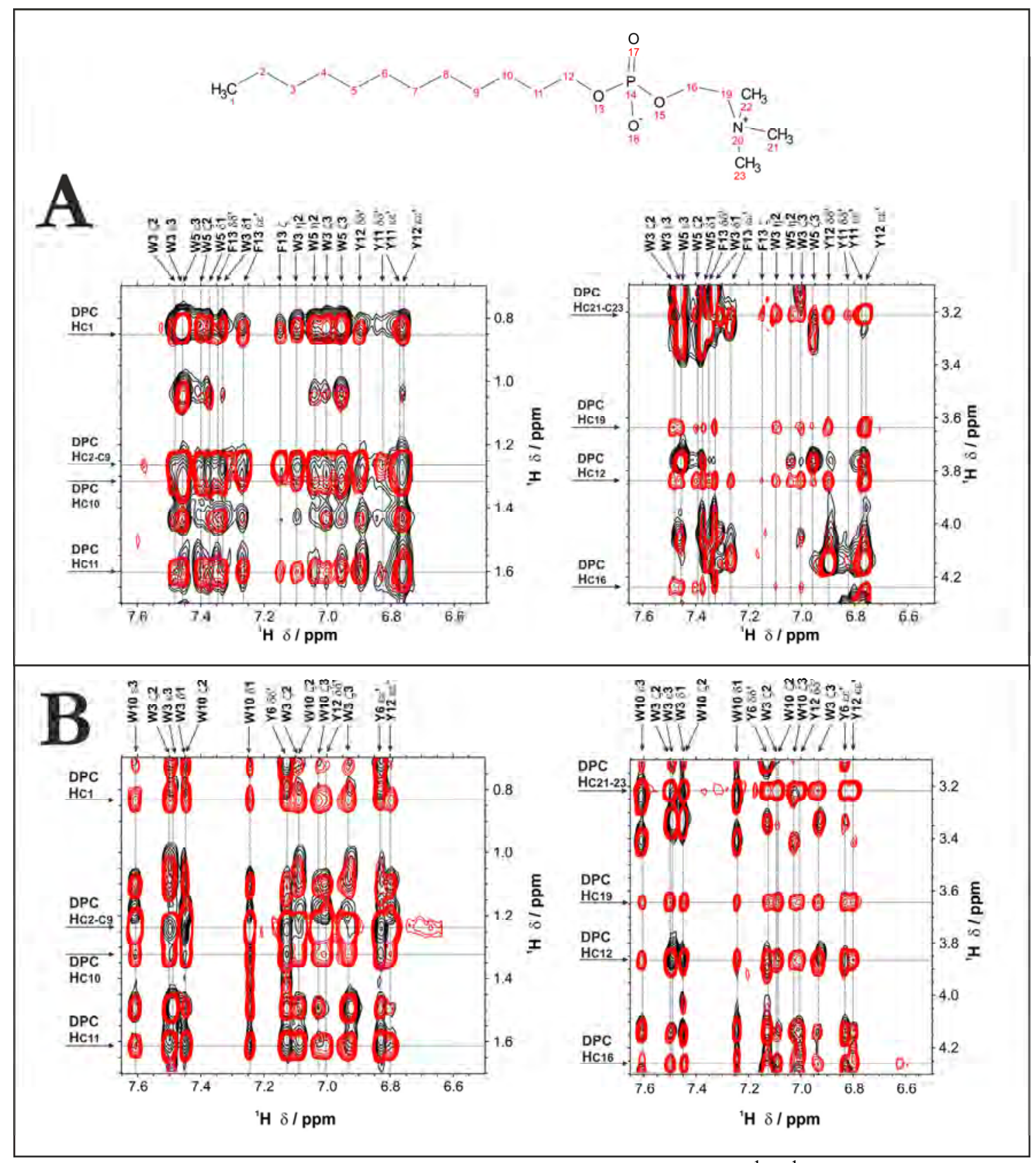

Figure S9. NOEs peptide/DPC for peptide variants. $2 \mathrm{D}{ }^{1} \mathrm{H},{ }^{1} \mathrm{H}-\mathrm{NOESY}$ spectral regions of W5K10-LytA239-252 (A), and I5Y6T11T13- LytA239-252 (B) in 15 mM [D 38$]-$ DPC and $15 \mathrm{mM}$ non-deuterated DPC (red contours) overlap onto the same regions in 30 $\mathrm{mM}\left[\mathrm{D}_{38}\right]-\mathrm{DPC}$ (black contours). Spectra were recorded at $25^{\circ} \mathrm{C}$ and $\mathrm{pH}$ 3.0. DPC and aromatic protons are indicated with arrows in the left vertical axis and in the top horizontal axis, respectively. The structure of a DPC molecule is shown on top (atoms are numbered). 


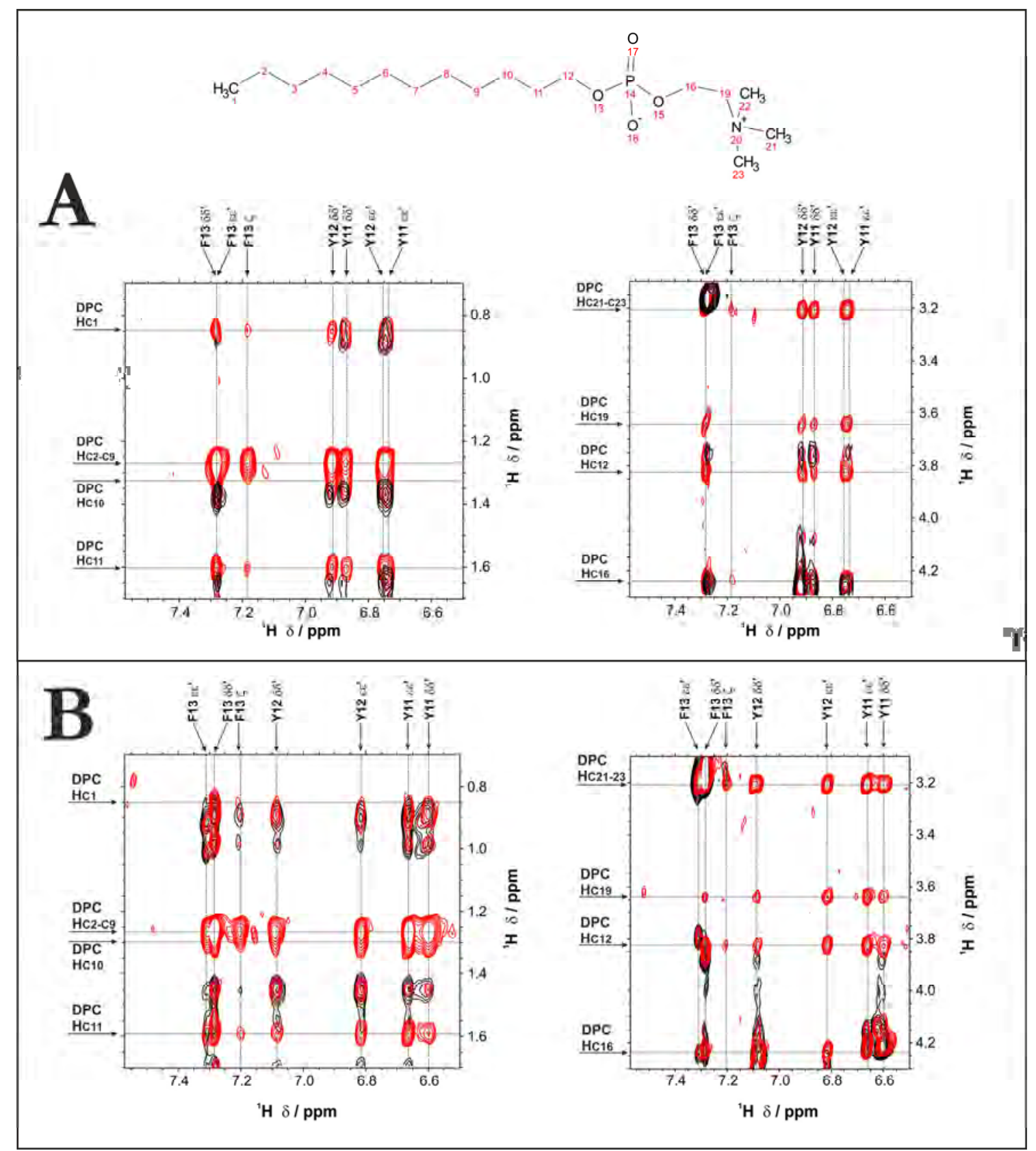

Figure S10. NOEs peptide/DPC for peptide variants. $2 \mathrm{D}{ }^{1} \mathrm{H},{ }_{1}^{1} \mathrm{H}-\mathrm{NOESY}$ spectral regions of S3S10-LytA239-252 (A), and I3V10-LytA239-252 (B) in $15 \mathrm{mM}$ [D38]-DPC and $15 \mathrm{mM}$ non-deuterated DPC (red contours) overlap onto the same regions in $30 \mathrm{mM}$ [D38]-DPC (black contours). Spectra were recorded at $25{ }^{\circ} \mathrm{C}$ and $\mathrm{pH}$ 3.0. DPC and aromatic protons are indicated with arrows in the left vertical axis and in the top horizontal axis, respectively. The structure of a DPC molecule is shown on top (atoms are numbered). 


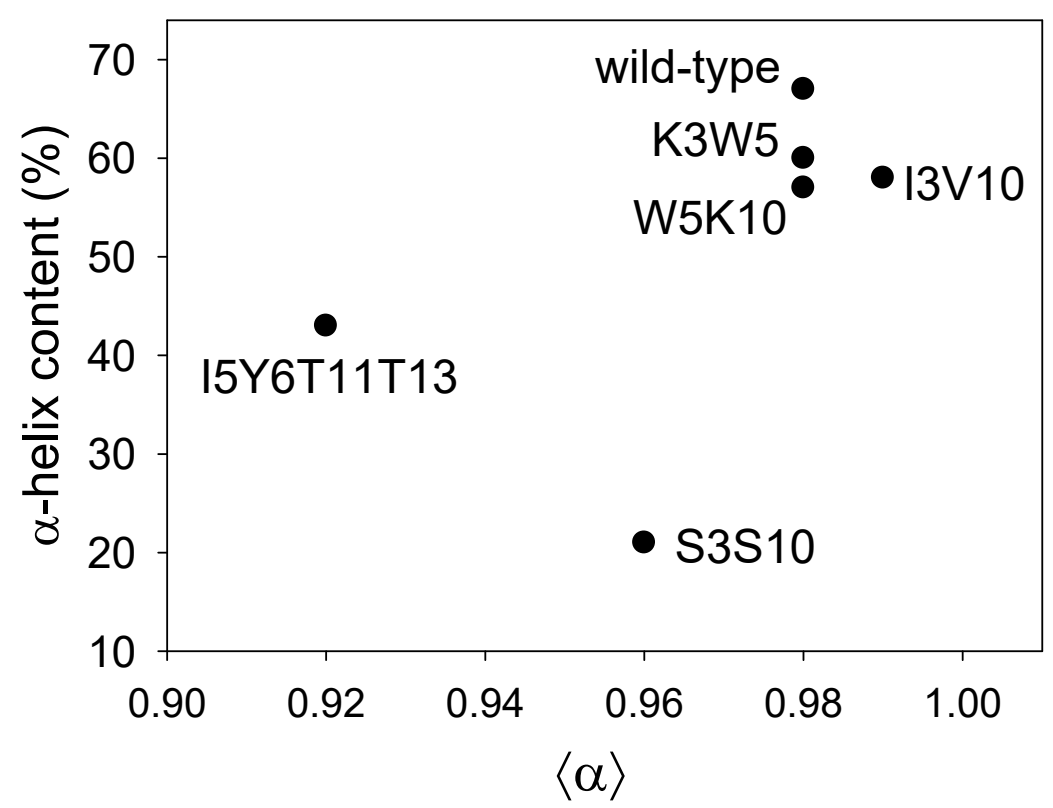

Figure S11. Graph representations of the NMR-calculated amount of $\alpha$-helix in DPC micelles as a function of $\langle\alpha\rangle$ 
Table S1. ${ }^{1} \mathrm{H}$ and ${ }^{13} \mathrm{C}$ chemical shifts (ppm from DSS) of peptide K3W5-LytA $239-252$ in aqueous solution $\left(\mathrm{H}_{2} \mathrm{O} / \mathrm{D}_{2} \mathrm{O} 9: 1 \mathrm{v} / \mathrm{v}\right)$ and in $30 \mathrm{mM}\left[\mathrm{D}_{38}\right]-\mathrm{DPC}$ at $\mathrm{pH} 3.0$ and $25^{\circ} \mathrm{C}$. "nd" stands for not determined. "Measured in $\mathrm{D}_{2} \mathrm{O}$ broad signal

\begin{tabular}{|c|c|c|c|c|c|}
\hline & Condition & \multicolumn{2}{|c|}{$\mathrm{H}_{2} \mathrm{O} / \mathrm{D}_{2} \mathrm{O} 9: 1(\mathrm{v} / \mathrm{v})$} & \multicolumn{2}{|c|}{$30 \mathrm{mM}$ DPC-d38 } \\
\hline \multicolumn{2}{|c|}{ Peptide structure } & \multicolumn{2}{|c|}{$\beta$-hairpin } & \multicolumn{2}{|c|}{$\alpha$-helix } \\
\hline Residue & Resonance & ${ }^{1} \mathrm{H} \delta, \mathrm{ppm}$ & ${ }^{13} \mathrm{C} \delta, \mathrm{ppm}$ & ${ }^{1} \mathrm{H} \delta, \mathrm{ppm}$ & ${ }^{13} \mathrm{C} \delta, \mathrm{ppm}$ \\
\hline \multirow[t]{3}{*}{ Thr 1 (239) } & $\mathrm{C}_{\alpha} \mathrm{H}$ & 4.04 & 61.8 & 3.99 & 61.5 \\
\hline & $\mathrm{C}_{\beta} \mathrm{H}$ & 4.16 & 69.5 & 4.30 & 69.3 \\
\hline & $\mathrm{C}_{\gamma} \mathrm{H}_{3}$ & 1.35 & 21.8 & 1.34 & 21.8 \\
\hline \multirow[t]{2}{*}{ Gly 2 (240) } & $\mathrm{H}_{\mathrm{N}}$ & 8.57 & & 9.12 & \\
\hline & $\mathrm{C}_{\alpha \alpha}, \mathrm{H}$ & $3.83,4.13$ & 45.1 & $3.99,4.07$ & 46.0 \\
\hline \multirow[t]{7}{*}{ Lys 3 (241) } & $\mathrm{H}_{\mathrm{N}}$ & 8.31 & & 8.56 & \\
\hline & $\mathrm{C}_{\alpha} \mathrm{H}$ & 5.19 & $55.5^{\mathrm{a}}$ & 4.22 & 57.8 \\
\hline & $\mathrm{C}_{\beta \beta}, \mathrm{H}$ & $1.42,1.58$ & 35.4 & $1.73,1.73$ & 33.1 \\
\hline & $\mathrm{C}_{\gamma \gamma}, \mathrm{H}$ & $1.04,1.04$ & 24.0 & $1.38,1.45$ & 25.2 \\
\hline & $\mathrm{C}_{\delta \delta}, \mathrm{H}$ & $0.84,1.21$ & 29.9 & 10.00 & 29.5 \\
\hline & $\mathrm{C}_{\varepsilon \varepsilon}, \mathrm{H}$ & $2.07,2.17$ & 41.8 & $2.90,2.90$ & 42.4 \\
\hline & $\mathrm{N}_{\zeta} \mathrm{H}_{3}$ & 6.96 & & 7.71 & \\
\hline \multirow[t]{7}{*}{ Lys 4 (242) } & $\mathrm{H}_{\mathrm{N}}$ & 9.17 & & 8.27 & \\
\hline & $\mathrm{C}_{\alpha} \mathrm{H}$ & $4.89^{\mathrm{a}}$ & $55.7^{\mathrm{a}}$ & 4.23 & 57.8 \\
\hline & $\mathrm{C}_{\beta \beta}, \mathrm{H}$ & $1.84,1.91$ & 36.8 & $1.78,1.83$ & 33.1 \\
\hline & $\mathrm{C}_{\gamma \gamma}, \mathrm{H}$ & $1.64,1.64$ & 25.2 & $1.42,1.45$ & 25.2 \\
\hline & $\mathrm{C}_{\delta \delta}^{\prime}, \mathrm{H}$ & $1.53,1.63$ & 29.7 & $1.68,1.68$ & 29.3 \\
\hline & $\mathrm{C}_{\varepsilon \varepsilon}, \mathrm{H}$ & $2.84,2.84$ & 42.3 & $2.98,2.98$ & 42.4 \\
\hline & $\mathrm{N}_{\zeta} \mathrm{H}_{3}$ & 7.51 & & 7.64 & \\
\hline \multirow[t]{9}{*}{$\operatorname{Trp} 5$ (243) } & $\mathrm{H}_{\mathrm{N}}$ & 8.84 & & 8.33 & \\
\hline & $\mathrm{C}_{\alpha} \mathrm{H}$ & 4.65 & $56.5^{\mathrm{a}}$ & 4.49 & $59.6^{\mathrm{a}}$ \\
\hline & $\mathrm{C}_{\beta \beta}, \mathrm{H}$ & $2.18,2.94$ & 29.2 & $3.33,3.33$ & 29.6 \\
\hline & $\mathrm{C}_{\delta 1} \mathrm{H}$ & 6.83 & 127.3 & 7.36 & 127.6 \\
\hline & $\mathrm{N}_{\varepsilon 1} \mathrm{H}$ & 9.75 & & 10.61 & \\
\hline & $\mathrm{C}_{\varepsilon 3} \mathrm{H}$ & $5.71^{\mathrm{b}}$ & nd & 7.47 & 121.0 \\
\hline & $\mathrm{C}_{\zeta 3} \mathrm{H}$ & 6.46 & 121.4 & 6.97 & 121.7 \\
\hline & $\mathrm{C}_{\eta 2} \mathrm{H}$ & 6.93 & 124.6 & 7.07 & 124.2 \\
\hline & $\mathrm{C}_{\zeta 2} \mathrm{H}$ & 7.24 & 114.1 & 7.48 & 114.8 \\
\hline \multirow[t]{6}{*}{ Ile 6 (244) } & $\mathrm{H}_{\mathrm{N}}$ & 8.38 & & 7.88 & \\
\hline & $\mathrm{C}_{\alpha} \mathrm{H}$ & 4.01 & 60.8 & 3.89 & 62.7 \\
\hline & $\mathrm{C}_{\beta} \mathrm{H}$ & 1.65 & 40.4 & 1.83 & 38.9 \\
\hline & $\mathrm{C}_{\gamma 2} \mathrm{H}_{3}$ & 0.70 & 17.1 & 0.86 & 18.0 \\
\hline & $\mathrm{C}_{\gamma \gamma 1}, \mathrm{H}$ & $0.94,1.34$ & 27.1 & $1.06,1.44$ & 28.3 \\
\hline & $\mathrm{C}_{\delta 1} \mathrm{H}_{3}$ & 0.62 & 13.2 & 0.83 & 13.7 \\
\hline \multirow[t]{3}{*}{ Ala 7 (245) } & $\mathrm{H}_{\mathrm{N}}$ & 8.59 & & 8.00 & \\
\hline & $\mathrm{C}_{\alpha} \mathrm{H}$ & 3.75 & 54.2 & 4.07 & 54.2 \\
\hline & $\mathrm{C}_{\beta} \mathrm{H}_{3}$ & 1.28 & 17.6 & 1.42 & 19.0 \\
\hline \multirow[t]{3}{*}{ Asp 8 (246) } & $\mathrm{H}_{\mathrm{N}}$ & 8.00 & & 8.27 & \\
\hline & $\mathrm{C}_{\alpha} \mathrm{H}$ & 3.91 & 54.2 & $4.56^{\mathrm{a}}$ & $54.9^{\mathrm{a}}$ \\
\hline & $\mathrm{C}_{\beta \beta}, \mathrm{H}$ & $2.77,2.86$ & 38.4 & $2.97,3.02$ & 42.3 \\
\hline \multirow[t]{7}{*}{ Lys 9 (247) } & $\mathrm{H}_{\mathrm{N}}$ & 6.85 & & 7.86 & \\
\hline & $\mathrm{C}_{\alpha} \mathrm{H}$ & 3.96 & 55.7 & 4.13 & 57.2 \\
\hline & $\mathrm{C}_{\beta \beta}, \mathrm{H}$ & $1.52,1.57$ & 35.2 & $1.60,1.65$ & 32.5 \\
\hline & $\mathrm{C}_{\gamma \gamma}, \mathrm{H}$ & $1.08,1.16$ & 24.0 & $0.99,1.15$ & 24.5 \\
\hline & $\mathrm{C}_{\delta \delta}^{\prime}, \mathrm{H}$ & $1.53,1.53$ & 29.4 & $1.40,1.45$ & 28.8 \\
\hline & $\mathrm{C}_{\varepsilon \varepsilon}, \mathrm{H}$ & $2.85,2.85$ & 42.3 & $2.58,2.76$ & 42.3 \\
\hline & $\mathrm{N}_{\zeta} \mathrm{H}_{3}$ & 7.46 & & 7.47 & \\
\hline
\end{tabular}




\begin{tabular}{llllll}
\hline & Condition & \multicolumn{2}{c}{$\mathrm{H}_{2} \mathrm{O} / \mathrm{D}_{2} \mathrm{O} 9: 1(\mathrm{v} / \mathrm{v})$} & \multicolumn{2}{c}{ 30 mM DPC-d38 } \\
\hline \multicolumn{2}{c}{ Peptide structure } & \multicolumn{2}{c}{$\beta$-hairpin } & \multicolumn{2}{c}{$\alpha$-helix } \\
\hline Residue & Resonance & ${ }^{1} \mathbf{H} \boldsymbol{\delta}, \mathbf{p p m}$ & ${ }^{\mathbf{1 3}} \mathbf{C} \boldsymbol{\delta}, \mathbf{p p m}$ & ${ }^{\mathbf{1}} \mathbf{H} \boldsymbol{\delta}, \mathbf{p p m}$ & ${ }^{13} \mathbf{C} \boldsymbol{\delta}, \mathbf{p p m}$ \\
\hline Trp 10 (248) & $\mathrm{H}_{\mathrm{N}}$ & 7.99 & & 7.98 & \\
& $\mathrm{C}_{\alpha} \mathrm{H}$ & 4.96 & 56.9 & 4.53 & $58.8^{\mathrm{a}}$ \\
& $\mathrm{C}_{\beta \beta} \cdot \mathrm{H}$ & $2.67,3.04$ & 30.9 & $3.23,3.23$ & 29.9 \\
& $\mathrm{C}_{\delta 1} \mathrm{H}$ & 7.42 & 128.1 & 7.02 & 127.5 \\
& $\mathrm{~N}_{\varepsilon 1} \mathrm{H}$ & 10.20 & & 10.52 & \\
& $\mathrm{C}_{\varepsilon 3} \mathrm{H}$ & 7.33 & 120.4 & 7.46 & 121.0 \\
& $\mathrm{C}_{\zeta 3} \mathrm{H}$ & 7.04 & 122.7 & 6.98 & 121.7 \\
& $\mathrm{C}_{\eta_{2} 2} \mathrm{H}$ & 7.18 & 124.7 & 7.10 & 124.4 \\
& $\mathrm{C}_{\zeta 2} \mathrm{H}$ & 7.35 & 115.3 & 7.47 & 114.8 \\
& ${ }^{13} \mathrm{C}_{\zeta 2}$ & & & & \\
Tyr 11 (249) & $\mathrm{H}_{\mathrm{N}}$ & 9.11 & & 7.98 & \\
& $\mathrm{C}_{\alpha} \mathrm{H}$ & 4.54 & $57.5^{\mathrm{a}}$ & 4.16 & 59.5 \\
& $\mathrm{C}_{\beta \beta} \cdot \mathrm{H}$ & $2.79,2.79$ & 40.8 & $2.70,2.88$ & 39.0 \\
& $\mathrm{C}_{\delta \delta} \cdot \mathrm{H}$ & $7.01,7.01$ & 133.6 & $6.77,6.77$ & 133.4 \\
& $\mathrm{C}_{\varepsilon \varepsilon} \mathrm{H}$ & $6.76,6.76$ & 118.5 & $6.77,6.77$ & 118.4 \\
Tyr 12 (250) & $\mathrm{H}_{\mathrm{N}}$ & 8.31 & & 7.61 & \\
& $\mathrm{C}_{\alpha} \mathrm{H}$ & $4.83^{\mathrm{a}}$ & $57.8^{\mathrm{a}}$ & 4.21 & 59.5 \\
& $\mathrm{C}_{\beta \beta} \cdot \mathrm{H}$ & $2.71,2.92$ & 39.8 & $2.71,2.83$ & 39.0 \\
& $\mathrm{C}_{\delta \delta} \cdot \mathrm{H}$ & $7.09,7.09$ & 133.5 & $6.83,6.83$ & 133.1 \\
& $\mathrm{C}_{\varepsilon \varepsilon} \mathrm{H}$ & $6.69,6.69$ & 118.1 & $6.74,6.74$ & 118.3 \\
Phe 13 (251) & $\mathrm{H}_{\mathrm{N}}$ & 8.15 & & 7.66 & \\
& $\mathrm{C}_{\alpha} \mathrm{H}$ & $4.76^{\mathrm{a}}$ & $56.9^{\mathrm{a}}$ & 4.47 & $58.1^{\mathrm{a}}$ \\
& $\mathrm{C}_{\beta \beta} \cdot \mathrm{H}$ & $2.95,3.12$ & 40.6 & $2.90,3.18$ & 39.9 \\
& $\mathrm{C}_{\delta \delta} \cdot \mathrm{H}$ & $7.20,7.20$ & 132.1 & $7.27,7.27$ & 132.4 \\
& $\mathrm{C}_{\varepsilon \varepsilon} \mathrm{H}$ & $7.24,7.24$ & 129.2 & $7.26,7.26$ & 129.4 \\
& $\mathrm{C}_{\zeta} \mathrm{H}$ & 7.20 & 131.2 & 7.17 & 131.2 \\
Asn 14 (252) & $\mathrm{H}_{\mathrm{N}}$ & 8.40 & & 7.99 & \\
& $\mathrm{C}_{\alpha} \mathrm{H}$ & 4.57 & $54.0^{\mathrm{a}}$ & 4.54 & $53.2^{\mathrm{a}}$ \\
& $\mathrm{C}_{\beta \beta} \cdot \mathrm{H}$ & $2.70,2.83$ & 40.3 & $2.56,2.68$ & 39.3 \\
& $\mathrm{~N}_{\delta \delta} \cdot \mathrm{H}_{2}$ & $6.89,7.59$ & & $6.63,7.36$ & \\
& & & & &
\end{tabular}


Table S2. ${ }^{1} \mathrm{H}$ and ${ }^{13} \mathrm{C}$ chemical shifts (ppm from DSS) of peptide W5K10-LytA239-252 in aqueous solution and in $30 \mathrm{mM}$ [D38]-DPC at pH 3.0 and $25{ }^{\circ} \mathrm{C}$. "nd" stands for not determined. ${ }^{\mathrm{a}}$ Measured in $\mathrm{D}_{2} \mathrm{O}$

\begin{tabular}{|c|c|c|c|c|c|}
\hline \multirow{2}{*}{\multicolumn{2}{|c|}{$\begin{array}{rr}\text { Condition } \\
\text { Peptide structure } \\
\end{array}$}} & \multirow{2}{*}{\multicolumn{2}{|c|}{$\frac{\mathrm{H}_{2} \mathrm{O} / \mathrm{D}_{2} \mathrm{O} 9: 1(\mathrm{v} / \mathrm{v})}{\beta \text {-hairpin }}$}} & \multicolumn{2}{|c|}{$30 \mathrm{mM}$ DPC-d38 } \\
\hline & & & & & elix \\
\hline & Resonance & ${ }^{1} \mathrm{H} \delta, \mathrm{ppm}$ & ${ }^{13} \mathrm{C} \delta, \mathrm{ppm}$ & ${ }^{1} \mathrm{H} \delta, \mathrm{ppm}$ & ${ }^{13} \mathrm{C} \delta, \mathrm{ppm}$ \\
\hline \multirow[t]{3}{*}{ Thr 1 (239) } & $\mathrm{C}_{\alpha} \mathrm{H}$ & 3.92 & 61.8 & 3.94 & 61.5 \\
\hline & $\mathrm{C}_{\beta} \mathrm{H}$ & 4.09 & 69.5 & 4.21 & 69.2 \\
\hline & $\mathrm{C}_{\gamma} \mathrm{H}_{3}$ & 1.30 & 21.7 & 1.28 & 21.6 \\
\hline \multirow[t]{2}{*}{ Gly 2 (240) } & $\mathrm{H}_{\mathrm{N}}$ & 8.54 & & 9.06 & \\
\hline & $\mathrm{C}_{\alpha \alpha}, \mathrm{H}$ & $3.90,4.01$ & 45.1 & $3.98,4.05$ & 45.8 \\
\hline \multirow[t]{9}{*}{$\operatorname{Trp} 3(241)$} & $\mathrm{H}_{\mathrm{N}}$ & 8.04 & & 8.53 & \\
\hline & $\mathrm{C}_{\alpha} \mathrm{H}$ & 5.07 & $56.4^{\mathrm{a}}$ & 4.58 & $57.8^{\mathrm{a}}$ \\
\hline & $\mathrm{C}_{\beta} \mathrm{H}$ & $2.75,2.75$ & 31.1 & $3.13,3.13$ & 29.7 \\
\hline & $\mathrm{C}_{\delta 1} \mathrm{H}$ & 7.08 & 127.7 & 7.33 & 127.5 \\
\hline & $\mathrm{N}_{\varepsilon 1} \mathrm{H}$ & 10.09 & & 10.62 & \\
\hline & $\mathrm{C}_{\varepsilon 3} \mathrm{H}$ & 7.15 & 120.7 & 7.46 & 121.1 \\
\hline & $\mathrm{C}_{\zeta 3} \mathrm{H}$ & 6.65 & 122.2 & 7.00 & 121.5 \\
\hline & $\mathrm{C}_{\eta 2} \mathrm{H}$ & 7.16 & 124.7 & 7.09 & 124.1 \\
\hline & $\mathrm{C}_{\zeta 2} \mathrm{H}$ & 7.43 & 114.9 & 7.49 & 114.9 \\
\hline \multirow[t]{7}{*}{ Lys 4 (242) } & $\mathrm{H}_{\mathrm{N}}$ & 8.89 & & 8.37 & \\
\hline & $\mathrm{C}_{\alpha} \mathrm{H}$ & 4.53 & $55.5^{\mathrm{a}}$ & 4.06 & 58.5 \\
\hline & $\mathrm{C}_{\beta \beta}, \mathrm{H}$ & $1.74,1.79$ & 35.8 & $1.79,1.79$ & 32.4 \\
\hline & $\mathrm{C}_{\gamma \gamma}, \mathrm{H}$ & $1.30,1.36$ & 24.8 & $1.30,1.30$ & 25.0 \\
\hline & $\mathrm{C}_{\delta \delta}^{\prime}, \mathrm{H}$ & $1.55,1.55$ & 29.6 & $1.63,1.63$ & 29.3 \\
\hline & $\mathrm{C}_{\varepsilon \varepsilon}, \mathrm{H}$ & $2.76,2.76$ & 42.3 & $2.89,2.93$ & 42.2 \\
\hline & $\mathrm{N}_{\zeta} \mathrm{H}_{3}$ & 7.46 & & 7.63 & \\
\hline \multirow[t]{9}{*}{ Trp 5 (243) } & $\mathrm{H}_{\mathrm{N}}$ & 8.65 & & 7.78 & \\
\hline & $\mathrm{C}_{\alpha} \mathrm{H}$ & 5.04 & $57.3^{\mathrm{a}}$ & 4.40 & $59.3^{\mathrm{a}}$ \\
\hline & $\mathrm{C}_{\beta \beta}, \mathrm{H}$ & $3.14,3.23$ & 30.3 & $3.26,3.31$ & 29.3 \\
\hline & $\mathrm{C}_{\delta 1} \mathrm{H}$ & 7.29 & 127.5 & 7.37 & 127.8 \\
\hline & $\mathrm{N}_{\varepsilon 1} \mathrm{H}$ & 10.21 & & 10.43 & \\
\hline & $\mathrm{C}_{\varepsilon 3} \mathrm{H}$ & 7.36 & 120.7 & 7.45 & 121.2 \\
\hline & $\mathrm{C}_{\zeta 3} \mathrm{H}$ & 6.97 & 122.2 & 6.95 & 121.7 \\
\hline & $\mathrm{C}_{\eta 2} \mathrm{H}$ & 7.14 & 124.8 & 7.04 & 124.3 \\
\hline & $\mathrm{C}_{\zeta 2} \mathrm{H}$ & 7.42 & 114.8 & 7.40 & 114.8 \\
\hline \multirow[t]{6}{*}{ Ile 6 (244) } & $\mathrm{H}_{\mathrm{N}}$ & 8.88 & & 7.46 & \\
\hline & $\mathrm{C}_{\alpha} \mathrm{H}$ & 4.20 & 61.5 & 3.77 & 63.4 \\
\hline & $\mathrm{C}_{\beta} \mathrm{H}$ & 1.86 & 39.8 & 1.77 & 38.2 \\
\hline & $\mathrm{C}_{\gamma 2} \mathrm{H}_{3}$ & 0.86 & 17.3 & 0.83 & 17.8 \\
\hline & $\mathrm{C}_{\gamma \gamma 1}, \mathrm{H}$ & $1.08,1.43$ & 27.4 & $1.05,1.34$ & 28.6 \\
\hline & $\mathrm{C}_{\delta 1} \mathrm{H}_{3}$ & 0.69 & 13.1 & 0.83 & 13.7 \\
\hline \multirow[t]{3}{*}{ Ala 7 (245) } & $\mathrm{H}_{\mathrm{N}}$ & 9.00 & & 7.86 & \\
\hline & $\mathrm{C}_{\alpha} \mathrm{H}$ & 4.00 & 53.8 & 4.12 & 54.3 \\
\hline & $\mathrm{C}_{\beta} \mathrm{H}_{3}$ & 1.45 & 17.8 & 1.44 & 18.7 \\
\hline \multirow[t]{3}{*}{ Asp 8 (246) } & $\mathrm{H}_{\mathrm{N}}$ & 8.58 & & 8.23 & \\
\hline & $\mathrm{C}_{\alpha} \mathrm{H}$ & 4.51 & $54.2^{\mathrm{a}}$ & 4.66 & $54.6^{\mathrm{a}}$ \\
\hline & $\mathrm{C}_{\beta \beta}, \mathrm{H}$ & $2.95,3.03$ & 38.6 & $2.94,3.05$ & 38.5 \\
\hline \multirow[t]{7}{*}{ Lys 9 (247) } & $\mathrm{H}_{\mathrm{N}}$ & 8.10 & & 8.05 & \\
\hline & $\mathrm{C}_{\alpha} \mathrm{H}$ & 4.53 & $55.7^{\mathrm{a}}$ & 4.15 & 57.8 \\
\hline & $\mathrm{C}_{\beta \beta}, \mathrm{H}$ & $1.76,1.76$ & 35.2 & $1.86,1.86$ & 32.3 \\
\hline & $\mathrm{C}_{\gamma \gamma}, \mathrm{H}$ & $1.32,1.42$ & 25.2 & $1.30,1.43$ & 24.9 \\
\hline & $\mathrm{C}_{\delta \delta}^{\prime}, \mathrm{H}$ & $1.68,1.68$ & 29.3 & $1.58,1.58$ & 29.2 \\
\hline & $\mathrm{C}_{\varepsilon \varepsilon}, \mathrm{H}$ & $2.97,2.97$ & 42.5 & $2.67,2.85$ & 42.2 \\
\hline & $\mathrm{N}_{\zeta} \mathrm{H}_{3}$ & 7.54 & & 7.75 & \\
\hline
\end{tabular}




\begin{tabular}{|c|c|c|c|c|c|}
\hline & Condition & \multirow{2}{*}{\multicolumn{2}{|c|}{$\frac{\mathrm{H}_{2} \mathrm{O} / \mathrm{D}_{2} \mathrm{O} 9: 1(\mathrm{v} / \mathrm{v})}{\beta \text {-hairpin }}$}} & \multicolumn{2}{|c|}{$30 \mathrm{mM}$ DPC-d38 } \\
\hline \multicolumn{2}{|c|}{ Peptide structure } & & & \multicolumn{2}{|c|}{$\alpha$-helix } \\
\hline Residue & Resonance & ${ }^{1} \mathbf{H} \delta$, ppm & ${ }^{13} \mathrm{C} \delta, \mathrm{ppm}$ & ${ }^{1} \mathbf{H} \delta$, ppm & ${ }^{13} \mathrm{C} \delta, \mathrm{ppm}$ \\
\hline \multirow[t]{7}{*}{ Lys 10 (248) } & $\mathrm{H}_{\mathrm{N}}$ & 8.09 & & 7.86 & \\
\hline & $\mathrm{C}_{\alpha} \mathrm{H}$ & 4.18 & 56.4 & 4.11 & 58.2 \\
\hline & $\mathrm{C}_{\beta \beta}, \mathrm{H}$ & $0.95,0.95$ & 33.4 & $1.78,1.78$ & 32.4 \\
\hline & $\mathrm{C}_{\gamma \gamma}, \mathrm{H}$ & $0.40,0.58$ & 25.0 & $1.30,1.30$ & 25.1 \\
\hline & $\mathrm{C}_{\delta \delta}, \mathrm{H}$ & $0.77,0.96$ & 29.4 & $1.63,1.63$ & 29.5 \\
\hline & $\mathrm{C}_{\varepsilon \varepsilon}, \mathrm{H}$ & $2.02,2.17$ & 41.8 & $2.89,2.96$ & 42.3 \\
\hline & $\mathrm{N}_{\zeta} \mathrm{H}_{3}$ & 7.01 & & 7.64 & \\
\hline \multirow[t]{5}{*}{ Tyr 249} & $\mathrm{H}_{\mathrm{N}}$ & 8.75 & & 7.70 & \\
\hline & $\mathrm{C}_{\alpha} \mathrm{H}$ & 4.59 & $56.9^{a}$ & 4.31 & 59.4 \\
\hline & $\mathrm{C}_{\beta \beta}, \mathrm{H}$ & $2.71,2.84$ & 41.0 & $2.89,2.89$ & 38.6 \\
\hline & $\mathrm{C}_{\delta \delta}, \mathrm{H}$ & $7.04,7.04$ & 133.7 & $6.78,6.78$ & 133.4 \\
\hline & $\mathrm{C}_{\varepsilon \varepsilon}, \mathrm{H}$ & $6.81,6.81$ & 118.4 & $6.75,6.75$ & 118.3 \\
\hline \multirow[t]{5}{*}{ Tyr 250} & $\mathrm{H}_{\mathrm{N}}$ & 8.31 & & 7.71 & \\
\hline & $\mathrm{C}_{\alpha} \mathrm{H}$ & 4.44 & 58.0 & 4.16 & 60.2 \\
\hline & $\mathrm{C}_{\beta \beta}, \mathrm{H}$ & $2.27,2.69$ & 39.4 & $2.63,2.70$ & 39.5 \\
\hline & $\mathrm{C}_{\delta \delta}, \mathrm{H}$ & $6.64,6.64$ & 133.3 & $6.90,6.90$ & 133.2 \\
\hline & $\mathrm{C}_{\varepsilon \varepsilon}, \mathrm{H}$ & $6.58,6.58$ & 118.0 & $6.76,6.76$ & 118.5 \\
\hline \multirow[t]{6}{*}{ Phe 251} & $\mathrm{H}_{\mathrm{N}}$ & 7.97 & & 7.84 & \\
\hline & $\mathrm{C}_{\alpha} \mathrm{H}$ & 4.60 & $57.4^{\mathrm{a}}$ & 4.62 & $57.6^{\mathrm{a}}$ \\
\hline & $\mathrm{C}_{\beta \beta}, \mathrm{H}$ & $2.87,3.05$ & 40.4 & $2.96,3.27$ & 40.1 \\
\hline & $\mathrm{C}_{\delta \delta}, \mathrm{H}$ & $7.18,7.18$ & 132.3 & $7.35,7.35$ & 132.5 \\
\hline & $\mathrm{C}_{\varepsilon \varepsilon}, \mathrm{H}$ & $7.21,7.21$ & 131.4 & $7.27,7.27$ & 131.2 \\
\hline & $\mathrm{C}_{\zeta} \mathrm{H}$ & 7.15 & 129.8 & 7.14 & 129.4 \\
\hline \multirow[t]{4}{*}{ Asn 252} & $\mathrm{H}_{\mathrm{N}}^{3}$ & 8.24 & & 8.06 & \\
\hline & $\mathrm{C}_{\alpha} \mathrm{H}$ & 4.49 & $54.3^{\mathrm{a}}$ & 4.64 & 53.4 \\
\hline & $\mathrm{C}_{\beta \beta}, \mathrm{H}$ & $2.70,2.77$ & 40.0 & $2.77,2.87$ & 39.7 \\
\hline & $\mathrm{N}_{\delta \delta}, \mathrm{H}_{2}$ & $6.89,7.56$ & & $6.89,7.64$ & \\
\hline
\end{tabular}


Table S3. ${ }^{1} \mathrm{H}$ and ${ }^{13} \mathrm{C}$ chemical shifts (ppm from DSS) of S3S10-LytA239-252 in aqueous solution and in $30 \mathrm{mM}$ [D38]-DPC at $\mathrm{pH} 3.0$ and $25^{\circ} \mathrm{C}$. "nd" stands for not determined. ${ }^{a}$ Measured in $\mathrm{D}_{2} \mathrm{O}$

\begin{tabular}{|c|c|c|c|c|c|}
\hline \multirow{3}{*}{\multicolumn{2}{|c|}{$\begin{array}{rr}\text { Condition } \\
\text { Peptide structure } \\
\text { Poson }\end{array}$}} & \multirow{2}{*}{\multicolumn{2}{|c|}{$\begin{array}{c}\mathrm{H}_{2} \mathrm{O} / \mathrm{D}_{2} \mathrm{O} 9: 1(\mathrm{v} / \mathrm{v}) \\
\text { Random coil }\end{array}$}} & \multicolumn{2}{|c|}{$30 \mathrm{mM}$ DPC-d38 } \\
\hline & & & & & elix \\
\hline & & ${ }^{1} \mathbf{H} \delta, \mathbf{p p m}$ & ${ }^{13} \mathrm{C} \delta, \mathrm{ppm}$ & ${ }^{1} \mathbf{H} \delta, \mathbf{p p m}$ & ${ }^{13} \mathrm{C} \delta, \mathrm{ppm}$ \\
\hline \multirow[t]{3}{*}{ Thr 1 (239) } & $\mathrm{C}_{\alpha} \mathrm{H}$ & 3.96 & 61.8 & 3.94 & 61.7 \\
\hline & $\mathrm{C}_{\beta} \mathrm{H}$ & 4.21 & 69.2 & 4.18 & 69.1 \\
\hline & $\mathrm{C}_{\gamma} \mathrm{H}_{3}$ & 1.34 & 21.6 & 1.32 & 21.6 \\
\hline \multirow[t]{2}{*}{ Gly 2 (240) } & $\mathrm{H}_{\mathrm{N}}$ & 8.84 & & 8.83 & \\
\hline & $\mathrm{C}_{\alpha \alpha}, \mathrm{H}$ & $4.08,4.08$ & 45.4 & $4.06,4.06$ & 45.3 \\
\hline \multirow[t]{3}{*}{ Ser 3 (241) } & $\mathrm{H}_{\mathrm{N}}$ & 8.40 & & 8.39 & \\
\hline & $\mathrm{C}_{\alpha} \mathrm{H}$ & 4.48 & 58.4 & 4.45 & 58.4 \\
\hline & $\mathrm{C}_{\beta \beta}, \mathrm{H}$ & $3.85,3.85$ & 64.3 & $3.83,3.83$ & 64.2 \\
\hline \multirow[t]{7}{*}{ Lys 4 (242) } & $\mathrm{H}_{\mathrm{N}}$ & 8.45 & & 8.46 & \\
\hline & $\mathrm{C}_{\alpha} \mathrm{H}$ & 4.33 & 56.5 & 4.30 & 56.6 \\
\hline & $\mathrm{C}_{\beta \beta}, \mathrm{H}$ & $1.74,1.82$ & 33.4 & $1.72,1.80$ & 33.3 \\
\hline & $\mathrm{C}_{\gamma \gamma}, \mathrm{H}$ & $1.39,1.43$ & 25.0 & $1.39,1.44$ & 25.0 \\
\hline & $\mathrm{C}_{\delta \delta}, \mathrm{H}$ & $1.66,1.66$ & 29.4 & $1.66,1.66$ & 29.3 \\
\hline & $\mathrm{C}_{\varepsilon \varepsilon}, \mathrm{H}$ & $2.98,2.98$ & 42.4 & $2.96,2.96$ & 42.2 \\
\hline & $\mathrm{N}_{\zeta} \mathrm{H}_{3}$ & 7.53 & & 7.54 & \\
\hline \multirow[t]{7}{*}{ Lys 5 (243) } & $\mathrm{H}_{\mathrm{N}}$ & 8.29 & & 8.36 & \\
\hline & $\mathrm{C}_{\alpha} \mathrm{H}$ & 4.30 & 56.8 & 4.29 & 56.8 \\
\hline & $\mathrm{C}_{\beta \beta}, \mathrm{H}$ & $1.72,1.78$ & 33.3 & $1.71,1.71$ & 33.3 \\
\hline & $\mathrm{C}_{\gamma \gamma}, \mathrm{H}$ & $1.37,1.37$ & 25.0 & $1.37,1.42$ & 25.1 \\
\hline & $\mathrm{C}_{\delta \delta}, \mathrm{H}$ & $1.65,1.65$ & 29.3 & $1.66,1.66$ & 29.4 \\
\hline & $\mathrm{C}_{\varepsilon \varepsilon}, \mathrm{H}$ & $2.97,2.97$ & 42.4 & $2.96,2.96$ & 42.2 \\
\hline & $\mathrm{N}_{\zeta} \mathrm{H}_{3}$ & 7.52 & & 7.55 & \\
\hline \multirow[t]{6}{*}{ Ile 6 (244) } & $\mathrm{H}_{\mathrm{N}}$ & 8.24 & & 8.20 & \\
\hline & $\mathrm{C}_{\alpha} \mathrm{H}$ & 4.13 & 61.1 & 4.09 & 61.3 \\
\hline & $\mathrm{C}_{\beta} \mathrm{H}$ & 1.83 & 39.0 & 1.82 & 38.9 \\
\hline & $\mathrm{C}_{\gamma 2} \mathrm{H}_{3}$ & 0.91 & 17.7 & 0.89 & 17.8 \\
\hline & $\mathrm{C}_{\gamma \gamma 1} \cdot \mathrm{H}$ & $1.18,1.46$ & 27.5 & $1.16,1.46$ & 27.6 \\
\hline & $\mathrm{C}_{\delta 1} \mathrm{H}_{3}$ & 0.85 & 13.0 & 0.83 & 13.1 \\
\hline \multirow[t]{3}{*}{ Ala 7 (245) } & $\mathrm{H}_{\mathrm{N}}$ & 8.44 & & 8.40 & \\
\hline & $\mathrm{C}_{\alpha} \mathrm{H}$ & 4.30 & 52.7 & 4.28 & 52.8 \\
\hline & $\mathrm{C}_{\beta} \mathrm{H}_{3}$ & 1.37 & 19.5 & 1.36 & 19.4 \\
\hline \multirow[t]{3}{*}{ Asp 8 (246) } & $\mathrm{H}_{\mathrm{N}}$ & 8.37 & & 8.37 & \\
\hline & $\mathrm{C}_{\alpha} \mathrm{H}$ & 4.64 & 53.5 & 4.62 & $53.5^{\mathrm{a}}$ \\
\hline & $\mathrm{C}_{\beta \beta}, \mathrm{H}$ & $2.80,2.88$ & 39.2 & $2.82,2.82$ & 39.2 \\
\hline \multirow[t]{7}{*}{ Lys 9 (247) } & $\mathrm{H}_{\mathrm{N}}$ & 8.39 & & 8.31 & \\
\hline & $\mathrm{C}_{\alpha} \mathrm{H}$ & 4.32 & 56.6 & 4.26 & 57.0 \\
\hline & $\mathrm{C}_{\beta \beta}, \mathrm{H}$ & $1.71,1.78$ & 33.3 & $1.72,1.72$ & 33.2 \\
\hline & $\mathrm{C}_{\gamma \gamma}, \mathrm{H}$ & $1.40,1.40$ & 25.0 & $1.37,1.37$ & 25.0 \\
\hline & $\mathrm{C}_{\delta \delta}, \mathrm{H}$ & $1.67,1.67$ & 29.3 & $1.65,1.65$ & 29.2 \\
\hline & $\mathrm{C}_{\varepsilon \varepsilon}, \mathrm{H}$ & $2.97,2.97$ & 42.5 & $2.93,2.93$ & 42.2 \\
\hline & $\mathrm{N}_{\zeta} \mathrm{H}_{3}$ & 7.52 & & 7.60 & \\
\hline \multirow[t]{3}{*}{ Ser 10 (248) } & $\mathrm{H}_{\mathrm{N}}$ & 8.23 & & 8.18 & \\
\hline & $\mathrm{C}_{\alpha} \mathrm{H}$ & 4.37 & 58.7 & 4.36 & 58.9 \\
\hline & $\mathrm{C}_{\beta \beta}, \mathrm{H}$ & $3.76,3.76$ & 64.0 & $3.76,3.76$ & 63.9 \\
\hline \multirow[t]{5}{*}{ Tyr 11 (249) } & $\mathrm{H}_{\mathrm{N}}$ & 8.06 & & 8.13 & \\
\hline & $\mathrm{C}_{\alpha} \mathrm{H}$ & 4.46 & 58.2 & 4.38 & 58.7 \\
\hline & $\mathrm{C}_{\beta \beta}, \mathrm{H}$ & $2.84,2.84$ & 39.2 & $2.83,2.83$ & 39.1 \\
\hline & $\mathrm{C}_{\delta \delta}, \mathrm{H}$ & $6.98,6.98$ & 133.5 & $6.89,6.89$ & 133.4 \\
\hline & $\mathrm{C}_{\varepsilon \varepsilon}, \mathrm{H}$ & $6.77,6.77$ & 118.4 & $6.75,6.75$ & 118.4 \\
\hline
\end{tabular}




\begin{tabular}{|c|c|c|c|c|c|}
\hline \multirow{2}{*}{\multicolumn{2}{|c|}{$\begin{array}{r}\text { Condition } \\
\text { Peptide structure }\end{array}$}} & \multirow{2}{*}{\multicolumn{2}{|c|}{$\frac{\mathrm{H}_{2} \mathrm{O} / \mathrm{D}_{2} \mathrm{O} 9: 1(\mathrm{v} / \mathrm{v})}{\text { Random coil }}$}} & \multicolumn{2}{|c|}{$30 \mathrm{mM}$ DPC-d38 } \\
\hline & & & & & lix \\
\hline Residue & Resonance & ${ }^{1} \mathrm{H} \delta, \mathrm{ppm}$ & ${ }^{13} \mathrm{C} \delta, \mathrm{ppm}$ & ${ }^{1} \mathrm{H} \delta, \mathbf{p p m}$ & ${ }^{13} \mathrm{C} \delta, \mathrm{ppm}$ \\
\hline \multirow[t]{5}{*}{ Tyr $12(250)$} & $\mathrm{H}_{\mathrm{N}}$ & 7.91 & & 7.94 & \\
\hline & $\mathrm{C}_{\alpha} \mathrm{H}$ & 4.47 & 57.9 & 4.30 & 59.1 \\
\hline & $\mathrm{C}_{\beta \beta} \cdot \mathrm{H}$ & $2.79,2.92$ & 39.3 & $2.71,2.82$ & 39.5 \\
\hline & $\mathrm{C}_{\delta \delta}, \mathrm{H}$ & $7.03,7.03$ & 133.4 & $6.94,6.94$ & 133.3 \\
\hline & $\mathrm{C}_{\varepsilon \varepsilon} \cdot \mathrm{H}$ & $6.81,6.81$ & 118.4 & $6.76,6.76$ & 118.4 \\
\hline \multirow[t]{6}{*}{ Phe 13 (251) } & $\mathrm{H}_{\mathrm{N}}$ & 7.97 & & 7.88 & \\
\hline & $\mathrm{C}_{\alpha} \mathrm{H}$ & 4.58 & 57.7 & 4.57 & $57.5^{\mathrm{a}}$ \\
\hline & $\mathrm{C}_{\beta \beta} \cdot \mathrm{H}$ & $2.97,3.11$ & 40.1 & $2.95,3.16$ & 40.1 \\
\hline & $\mathrm{C}_{\delta \delta}, \mathrm{H}$ & $7.24,7.24$ & 132.2 & $7.28,7.28$ & 132.4 \\
\hline & $\mathrm{C}_{\varepsilon \varepsilon} \cdot \mathrm{H}$ & $7.35,7.35$ & 131.7 & $7.30,7.30$ & 131.4 \\
\hline & $\mathrm{C}_{\zeta} \mathrm{H}$ & 7.28 & 130.1 & 7.20 & 129.7 \\
\hline \multirow[t]{4}{*}{ Asn 14 (252) } & $\mathrm{H}_{\mathrm{N}}$ & 8.11 & & 8.14 & \\
\hline & $\mathrm{C}_{a} \mathrm{H}$ & 4.58 & 53.1 & 4.59 & $53.0^{\mathrm{a}}$ \\
\hline & $\mathrm{C}_{\beta \beta} \cdot \mathrm{H}$ & $2.71,2.79$ & 39.6 & $2.71,2.78$ & 39.7 \\
\hline & $\mathrm{N}_{\delta \delta}, \mathrm{H}_{2}$ & $6.87,7.55$ & & $6.86,7.58$ & \\
\hline
\end{tabular}


Table S4. ${ }^{1} \mathrm{H}$ and ${ }^{13} \mathrm{C}$ chemical shifts (ppm from DSS) of I3V10-LytA239-252 in aqueous solution and in $30 \mathrm{mM}$ [D38]-DPC at $\mathrm{pH} 3.0$ and $25^{\circ} \mathrm{C}$. "nd" stands for not determined. ${ }^{a}$ Measured in $\mathrm{D}_{2} \mathrm{O}$

\begin{tabular}{|c|c|c|c|c|c|}
\hline \multirow{2}{*}{\multicolumn{2}{|c|}{$\begin{array}{r}\text { Condition } \\
\text { Peptide structure } \\
\end{array}$}} & \multirow{2}{*}{\multicolumn{2}{|c|}{$\frac{\mathrm{H}_{2} \mathrm{O} / \mathrm{D}_{2} \mathrm{O} 9: 1(\mathrm{v} / \mathrm{v})}{\beta \text {-hairpin }}$}} & \multicolumn{2}{|c|}{$30 \mathrm{mM}$ DPC-d38 } \\
\hline & & & & & elix \\
\hline Residue & Resonance & ${ }^{1} \mathrm{H} \delta, \mathrm{ppm}$ & ${ }^{13} \mathrm{C} \delta, \mathrm{ppm}$ & ${ }^{1} \mathrm{H} \delta, \mathrm{ppm}$ & ${ }^{13} \mathrm{C} \delta, \mathrm{ppm}$ \\
\hline \multirow[t]{3}{*}{ Thr 1 (239) } & $\mathrm{C}_{\alpha} \mathrm{H}$ & 3.95 & 61.8 & 3.97 & 61.6 \\
\hline & $\mathrm{C}_{\beta} \mathrm{H}$ & 4.19 & 69.2 & 4.23 & 69.2 \\
\hline & $\mathrm{C}_{\gamma} \mathrm{H}_{3}$ & 1.33 & 21.6 & 1.34 & 21.7 \\
\hline \multirow[t]{2}{*}{ Gly 2 (240) } & $\mathrm{H}_{\mathrm{N}}$ & 8.79 & & 9.00 & \\
\hline & $\mathrm{C}_{\alpha \alpha}, \mathrm{H}$ & $3.97,4.09$ & 45.2 & $4.01,4.20$ & 45.9 \\
\hline \multirow[t]{6}{*}{ Ile 3 (241) } & $\mathrm{H}_{\mathrm{N}}$ & 8.23 & & 8.59 & \\
\hline & $\mathrm{C}_{\alpha} \mathrm{H}$ & 4.22 & 61.3 & 3.99 & 63.2 \\
\hline & $\mathrm{C}_{\beta} \mathrm{H}$ & 1.80 & 39.4 & 1.89 & 38.6 \\
\hline & $\mathrm{C}_{\gamma_{2}} \mathrm{H}_{3}$ & 0.88 & 17.7 & 0.92 & 18.2 \\
\hline & $\mathrm{C}_{\gamma \gamma 1} \cdot \mathrm{H}$ & $1.16,1.46$ & 27.5 & $1.25,1.56$ & 28.9 \\
\hline & $\mathrm{C}_{\delta 1} \mathrm{H}_{3}$ & 0.86 & 13.2 & 0.90 & 13.7 \\
\hline \multirow[t]{7}{*}{ Lys 4 (242) } & $\mathrm{H}_{\mathrm{N}}$ & 8.48 & & 8.49 & \\
\hline & $\mathrm{C}_{\alpha} \mathrm{H}$ & 4.34 & 56.3 & 3.99 & 59.5 \\
\hline & $\mathrm{C}_{\beta \beta}, \mathrm{H}$ & $1.69,1.77$ & 33.6 & $1.84,1.84$ & 32.6 \\
\hline & $\mathrm{C}_{\gamma \gamma}, \mathrm{H}$ & $1.33,1.42$ & 25.0 & $1.37,1.49$ & 25.8 \\
\hline & $\mathrm{C}_{\delta \delta} \cdot \mathrm{H}$ & $1.65,1.65$ & 29.4 & $1.71,1.71$ & 29.3 \\
\hline & $\mathrm{C}_{\varepsilon \varepsilon}, \mathrm{H}$ & $2.96,2.96$ & 42.3 & $2.97,2.97$ & 42.2 \\
\hline & $\mathrm{N}_{\zeta} \mathrm{H}_{3}$ & 7.53 & & 7.70 & \\
\hline \multirow[t]{7}{*}{ Lys 5 (243) } & $\mathrm{H}_{\mathrm{N}}$ & 8.43 & & 7.90 & \\
\hline & $\mathrm{C}_{\alpha} \mathrm{H}$ & 4.40 & 56.3 & 4.18 & 58.5 \\
\hline & $\mathrm{C}_{\beta \beta}, \mathrm{H}$ & $1.70,1.77$ & 33.5 & $1.85,1.85$ & 32.6 \\
\hline & $\mathrm{C}_{\gamma \gamma}, \mathrm{H}$ & $1.33,1.40$ & 25.0 & $1.42,1.51$ & 25.4 \\
\hline & $\mathrm{C}_{\delta \delta}, \mathrm{H}$ & $1.65,1.65$ & 29.4 & $1.71,1.71$ & 29.3 \\
\hline & $\mathrm{C}_{\varepsilon \varepsilon}, \mathrm{H}$ & $2.96,2.96$ & 42.4 & $2.96,2.96$ & 42.2 \\
\hline & $\mathrm{N}_{\zeta} \mathrm{H}_{3}$ & 7.53 & & 7.62 & \\
\hline \multirow[t]{6}{*}{ Ile 6 (244) } & $\mathrm{H}_{\mathrm{N}}$ & 8.31 & & 7.81 & \\
\hline & $\mathrm{C}_{\alpha} \mathrm{H}$ & 4.15 & 61.1 & 3.87 & 63.7 \\
\hline & $\mathrm{C}_{\beta} \mathrm{H}$ & 1.83 & 39.2 & 1.95 & 38.4 \\
\hline & $\mathrm{C}_{\gamma 2} \mathrm{H}_{3}$ & 0.91 & 17.7 & 0.91 & 18.0 \\
\hline & $\mathrm{C}_{\gamma \gamma 1}^{\prime} \cdot \mathrm{H}$ & $1.16,1.46$ & 27.5 & $1.18,1.64$ & 28.7 \\
\hline & $\mathrm{C}_{\delta 1} \mathrm{H}_{3}$ & 0.83 & 13.0 & 0.85 & 13.4 \\
\hline \multirow[t]{3}{*}{ Ala 7 (245) } & $\mathrm{H}_{\mathrm{N}}$ & 8.52 & & 8.44 & \\
\hline & $\mathrm{C}_{\alpha} \mathrm{H}$ & 4.28 & 52.8 & 4.03 & 54.9 \\
\hline & $\mathrm{C}_{\beta} \mathrm{H}_{3}$ & 1.39 & 19.3 & 1.45 & 18.8 \\
\hline \multirow[t]{3}{*}{ Asp 8 (246) } & $\mathrm{H}_{\mathrm{N}}$ & 8.40 & & 8.39 & \\
\hline & $\mathrm{C}_{\alpha} \mathrm{H}$ & 4.61 & 53.7 & 4.58 & $55.4^{\mathrm{a}}$ \\
\hline & $\mathrm{C}_{\beta \beta}, \mathrm{H}$ & $2.78,2.87$ & 39.2 & $2.96,2.96$ & 38.6 \\
\hline \multirow[t]{7}{*}{ Lys 9 (247) } & $\mathrm{H}_{\mathrm{N}}$ & 8.19 & & 7.88 & \\
\hline & $\mathrm{C}_{\alpha} \mathrm{H}$ & 4.27 & 56.5 & 4.24 & 58.0 \\
\hline & $\mathrm{C}_{\beta \beta}, \mathrm{H}$ & $1.69,1.69$ & 33.5 & $1.91,1.98$ & 32.9 \\
\hline & $\mathrm{C}_{\gamma \gamma}, \mathrm{H}$ & $1.25,1.31$ & 25.0 & $1.51,1.55$ & 25.4 \\
\hline & $\mathrm{C}_{\delta \delta}, \mathrm{H}$ & $1.62,1.62$ & 29.3 & $1.71,1.71$ & 29.4 \\
\hline & $\mathrm{C}_{\varepsilon \varepsilon} \cdot \mathrm{H}$ & $2.91,2.91$ & 42.4 & $2.94,2.94$ & 42.2 \\
\hline & $\mathrm{N}_{\zeta} \mathrm{H}_{3}$ & 7.52 & & 7.78 & \\
\hline \multirow[t]{5}{*}{ Val 10 (248) } & $\mathrm{H}_{\mathrm{N}}$ & 8.00 & & 7.85 & \\
\hline & $\mathrm{C}_{\alpha} \mathrm{H}$ & 4.01 & 62.4 & 3.88 & 64.3 \\
\hline & $\mathrm{C}_{\beta} \mathrm{H}$ & 1.85 & 33.2 & 2.14 & 32.5 \\
\hline & $\mathrm{C}_{\gamma 1} \mathrm{H}_{3}$ & 0.67 & 21.3 & 0.87 & 22.0 \\
\hline & $\mathrm{C}_{\gamma 2} \mathrm{H}_{3}$ & 0.82 & 20.9 & 0.97 & 22.0 \\
\hline
\end{tabular}




\begin{tabular}{|c|c|c|c|c|c|}
\hline \multirow{2}{*}{\multicolumn{2}{|c|}{$\begin{array}{r}\text { Condition } \\
\text { Peptide structure }\end{array}$}} & \multicolumn{2}{|c|}{$\mathrm{H}_{2} \mathrm{O} / \mathrm{D}_{2} \mathrm{O} 9: 1(\mathrm{v} / \mathrm{v})$} & \multicolumn{2}{|c|}{$30 \mathrm{mM}$ DPC-d38 } \\
\hline & & \multicolumn{2}{|c|}{$\beta$-hairpin } & \multicolumn{2}{|c|}{$\alpha$-helix } \\
\hline Residue & Resonance & ${ }^{1} \mathrm{H} \delta, \mathrm{ppm}$ & ${ }^{13} \mathrm{C} \delta, \mathrm{ppm}$ & ${ }^{1} \mathrm{H} \delta, \mathrm{ppm}$ & ${ }^{13} \mathrm{C} \delta, \mathrm{ppm}$ \\
\hline \multirow[t]{5}{*}{ Tyr 11 (249) } & $\mathrm{H}_{\mathrm{N}}$ & 8.26 & & 8.09 & \\
\hline & $\mathrm{C}_{\alpha} \mathrm{H}$ & 4.48 & 57.8 & 4.23 & 60.0 \\
\hline & $\mathrm{C}_{\beta \beta} \cdot \mathrm{H}$ & $2.74,2.82$ & 39.7 & $2.82,2.82$ & 39.6 \\
\hline & $\mathrm{C}_{\delta \delta}, \mathrm{H}$ & $7.04,7.04$ & 133.5 & $6.62,6.62$ & 133.2 \\
\hline & $\mathrm{C}_{\varepsilon \varepsilon} \cdot \mathrm{H}$ & $6.77,6.77$ & 118.4 & $6.66,6.66$ & 118.3 \\
\hline \multirow[t]{5}{*}{ Tyr 12 (250) } & $\mathrm{H}_{\mathrm{N}}$ & 8.02 & & 7.74 & \\
\hline & $\mathrm{C}_{\alpha} \mathrm{H}$ & 4.54 & 57.7 & 4.32 & 59.0 \\
\hline & $\mathrm{C}_{\beta \beta} \cdot \mathrm{H}$ & $2.77,2.92$ & 39.6 & $2.79,2.99$ & 38.6 \\
\hline & $\mathrm{C}_{\delta \delta}, \mathrm{H}$ & $7.04,7.04$ & 133.5 & $7.09,7.09$ & 133.5 \\
\hline & $\mathrm{C}_{\varepsilon \varepsilon} \cdot \mathrm{H}$ & $6.77,6.77$ & 118.4 & $6.82,6.82$ & 118.4 \\
\hline \multirow[t]{6}{*}{ Phe 13 (251) } & $\mathrm{H}_{\mathrm{N}}$ & 8.12 & & 7.75 & \\
\hline & $\mathrm{C}_{\alpha} \mathrm{H}$ & 4.60 & 57.5 & 4.49 & $58.3^{\mathrm{a}}$ \\
\hline & $\mathrm{C}_{\beta \beta} \cdot \mathrm{H}$ & $2.96,3.12$ & 40.2 & $3.13,3.19$ & 39.7 \\
\hline & $\mathrm{C}_{\delta \delta}, \mathrm{H}$ & $7.23,7.23$ & 132.3 & $7.28,7.28$ & 132.4 \\
\hline & $\mathrm{C}_{\varepsilon \varepsilon} \cdot \mathrm{H}$ & $7.32,7.32$ & 131.7 & $7.29,7.29$ & 131.4 \\
\hline & $\mathrm{C}_{\zeta} \mathrm{H}$ & 7.25 & 130.1 & 7.21 & 129.7 \\
\hline \multirow[t]{4}{*}{ Asn 14 (252) } & $\mathrm{H}_{\mathrm{N}}$ & 8.17 & & 7.99 & \\
\hline & $\mathrm{C}_{\alpha} \mathrm{H}$ & 4.57 & 53.2 & 4.57 & $52.9^{\mathrm{a}}$ \\
\hline & $\mathrm{C}_{\beta \beta} \cdot \mathrm{H}$ & $2.73,2.78$ & 39.7 & $2.67,2.78$ & 39.8 \\
\hline & $\mathrm{N}_{\delta \delta}, \mathrm{H}_{2}$ & $6.87,7.55$ & & $6.77,7.56$ & \\
\hline
\end{tabular}


Table S5. ${ }^{1} \mathrm{H}$ and ${ }^{13} \mathrm{C}$ chemical shifts (ppm from DSS) of I5Y6T11T13-LytA $239-252$ in aqueous solution and in $30 \mathrm{mM}$ [D38]-DPC at pH 3.0 and $25{ }^{\circ} \mathrm{C}$. "nd" stands for not determined. ${ }^{a}$ Measured in $\mathrm{D}_{2} \mathrm{O}$

\begin{tabular}{|c|c|c|c|c|c|}
\hline & Condition & \multicolumn{2}{|c|}{$\mathrm{H}_{2} \mathrm{O} / \mathrm{D}_{2} \mathrm{O} 9: 1(\mathrm{v} / \mathrm{v})$} & \multicolumn{2}{|c|}{$30 \mathrm{mM}$ DPC-d38 } \\
\hline \multicolumn{2}{|c|}{$\begin{array}{l}\text { Peptide structure } \\
\end{array}$} & \multicolumn{2}{|c|}{$\beta$-hairpin } & \multicolumn{2}{|c|}{$\alpha$-helix } \\
\hline Residue & Resonance & ${ }^{1} \mathbf{H} \delta, \mathbf{p p m}$ & ${ }^{13} \mathrm{C} \delta, \mathrm{ppm}$ & ${ }^{1} \mathbf{H} \delta, \mathrm{ppm}$ & ${ }^{13} \mathrm{C} \delta, \mathrm{ppm}$ \\
\hline \multirow{3}{*}{ Thr 1 (239) } & $\mathrm{C}_{\alpha} \mathrm{H}$ & 3.84 & 61.7 & 3.89 & 63.0 \\
\hline & $\mathrm{C}_{\beta} \mathrm{H}$ & 4.08 & 69.2 & 4.14 & 69.2 \\
\hline & $\mathrm{C}_{\gamma} \mathrm{H}_{3}$ & 1.25 & 21.6 & 1.23 & 21.7 \\
\hline \multirow[t]{2}{*}{ Gly 2 (240) } & $\mathrm{H}_{\mathrm{N}}$ & 8.58 & & 8.94 & \\
\hline & $\mathrm{C}_{\alpha \alpha}, \mathrm{H}$ & $3.90,4.06$ & 45.2 & $4.01,4.14$ & 45.9 \\
\hline \multirow[t]{9}{*}{$\operatorname{Trp} 3(241)$} & $\mathrm{H}_{\mathrm{N}}$ & 8.27 & & 8.58 & \\
\hline & $\mathrm{C}_{\alpha} \mathrm{H}$ & $4.84^{\mathrm{a}}$ & $57.4^{\mathrm{a}}$ & 4.58 & $59.0^{\mathrm{a}}$ \\
\hline & $\mathrm{C}_{\beta} \mathrm{H}$ & $3.16,3.24$ & 30.4 & $3.32,3.32$ & \\
\hline & $\mathrm{C}_{\delta 1} \mathrm{H}$ & 7.25 & 127.6 & 7.43 & 127.6 \\
\hline & $\mathrm{N}_{\varepsilon 1} \mathrm{H}$ & 10.14 & & 10.70 & \\
\hline & $\mathrm{C}_{\varepsilon 3} \mathrm{H}$ & 7.55 & 121.0 & 7.46 & 120.8 \\
\hline & $\mathrm{C}_{\zeta 3} \mathrm{H}$ & 7.13 & 122.3 & 6.90 & 121.5 \\
\hline & $\mathrm{C}_{\eta 2} \mathrm{H}$ & 7.21 & 124.9 & 7.07 & 124.1 \\
\hline & $\mathrm{C}_{\zeta 2} \mathrm{H}$ & 7.46 & 115.0 & 7.49 & 115.0 \\
\hline \multirow[t]{7}{*}{ Lys 4 (242) } & $\mathrm{H}_{\mathrm{N}}$ & 8.45 & & 8.20 & \\
\hline & $\mathrm{C}_{\alpha} \mathrm{H}$ & 4.32 & 56.4 & 3.83 & 59.3 \\
\hline & $\mathrm{C}_{\beta \beta}, \mathrm{H}$ & $1.56,1.62$ & 34.3 & $1.56,1.65$ & 32.4 \\
\hline & $\mathrm{C}_{\gamma \gamma}, \mathrm{H}$ & $1.18,1.18$ & 24.7 & $1.01,1.05$ & 25.3 \\
\hline & $\mathrm{C}_{\delta \delta}, \mathrm{H}$ & $1.57,1.57$ & 29.3 & $1.58,1.58$ & 29.3 \\
\hline & $\mathrm{C}_{\varepsilon \varepsilon}, \mathrm{H}$ & $2.86,2.86$ & 42.4 & $2.89,2.89$ & 42.2 \\
\hline & $\mathrm{N}_{\zeta} \mathrm{H}_{3}$ & 7.48 & & 7.69 & \\
\hline \multirow[t]{6}{*}{ Ile 5 (243) } & $\mathrm{H}_{\mathrm{N}}$ & 8.05 & & 7.59 & \\
\hline & $\mathrm{C}_{\alpha} \mathrm{H}$ & 4.11 & 60.9 & 3.89 & 61.7 \\
\hline & $\mathrm{C}_{\beta} \mathrm{H}$ & 1.46 & 38.7 & 1.76 & 37.9 \\
\hline & $\mathrm{C}_{\gamma 2} \mathrm{H}_{3}$ & 0.70 & 17.3 & 0.70 & 17.7 \\
\hline & $\mathrm{C}_{\gamma \gamma 1} \cdot \mathrm{H}$ & $0.79,1.11$ & 27.5 & $1.15,1.31$ & 28.2 \\
\hline & $\mathrm{C}_{\delta 1} \mathrm{H}_{3}$ & 0.65 & 12.9 & 0.78 & 13.2 \\
\hline \multirow[t]{5}{*}{ Tyr 6 (244) } & $\mathrm{H}_{\mathrm{N}}$ & 8.35 & & 7.48 & \\
\hline & $\mathrm{C}_{\alpha} \mathrm{H}$ & 4.51 & 58.0 & 4.28 & $60.3^{a}$ \\
\hline & $\mathrm{C}_{\beta \beta}, \mathrm{H}$ & $2.86,2.99$ & 39.6 & $3.00,3.06$ & 39.2 \\
\hline & $\mathrm{C}_{\delta \delta}, \mathrm{H}$ & $7.09,7.09$ & 133.5 & $7.11,7.11$ & 133.0 \\
\hline & $\mathrm{C}_{\varepsilon \varepsilon}, \mathrm{H}$ & $6.80,6.80$ & 118.4 & $6.81,6.81$ & 118.6 \\
\hline \multirow[t]{3}{*}{ Ala 7 (245) } & $\mathrm{H}_{\mathrm{N}}$ & 8.35 & & 8.05 & \\
\hline & $\mathrm{C}_{\alpha} \mathrm{H}$ & 4.09 & 53.0 & 4.12 & 54.3 \\
\hline & $\mathrm{C}_{\beta} \mathrm{H}_{3}$ & 1.27 & 18.7 & 1.48 & 19.0 \\
\hline \multirow[t]{3}{*}{ Asp 8 (246) } & $\mathrm{H}_{\mathrm{N}}$ & 8.28 & & 8.13 & \\
\hline & $\mathrm{C}_{\alpha} \mathrm{H}$ & 4.42 & 53.8 & 4.56 & $54.6^{\mathrm{a}}$ \\
\hline & $\mathrm{C}_{\beta \beta}, \mathrm{H}$ & $2.80,2.80$ & 38.7 & $2.90,2.90$ & 38.4 \\
\hline \multirow[t]{7}{*}{ Lys 9 (247) } & $\mathrm{H}_{\mathrm{N}}$ & 8.03 & & 7.82 & \\
\hline & $\mathrm{C}_{\alpha} \mathrm{H}$ & 4.33 & 56.2 & 4.19 & 57.3 \\
\hline & $\mathrm{C}_{\beta \beta}, \mathrm{H}$ & $1.65,1.71$ & 33.7 & $1.77,1.77$ & 32.8 \\
\hline & $\mathrm{C}_{\gamma \gamma}, \mathrm{H}$ & $1.26,1.26$ & 24.6 & $1.32,1.39$ & 25.1 \\
\hline & $\mathrm{C}_{\delta \delta}, \mathrm{H}$ & $1.60,1.60$ & 29.3 & $1.58,1.58$ & 29.4 \\
\hline & $\mathrm{C}_{\varepsilon \varepsilon}, \mathrm{H}$ & $2.91,2.91$ & 42.3 & $2.84,2.89$ & 42.2 \\
\hline & $\mathrm{N}_{\zeta} \mathrm{H}_{3}$ & 7.51 & & 7.65 & \\
\hline
\end{tabular}




\begin{tabular}{|c|c|c|c|c|c|}
\hline \multirow{2}{*}{\multicolumn{2}{|c|}{$\begin{array}{rr}\text { Condition } \\
\text { Peptide structure } \\
\end{array}$}} & \multirow{2}{*}{\multicolumn{2}{|c|}{$\begin{array}{c}\mathrm{H}_{2} \mathrm{O} / \mathrm{D}_{2} \mathrm{O} 9: 1(\mathrm{v} / \mathrm{v}) \\
\beta \text {-hairpin }\end{array}$}} & \multicolumn{2}{|c|}{$30 \mathrm{mM}$ DPC-d38 } \\
\hline & & & & & elix \\
\hline & & ${ }^{1} \mathbf{H} \delta, \mathbf{p p m}$ & ${ }^{13} \mathrm{C} \delta, \mathrm{ppm}$ & ${ }^{1} \mathbf{H} \delta, p p m$ & ${ }^{13} \mathrm{C} \delta, \mathrm{ppm}$ \\
\hline \multirow[t]{9}{*}{ Trp 10 (248) } & $\mathrm{H}_{\mathrm{N}}$ & 8.31 & & 7.94 & \\
\hline & $\mathrm{C}_{\alpha} \mathrm{H}$ & 4.78 & nd & 4.65 & $58.0^{\mathrm{a}}$ \\
\hline & $\mathrm{C}_{\beta \beta} \cdot \mathrm{H}$ & $3.18,3.26$ & 29.9 & $3.23,3.40$ & 29.9 \\
\hline & $\mathrm{C}_{\delta 1} \mathrm{H}$ & 7.15 & 127.5 & 7.22 & 127.0 \\
\hline & $\mathrm{N}_{\varepsilon 1} \mathrm{H}$ & 10.01 & & 10.33 & \\
\hline & $\mathrm{C}_{\varepsilon 3} \mathrm{H}$ & 7.56 & 121.0 & 7.59 & 121.1 \\
\hline & $\mathrm{C}_{\zeta 3} \mathrm{H}$ & 7.08 & 122.2 & 7.01 & 121.7 \\
\hline & $\mathrm{C}_{\eta_{2} 2} \mathrm{H}$ & 7.24 & 125.0 & 7.07 & 124.1 \\
\hline & $\mathrm{C}_{\zeta_{2}} \mathrm{H}$ & 7.46 & 115.0 & 7.43 & 114.6 \\
\hline \multirow[t]{4}{*}{ Thr 11 (249) } & $\mathrm{H}_{\mathrm{N}}$ & 8.27 & & 7.69 & \\
\hline & $\mathrm{C}_{\alpha} \mathrm{H}$ & 4.40 & 61.9 & 4.28 & 62.0 \\
\hline & $\mathrm{C}_{\beta} \mathrm{H}$ & 4.06 & 70.8 & 4.13 & 70.0 \\
\hline & $\mathrm{C}_{\gamma} \mathrm{H}_{3}$ & 1.09 & 21.5 & 1.09 & 21.6 \\
\hline \multirow[t]{5}{*}{ Tyr 12 (250) } & $\mathrm{H}_{\mathrm{N}}$ & 8.20 & & 7.67 & \\
\hline & $\mathrm{C}_{a} \mathrm{H}$ & 4.44 & 58.1 & 4.47 & $58.5^{\mathrm{a}}$ \\
\hline & $\mathrm{C}_{\beta \beta} \cdot \mathrm{H}$ & $2.42,2.83$ & 38.89 & $2.79,2.98$ & 39.2 \\
\hline & $\mathrm{C}_{\delta \delta}, \mathrm{H}$ & $6.76,6.76$ & 133.4 & $6.99,6.99$ & 133.4 \\
\hline & $\mathrm{C}_{\varepsilon \varepsilon} \cdot \mathrm{H}$ & $6.73,6.73$ & 118.4 & $6.78,6.78$ & 118.5 \\
\hline \multirow[t]{4}{*}{ Thr 13 (251) } & $\mathrm{H}_{\mathrm{N}}$ & 7.92 & & 7.88 & \\
\hline & $\mathrm{C}_{a} \mathrm{H}$ & 4.31 & 61.5 & 4.30 & 61.8 \\
\hline & $\mathrm{C}_{\beta} \mathrm{H}$ & 4.11 & 70.5 & 4.19 & 70.1 \\
\hline & $\mathrm{C}_{\gamma} \mathrm{H}_{3}$ & 1.13 & 21.6 & 1.17 & 21.8 \\
\hline \multirow[t]{4}{*}{ Asn 14 (252) } & $\mathrm{H}_{\mathrm{N}}$ & 8.14 & & 8.15 & \\
\hline & $\mathrm{C}_{a} \mathrm{H}$ & 4.54 & $53.7^{\mathrm{a}}$ & 4.61 & $53.0^{\mathrm{a}}$ \\
\hline & $\mathrm{C}_{\beta \beta} \cdot \mathrm{H}$ & $2.71,2.80$ & 39.8 & $2.73,2.80$ & 39.6 \\
\hline & $\mathrm{N}_{\delta \delta}, \mathrm{H}_{2}$ & $6.88,7.55$ & & $6.87,7.58$ & \\
\hline
\end{tabular}


Table S6. Summary of non-sequential cross-strand NOEs involving side chain protons observed for the peptides LytA239-252 (Zamora-Carreras et al., 2015), K3W5-, K5W10-, and I5Y6T11T13-LytA239-252 in aqueous solution. No cross-strand NOE was observed for peptide S3S10-LytA239-252, and only one, a diagonal between residues K5 and Y12, was found for peptide I3V10-LytA239-252.

\begin{tabular}{|c|c|c|c|c|}
\hline \multirow{2}{*}{$\begin{array}{l}\text { Side chains from non-HB } \\
\text { residues }\end{array}$} & \multicolumn{4}{|c|}{ Peptide } \\
\hline & LytA $239-252$ & $\begin{array}{c}\text { K3W5- } \\
\text { LytA } 239-252\end{array}$ & $\begin{array}{c}\text { K5W10- } \\
\text { LytA 239-252 }\end{array}$ & $\begin{array}{l}\text { I5Y6T11T13- } \\
\text { LytA }_{239-252}\end{array}$ \\
\hline Facing residues $5 / 10$ & K5/W10 & $\mathrm{W} 5 / \mathrm{W} 10$ & $\mathrm{~W} 5 / \mathrm{K} 10$ & $\mathrm{I} 5 / \mathrm{W} 10$ \\
\hline No. NOEs & 15 & 1 & 10 & 1 \\
\hline Facing residues $3 / 12$ & $\mathrm{~W} 3 / \mathrm{Y} 12$ & $\mathrm{~K} 3 / \mathrm{Y} 12$ & W3/Y12 & W3/Y12 \\
\hline No. NOEs & 8 & 7 & 0 & 0 \\
\hline Facing residues $1 / 14$ & T1/N14 & T1/N14 & T1/N14 & T1/N14 \\
\hline No. NOEs & 3 & 0 & 0 & 0 \\
\hline Diagonal residues 5/12 & K5/Y12 & W5/Y12 & W5/Y12 & I5/Y12 \\
\hline No. NOEs & 0 & 0 & 0 & 1 \\
\hline Diagonal residues $3 / 10$ & W3/W10 & $\mathrm{K} 3 / \mathrm{W} 10$ & $\mathrm{~W} 3 / \mathrm{K} 10$ & W3/W10 \\
\hline No. NOEs & 11 & 6 & 0 & 2 \\
\hline Diagonal residues $1 / 12$ & $\mathrm{~T} 1 / \mathrm{Y} 12$ & $\mathrm{~T} 1 / \mathrm{Y} 12$ & $\mathrm{~T} 1 / \mathrm{Y} 12$ & $\mathrm{~T} 1 / \mathrm{Y} 12$ \\
\hline No. NOEs & 1 & 1 & 2 & 1 \\
\hline \multicolumn{5}{|l|}{$\begin{array}{l}\text { Side chains from HB } \\
\text { residues }\end{array}$} \\
\hline Facing residues $6 / 9$ & I6/K9 & I6/K9 & I6/K9 & Y6/K9 \\
\hline No. NOEs & 2 & 0 & 0 & 4 \\
\hline Facing residues $4 / 11$ & $\mathrm{~K} 4 / \mathrm{Y} 11$ & $\mathrm{~K} 4 / \mathrm{Y} 11$ & $\mathrm{~K} 4 / \mathrm{Y} 11$ & $\mathrm{~K} 4 / \mathrm{T} 11$ \\
\hline No. NOEs & 0 & 3 & 4 & 0 \\
\hline Diagonal residues $6 / 11$ & $\mathrm{I} 6 / \mathrm{Y} 11$ & $\mathrm{I} 6 / \mathrm{Y} 11$ & $\mathrm{I} 6 / \mathrm{Y} 11$ & Y6/T11 \\
\hline No. NOEs & 11 & 9 & 10 & 1 \\
\hline Diagonal residues 4/13 & $\mathrm{K} 4 / \mathrm{F} 13$ & $\mathrm{~K} 4 / \mathrm{F} 13$ & $\mathrm{~K} 4 / \mathrm{F} 13$ & $\mathrm{~K} 4 / \mathrm{T} 13$ \\
\hline No. NOEs & 12 & 6 & 3 & 0 \\
\hline
\end{tabular}


Table S7. Structural statistics parameters for the ensemble of the 20 lowest target function conformers calculated for the designed LytA $239-252$ variants in aqueous solution and in DPC micelles.

\begin{tabular}{|c|c|c|c|c|c|c|c|c|}
\hline & \multicolumn{3}{|c|}{ Aqueous solution } & \multicolumn{5}{|c|}{ DPC micelles } \\
\hline & $\begin{array}{c}\text { K3W5- } \\
\text { LytA }_{239-252}\end{array}$ & $\begin{array}{c}\text { W5K10 } \\
\text {-LytA } 239-252 \\
\end{array}$ & $\begin{array}{c}\text { I5Y6T11T13 } \\
\text {-LytA } 239-252 \\
\end{array}$ & $\begin{array}{c}\text { K3W5 } \\
\text {-LytA } 239-252 \\
\end{array}$ & $\begin{array}{c}\text { W5K10 } \\
\text {-LytA } 239-252 \\
\end{array}$ & $\begin{array}{l}\text { I5Y6T11T13 } \\
\text {-LytA } 239-252 \\
\end{array}$ & $\begin{array}{c}\text { I3V10- } \\
\text { LytA }_{239-252}\end{array}$ & $\begin{array}{c}\text { S3S10- } \\
\text { LytA }_{239-252}\end{array}$ \\
\hline \multicolumn{9}{|l|}{ Number of distance restraints } \\
\hline Intraresidue $\&$ sequential $(\mathrm{i}-\mathrm{j} \leq 1)$ & 43 & 96 & 113 & 109 & 126 & 175 & 176 & 112 \\
\hline Medium range $(1<|\mathrm{i}-\mathrm{j}|<5)$ & 11 & 2 & 5 & 6 & 39 & 43 & 68 & 2 \\
\hline Long range $(|i-j| \geq 5)$ & 35 & 26 & 2 & 0 & 0 & 0 & 0 & 0 \\
\hline Total number & 83 & 124 & 120 & 115 & 165 & 218 & 244 & 114 \\
\hline \multicolumn{9}{|l|}{ Averaged total number per residue } \\
\hline \multicolumn{9}{|l|}{ Number of dihedral angle constraints } \\
\hline Number of restricted $\phi$ angles & 10 & 10 & 8 & 11 & 11 & 11 & 11 & 11 \\
\hline Number of restricted $\psi$ angles & 10 & 10 & 8 & 10 & 11 & 7 & 10 & 4 \\
\hline Total number & 20 & 20 & 16 & 21 & 22 & 18 & 21 & 15 \\
\hline \multicolumn{9}{|l|}{ Pairwise RMSD ( $\AA$ ) for residues $2-13$} \\
\hline Backbone atoms & $0.5 \pm 0.2$ & $1.3 \pm 0.5$ & $1.8 \pm 0.6$ & $1.0 \pm 0.3$ & $0.4 \pm 0.1$ & $0.2 \pm 0.1$ & $0.3 \pm 0.1$ & $\begin{array}{l}3.0 \pm 0.9 \\
0.5 \pm 0.2^{[\mathrm{a}]}\end{array}$ \\
\hline All heavy atoms & $1.6 \pm 0.4$ & $2.2 \pm 0.6$ & $3.7 \pm 1.3$ & $2.5 \pm 0.6$ & $1.2 \pm 0.2$ & $0.7 \pm 0.2$ & $1.0 \pm 0.2$ & $\begin{array}{l}4.6 \pm 1.0 \\
1.7 \pm 0.5^{[\mathrm{a}]}\end{array}$ \\
\hline \multicolumn{9}{|l|}{ Ramachandran plot (\%) } \\
\hline Most favoured regions & 97.7 & 82.7 & 79.1 & 95.5 & 99.1 & 72.7 & 100 & 62.7 \\
\hline Additionally allowed regions & 2.3 & 17.3 & 20.5 & 4.5 & 0.9 & 27.3 & 0 & 37.3 \\
\hline Generously allowed regions & 0 & 0 & 0 & 0 & 0 & 0 & 0 & 0 \\
\hline Disallowed regions & 0 & 0 & 0.5 & 0 & 0 & 0 & 0 & 0 \\
\hline
\end{tabular}


Table S8. ${ }^{1} \mathrm{H}$ chemical shifts $(\delta$, ppm) for side chains of $3 / 12$ and $5 / 10$ cross-strand pairs in Trp-containing peptides (Figure 2$)$ in aqueous solution at $\mathrm{pH} 3.0$ and $25^{\circ} \mathrm{C}$. Random coil values taken from Wishart et al. 1995 are indicated. ${ }^{3}$ Being $\Delta \delta=\delta^{\text {observed }}-\delta^{\mathrm{RC}}, \delta$-values with $|\Delta \delta|>0.5$ ppm are shown in bold. FtE stands for Face-to-edge and EtF for Edge-to-face.

\begin{tabular}{|c|c|c|c|c|c|c|c|c|}
\hline \multirow[t]{2}{*}{ Cross-strand pair } & \multirow[t]{2}{*}{ Peptide } & \multirow[t]{2}{*}{ Residue } & \multicolumn{6}{|c|}{ Trp protons } \\
\hline & & & $\mathrm{C}_{\beta \beta}, \mathrm{H}$ & $\mathrm{C}_{\delta 1} \mathrm{H}$ & $\mathrm{C}_{\varepsilon 3} \mathrm{H}$ & $\mathrm{C}_{{ }_{3} \mathrm{H}} \mathrm{H}$ & $\mathrm{C}_{\eta 2} \mathrm{H}$ & $\mathrm{C}_{\zeta 2} \mathrm{H}$ \\
\hline & Random coil & $\mathrm{W}$ & $3.29,3.27$ & 7.27 & 7.65 & 7.18 & 7.25 & 7.50 \\
\hline FtE W3/Y12 & LytA $_{239-252}$ & W3 & $3.19,3.51$ & 7.41 & 7.68 & 7.03 & 7.20 & 7.34 \\
\hline FtE W3/Y12 & W5K10- LytA $239-252$ & W3 & $2.75,2.75$ & 7.05 & 7.15 & 6.65 & 7.16 & 7.43 \\
\hline FtE W3/Y12 & I5Y6T11T13- LytA $239-252$ & W3 & $3.16,3.25$ & 7.25 & 7.55 & 7.13 & 7.21 & 7.46 \\
\hline K5/W10 & LytA $_{239-252}$ & W10 & $2.99,3.31$ & 7.22 & 7.63 & 7.08 & 7.29 & 7.50 \\
\hline EtF W5/W10 & K3W5- LytA $239-252$ & W5 $5^{\text {edge }}$ & 2.18, 2.94 & 6.83 & 5.71 & 6.46 & 6.93 & 7.24 \\
\hline EtF W5/W10 & K3W5- LytA 239-252 & W10 & $2.67,3.04$ & 7.42 & 7.33 & 7.04 & 7.18 & 7.35 \\
\hline W5/K10 & W5K10- LytA $239-252$ & W5 & $3.14,3.23$ & 7.29 & 7.36 & 6.97 & 7.14 & 7.42 \\
\hline \multirow{4}{*}{$\mathrm{I} 5 / \mathrm{W} 10$} & I5Y6T11T13- LytA 239-252 & W10 & $3.18,3.26$ & 7.15 & 7.56 & 7.08 & 7.24 & 7.46 \\
\hline & & & \multicolumn{6}{|c|}{ Tyr protons } \\
\hline & & & $\mathrm{C}_{\beta \beta}, \mathrm{H}$ & $\mathrm{C}_{\delta \delta}, \mathrm{H}$ & $\mathrm{C}_{\varepsilon \varepsilon}, \mathrm{H}$ & & & \\
\hline & Random coil & $\mathrm{Y}$ & $2.98,3.03$ & $7.14,7.14$ & $6.84,6.84$ & & & \\
\hline FtE W3/Y12 & LytA $239-252$ & Y $12^{\text {edge }}$ & $0.94,2.18$ & $5.78,5.78$ & $6.54,6.54$ & & & \\
\hline FtE W3/Y12 & W5K10- LytA $239-252$ & Y12 edge & $1.16,2.25$ & $6.64,6.64$ & $6.58,6.58$ & & & \\
\hline FtE W3/Y12 & I5Y6T11T13- LytA $239-252$ & Y12 $2^{\text {edge }}$ & $2.42,2.83$ & $6.76,6.76$ & $6.73,6.73$ & & & \\
\hline \multirow[t]{4}{*}{$\mathrm{K} 3 / \mathrm{Y} 12$} & K3W5- LytA $239-252$ & Y12 & $2.71,2.92$ & $7.09,7.09$ & $6.69,6.69$ & & & \\
\hline & & & \multicolumn{6}{|c|}{ Lys protons } \\
\hline & & & $\mathrm{C}_{\beta \beta}, \mathrm{H}$ & $\mathrm{C}_{\gamma \gamma}, \mathrm{H}$ & $\mathrm{C}_{\delta \delta}, \mathrm{H}$ & $\mathrm{C}_{\varepsilon \varepsilon} \mathrm{H}$ & & \\
\hline & Random coil & $\mathrm{K}$ & $1.75,1.84$ & $1.44,1.44$ & $1.68,1.68$ & $2.99,2.99$ & & \\
\hline $\mathrm{K} 5 / \mathrm{W} 10$ & LytA $_{239-252}$ & K5 & $-0.19,1.18$ & $-0.04,0.60$ & $1.15,1.15$ & $2.50,2.62$ & & \\
\hline $\mathrm{K} 3 / \mathrm{Y} 12$ & K3W5- LytA 239-252 & K3 & $1.42,1.58$ & $1.48,1.63$ & $\mathbf{0 . 8 4}, 1.21$ & $2.07,2.17$ & & \\
\hline \multirow[t]{4}{*}{$\mathrm{W} 5 / \mathrm{K} 10$} & W5K10- LytA $239-252$ & K10 & $0.96,0.96$ & $0.40,0.58$ & $0.77,0.96$ & $2.02,2.17$ & & \\
\hline & & & \multicolumn{6}{|c|}{ Ile protons } \\
\hline & & & $\mathrm{C}_{\beta} \mathrm{H}$ & $\mathrm{C}_{\gamma \gamma} \cdot \mathrm{H}$ & $\mathrm{C}_{\gamma} \mathrm{H}_{3}$ & $\mathrm{C}_{\delta} \mathrm{H}_{3}$ & & \\
\hline & Random coil & I & 1.87 & $1.16,1.45$ & 0.91 & 0.86 & & \\
\hline $\mathrm{I} 5 / \mathrm{W} 10$ & II5Y6T11T13- LytA 239-252 & I5 & 1.46 & $0.79,1.11$ & 0.70 & 0.65 & & \\
\hline
\end{tabular}

